\title{
CONSUMER EVALUATION OF CHEESE: LINKING HEDONICS, EMOTIONS AND PERCEPTION OF PRODUCT ATTRIBUTES
}

\author{
A Thesis \\ presented to \\ the Faculty of California Polytechnic State University, \\ San Luis Obispo
}

\author{
In Partial Fulfillment \\ of the Requirements for the Degree
}

Master of Science in Agriculture with a Specialization in Food Science

by

Kristine Martinez

June 2014 
(C) 2014

Kristine Martinez ALL RIGHTS RESERVED 


\section{COMMITTEE MEMBERSHIP}

TITLE:

Consumer Evaluation of Cheese: Linking Hedonics, Emotions and Perception of Product Attributes

Kristine Martinez

AUTHOR:

DATE SUBMITTED:

June 2014

COMMITTEE CHAIR:

Amy Lammert, PhD

Assistant Professor of Food Science and Nutrition

COMMITTEE MEMBER: Karen McGaughey, PhD

Associate Professor of Statistics

COMMITTEE MEMBER: $\quad$ Rafael Jimenez-Flores, PhD

Professor of Dairy Science 


\section{ABSTRACT \\ Consumer Evaluation of Cheese: Linking Hedonics, Emotions and Perception of Product Attributes}

Kristine Martinez

As the food industry continues to grow and the marketplace becomes saturated with similar products, consumer researchers and sensory scientists are looking to dig deeper into the minds of consumers to reveal greater distinctions between products and ultimately deliver multi-dimensionally desirable products to consumers. Concurrently, rates of adult and childhood obesity have been increasing nationwide. Food companies are now facing a paradigm shift as health initiatives and consumers are beginning to demand healthier alternatives to commonly consumed food products. With this in mind, it has become imperative to identify product attributes that drive consumption so they can be replicated in the alternative nutrition products. Additionally, foods high in undesirable nutrients, such as sodium, which has a positive correlation with cardiovascular disease and stroke, should be investigated in an effort to reduce this food ingredient and work toward increasing the nation's health.

Mozzarella cheese is the most consumed type of cheese in the U.S., and one serving provides $8 \%$ of your Daily Value for sodium. Considering the obesity epidemic and increasing prevalence of hypertension, there are opportunities to investigate sodium reduction in mozzarella cheese. Determining the attributes of cheese that drive consumption and the emotions that such products may elicit, can guide manufacturers in the production of a low sodium product that is accepted and preferred by the consumers. In order to do so, two phases of researcher were conducted. 
Phase 1 was conducted to (1) determine the hedonic and texture attributes of different cheeses that affect the end emotional state of a panelist, and (2) determine if the initial emotions and hedonics could better represent end product liking than hedonics alone. Seven convenience string cheese varieties with varying sodium and fat contents were evaluated using the Image Measurement of Emotion and Texture (IMET) method. Seven emotions (excited, sociable, self-confident, fatigued, judgmental, raging, and sad) scaled from 1- "slightly" to 5-“extremely" (with 0 representing "not at all") were used, with each emotion at each level of intensity anchored by self-selected images that subjects chose prior to testing. Using a check-all-that-apply (CATA) format, subjects reported his/her emotional state and perception of textural attributes at the beginning and at the end of consumption. Hedonic attribute questions were measured using a 9-point hedonic scale and presented to subjects at the beginning and at the end of consuming each product. Compusense ${ }^{\circledR}$ at-hand was used for data collection. The results indicated: (1) the effect of texture attributes on the end emotional response of consumers depends on the cheese sample and (2) the hedonic principal components were sufficient to predict end overall liking.

Phase two was conducted to (1) determine if the emotion calibration step is effective in creating an emotional baseline between samples, (2) determine differences in product acceptance based on partial $\mathrm{NaCl}$ substitution, and (3) evaluate product preparation procedures during formulation of low sodium cheeses. Low moisture part skim mozzarella samples were produced with three different salt/salt substitutes $(\mathrm{NaCl}$, $\mathrm{KCl}$, and Salona $\left.{ }^{\mathrm{TM}}\right)$ at two levels $(100 \%$ and $50 \%)$ with two antimicrobials (CytoGuard ${ }^{\mathbf{T M}}$ LA 20 and NovaGARD®). All samples were evaluated by consumers 
$(\mathrm{N}=54)$, which involved emotion, hedonic and texture measurements. Subjects were asked his/her emotional state (excited, sociable, self-confident, fatigued, judgmental, raging and sad; scaled from 1- "slightly" to 5-“extremely" (with a 0 -“not at all" option) in a CATA format before and after consuming each sample. Hedonic questions (9-point hedonic scale) and perception of texture were assessed during and at the end of consumption. An emotional calibration step was added between samples. All data was collected using Compusense ${ }^{\circledR}$ at-hand. The results indicated: (1) there was no significant variations in panelists' reported initial emotions between samples, (2) the full sodium and $100 \% \mathrm{KCl}$ samples were consistently liked more compared to the other samples, and (3) special considerations for antimicrobial application should be made during production and preparation of experimentally developed low sodium cheese. 


\section{ACKNOWLEDGMENTS}

I would like to thank my committee chair and advisor, Dr. Amy Lammert, and my committee members, Dr. Rafael Jimenez-Flores and Dr. Karen McGaughey. I truly appreciate your tireless guidance, support and encouragement over the last 2 years. You have provided me with many opportunities and I am forever grateful.

Thank you to the faculty, students and staff in the FSN Department and at the DPTC. Your encouragement and involvement in my research has made an incredible impact. You have all contributed to my positive experiences at Cal Poly, making it unforgettable and something I will always cherish.

Thank you to California State University Agricultural Research Institute; without the funding, this research would not have been possible.

I wish to thank my research partners. Malori Comer, without your help I would have been lost. Thank you for the countless hours you spent prepping my samples, running my sensory tests, reading my papers and offering me sage advice (the list goes on). I truly appreciate all that you have done! And Hector Herrera, I'm so thankful for your time and patience! Your work is priceless!

Thank you to my family and friends. I would not have made it this far without your endless love and support. Mom, dad, Carrie, Scott and my loving grandparents, you have been my inspiration and have always been there for me, especially when I needed it the most! You have been my foundation and biggest fans, lifting me up and always cheering me on. I cannot thank you enough!

Finally, a big thank you to Chris White! You have supported me with your constant love, friendship, and encouragement. I would not have gotten through these last few years without you. Thank you for always being there for me. Your presence in my life has filled me with joy. I am so proud of you and look forward to what we will accomplish together. 


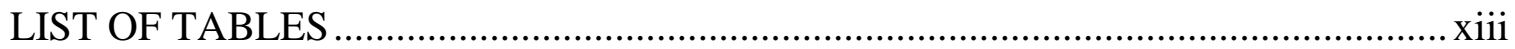

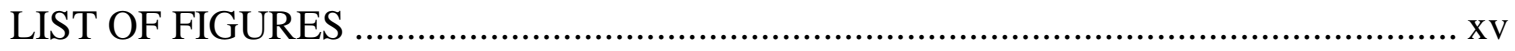

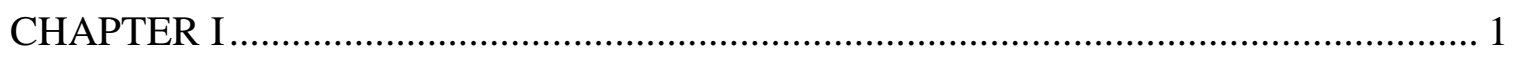

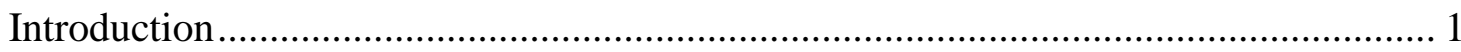

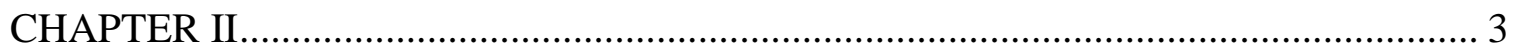

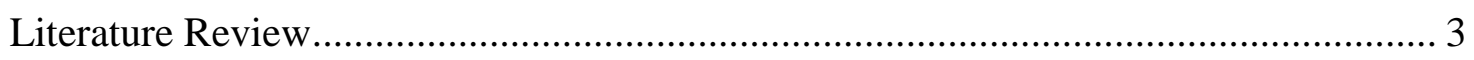

Traditional Sensory Methods ............................................................................ 4

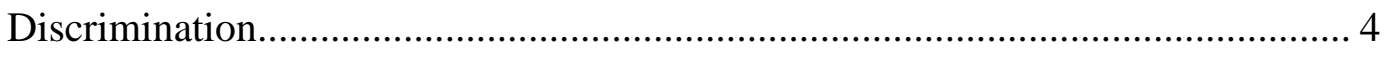

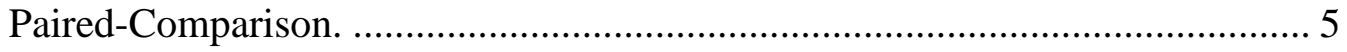

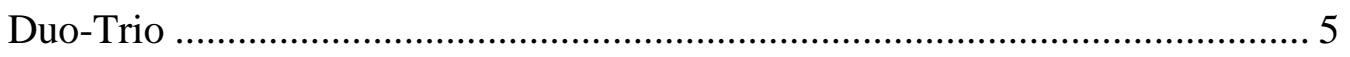

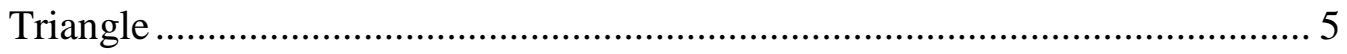

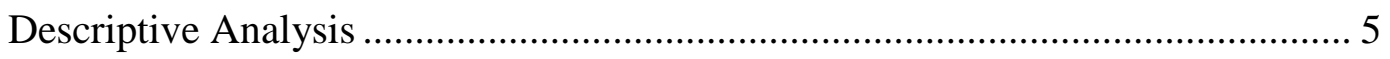

Quantitative Descriptive Analysis (QDA®)............................................. 6

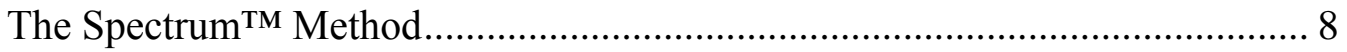

Qualitative Multivariate Analysis ….................................................... 8

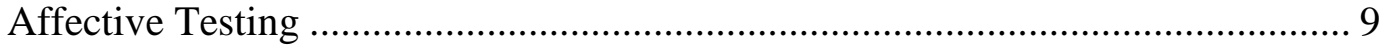

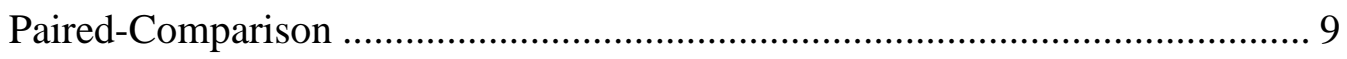

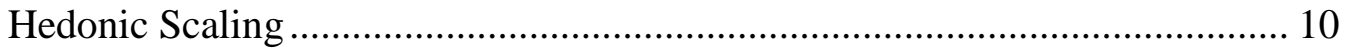

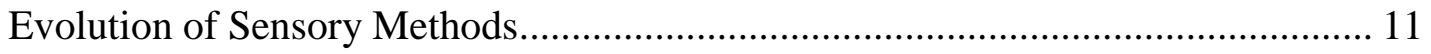

The Role of the Hedonic Scale ................................................................. 11 
Limitations of Traditional Methods ............................................................. 12

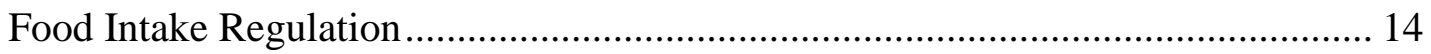

Traditional View of Homeostatic Regulation ............................................... 15

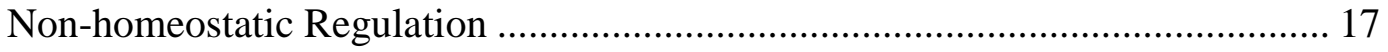

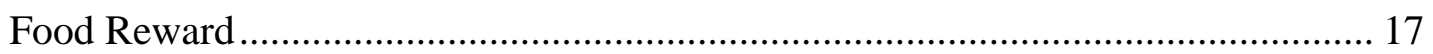

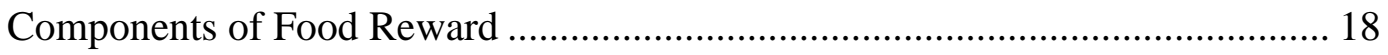

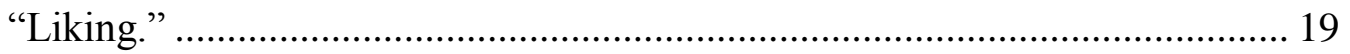

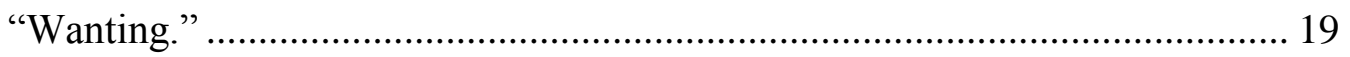

Dissecting Liking from Wanting. ............................................................ 20

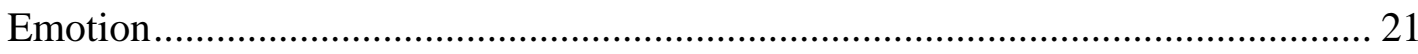

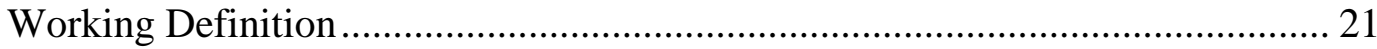

Distinguishing Features of Affective Phenomena ….................................... 23

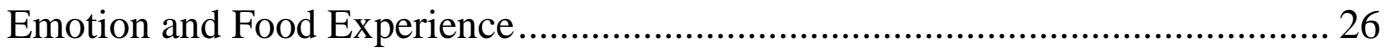

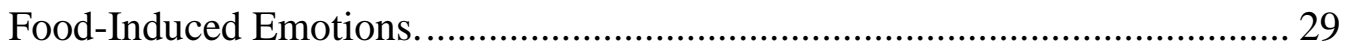

Current Emotion Methodologies................................................................ 31

Product Emotion Measurement Instrument (PrEmo) ........................................ 31

The Geneva Emotion and Odor Scale (GEOS) and ScentMove ${ }^{\mathrm{TM}}$..................... 34

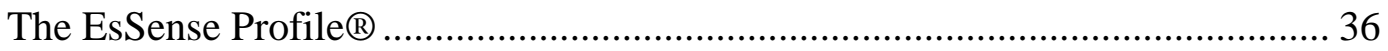

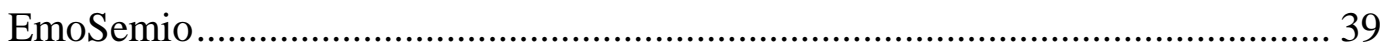

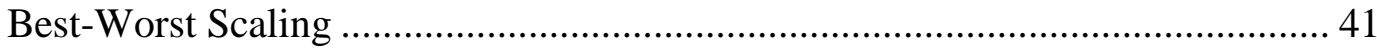

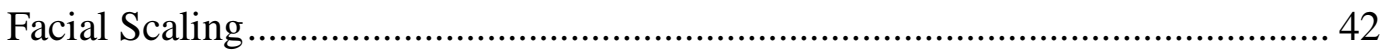

Image Measurement of Emotions and Texture ........................................... 44

Decreasing Sodium Consumption............................................................. 47 


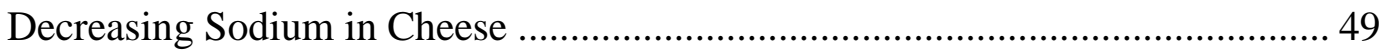

Properties of Low Sodium Cheese................................................................... 50

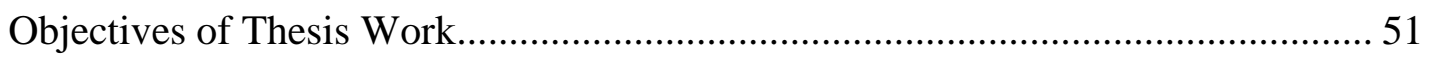

Phase 1: Evaluation of Commercial Convenience Cheeses................................... 52

Phase 2: Emotion Calibration and Low Sodium Cheese ...................................... 53

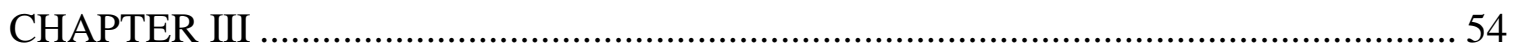

Consumer evaluation of commercially produced convenience cheeses using a scaled emotion Image Measurement of Emotion and Texture (IMET) Method........ 54

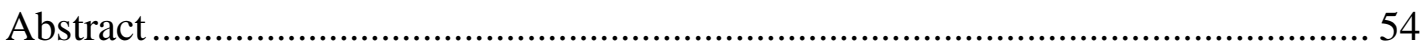

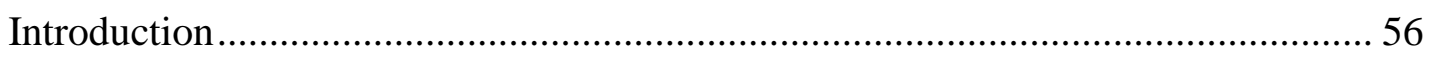

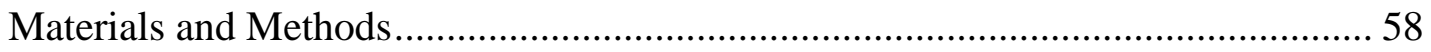

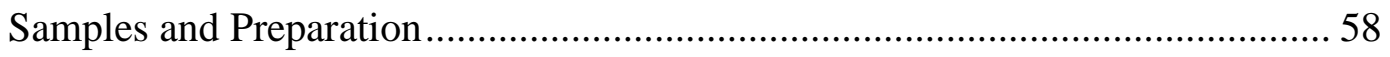

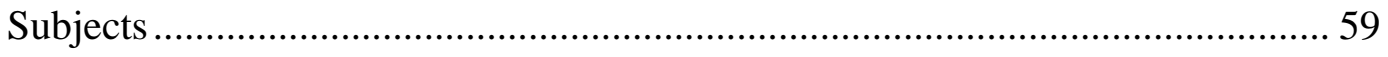

Questionnaire and Testing Procedure ………………....................................... 59

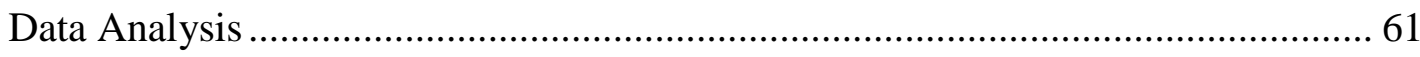

Effects of Hedonics and Texture on End Emotional Response ............................. 61

Effect of Emotions and Hedonics on End Product Liking .................................... 62

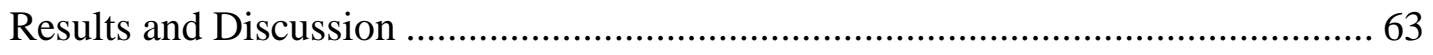

Effects of Hedonics and Texture on End Emotional Response .............................. 63

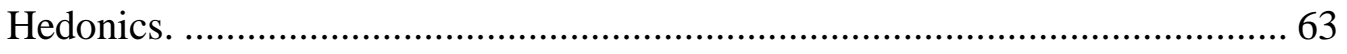

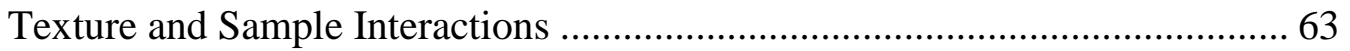

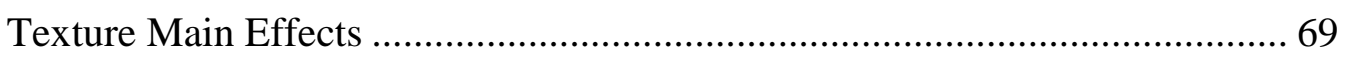

Effects of Initial Emotions and Hedonics on End Product Liking......................... 70 
Conclusion

CHAPTER IV

Do we need an emotional cleanser? An example using experimentally

developed low moisture part skim mozzarella with partial $\mathrm{NaCl}$ substitution 74

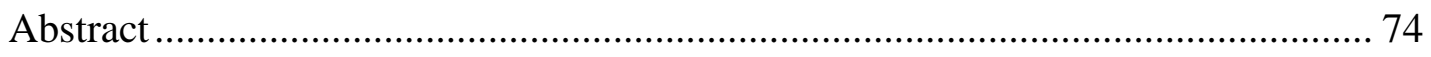

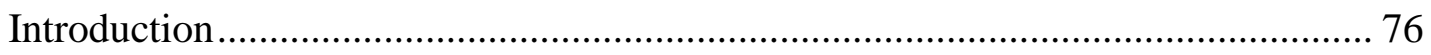

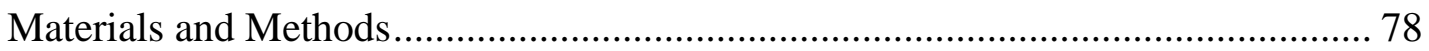

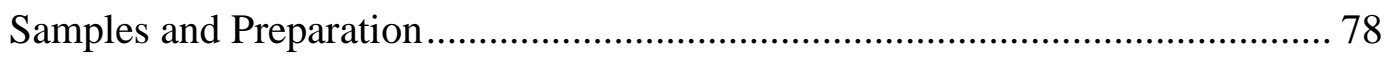

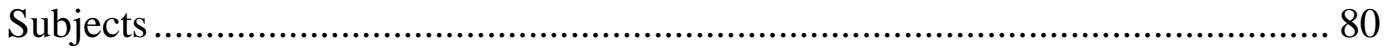

Questionnaire and Testing Procedure ........................................................ 80

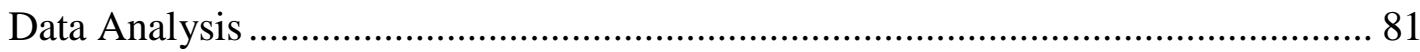

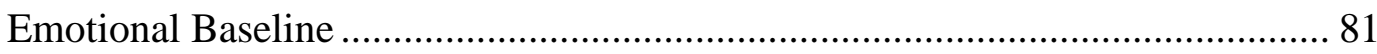

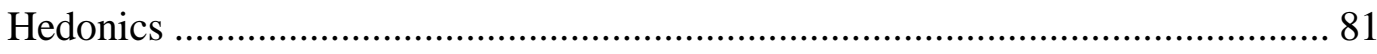

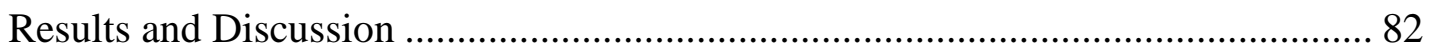

Emotional Baseline ................................................................................... 82

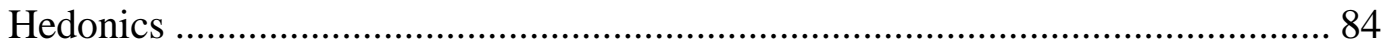

Evaluation of Product Preparation and Study Limitations ............................... 86

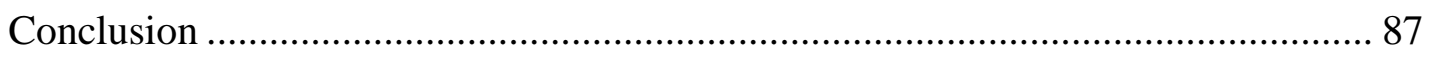

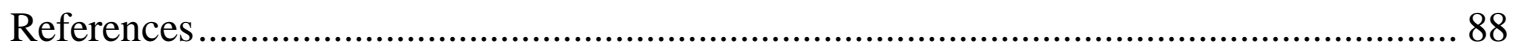

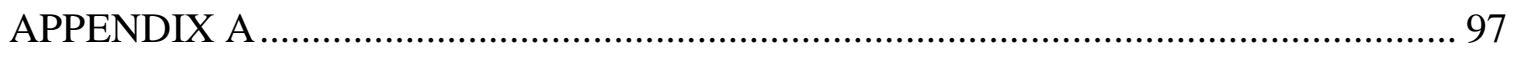

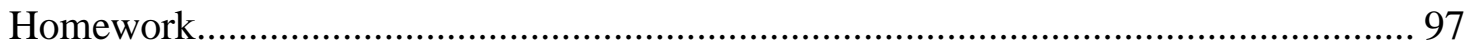

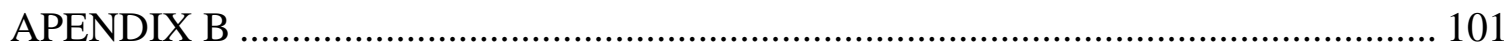

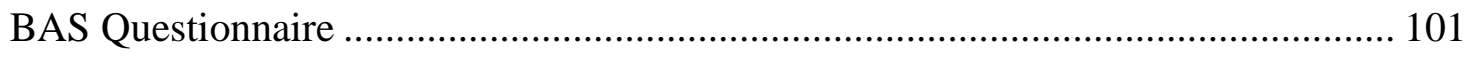




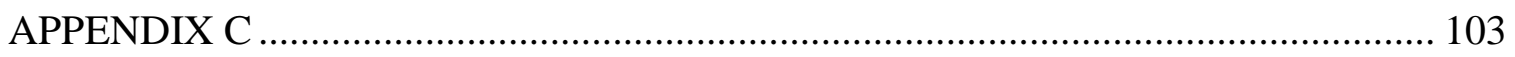

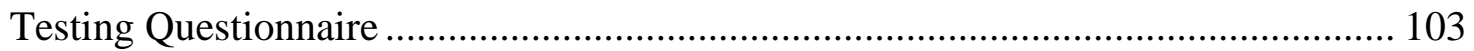

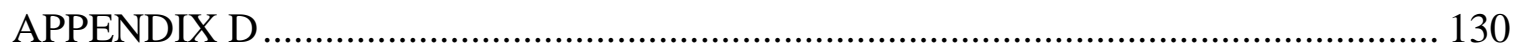

Texture Card .............................................................................................. 130

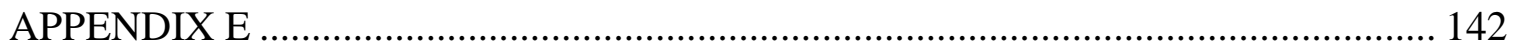

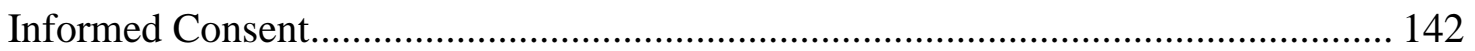

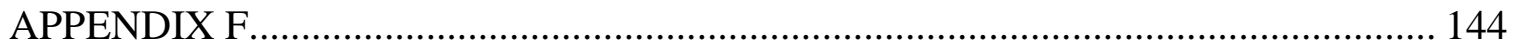

Video Release Form................................................................................... 144 


\section{LIST OF TABLES}

Table

Page

Table 1. Design feature differentiation of different types of affective phenomena (excerpted from Scherer, 2005). 25

Table 2. List of emotions used in the EsSense Profile ${ }^{\circledR}$ questionnaire (excerpted from King \& Miselman, 2010).

Table 3. EmoSemio questionnaire for chocolate and/or hazelnut spreads (excerpted from Spinelli et al., 2013).

Table 4. Serving size, percent water, sodium per serving, and per capita consumption of commonly consumed cheeses

Table 5. Description of seven cheese samples 59

Table 6. Loading matrix for the initial emotion and hedonic attribute principle components

Table 7. Effect of the interaction of the texture attributes and the sample on the end emotion

Table 8. Effect of texture attributes on end emotional responses

Table 9. Comparison of three models to determine if hedonics and emotions better predict overall liking than hedonics alone

Table 10. Moisture content of all cheese samples prior antimicrobial dip

Table 11. Self-reported emotion scores (with $0=$ not at all, $1=$ slightly and $5=$ extremely) reported prior to consuming each cheese sample (mean \pm standard deviation)* 
Table 12. End hedonics scores for each cheese sample

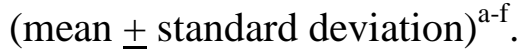




\section{LIST OF FIGURES}

$\begin{array}{ll}\text { Figure } & \text { Page }\end{array}$

Figure 1. Graphical representation of the sensory profiles of reduced fat milk stored at $6^{\circ} \mathrm{C}$. Individual attributes are positioned like the spokes of a wheel around a center (zero, or not detected) point, with the spokes representing attribute intensity scales, with higher (more intense) values radiating outward (excerpted from Chapman, Lawless, \& Boor, 2001) ............................................................................ 7

Figure 2. Example of a 9-point hedonic scale...................................................... 10

Figure 3. A simple illustration of the stimulus-response model (adapted from Lim, 2011).

Figure 4. Perception and conceptualization (excerpted from Thomson et al., 2010). 13

Figure 5. Highly schematic diagram showing neural systems and flow of information involved in the control of food intake and regulation of energy balance. The traditional regulatory circuitry using neural and hormonal feedback from the internal milieu acting on hypothalamus and brainstem is shown on the bottom (dark grey boxes). Sensory and cortico-limbic brain areas used for processing information from the environment are shown in the upper half of the diagram (light gray boxes). The extensive influence of circulating and neural internal feedback signals on sensory processing and cortico-limbic systems concerned with reward, emotion, learning and memory is emphasized with broken line/open arrows (excerpted from Shin et al., 2009).

Figure 6. Areas of the human brain activated in response to palatable food or foodassociation cues (excerpted from Kenny, 2011).

Figure 7. Schematic diagram showing some of the gustatory, olfactory, visual and somatosensory pathways to the orbitofrontal cortex, and some of the outputs of the orbitofrontal cortex in primates. The secondary taste cortex and the secondary olfactory cortex are within the orbitofrontal cortex. V1-primary visual cortex, V4-visual cortical area V4 (excerpted from Rolls, 2006). 
Figure 8. A flow diagram to predict basic classes of emotion-induced changes of eating (excerpted from Macht, 2008). The outlined area represents the main focus of this review

Figure 9. PrEmo animations (excerpted from Desmet, 2005).

Figure 10. Example of an emotion poster board created by a participant and used during testing as part of the IMET method.....

Figure 11. Average daily intake of sodium by gender and age group ${ }^{\mathrm{a}}$

${ }^{a}$ Data from USDA ARS, What We Eat in America, NHANES 2009-2010 (USDA Agricultural Research Service, 2010), ${ }^{\mathrm{b}}$ Tolerable Upper Intake Level as recommended by the Institute of Medicine (Centers for Disease Control and Prevention, 2011),

${ }^{\mathrm{c}}$ Recommended Adequate Intake Level as recommended by the Institute of Medicine (Centers for Disease Control and Prevention, 2011)

Figure 12. Effect of shear on the predicted end sociable response for each cheese sample

Figure 13. Effect of shear on the predicted end fatigued response for each cheese sample

Figure 14. Effect of soft on the predicted end fatigued response for each cheese sample

Figure 15. Effect of sponginess on the predicted end fatigued response for each cheese sample 67

Figure 16. Effect of sponginess on the predicted end raging response for each cheese sample. 68 


\section{CHAPTER I}

\section{Introduction}

Rates of adult and childhood obesity have been increasing rapidly nationwide, presenting many social and health concerns. A person with a body mass index (BMI) of $\geq$ $30 \mathrm{~kg} / \mathrm{m}^{2}$ is considered obese (Centers for Disease Control and Prevention, 2012a). This chronic disease poses increased health risks for other conditions including hypertension, type 2 diabetes, and cardiovascular disease thus directly increasing morbidity and mortality (National Institute of Health, 1998). According to the National Health Nutrition and Examination Survey of 2009-1010, more than $33 \%$ of adults in the US and $17 \%$ of adolescents are obese (Ogden, Carroll, Kit, \& Flegal, 2012). This alarming data has caught the attention of multiple disciplines and spurred significant health initiatives. Understanding that the onset of obesity is a result of multiple factors, a multifaceted approach must be taken to improve the health of our nation.

With the growing food industry and thousands of new food products introduced annually, it becomes a challenge for many to accurately assess a product based on its functionality (i.e. nutritional attributes) and make adequate selections. Energy dense foods are often the most cost-effective, however, lack nutritional value. This, paired with a sedentary life style, creates an imbalance in energy where more calories are consumed than expended, thus causing weight gain and increased adiposity.

Additionally, hypertension, or high blood pressure, is often associated with increased sodium consumption and also poses severe health complications. It is estimated that 68 million U.S. adults have high blood pressure. This condition is known to be a risk factor for cardiovascular disease and stroke, the two leading causes of death (Centers for 
Disease Control and Prevention, 2013). In addition to the consumption of salt, people who are obese have a higher risk of high blood pressure than those with a normal body weight. With this in mind, it becomes imperative to investigate products in which sodium can be reduced to create healthier, alternative nutrition products, which are accepted or even preferred by consumers. To do this, favorable attributes of specific products that are desired by consumers must be identified. Understanding these attributes and replicating them in healthier alternative products may encourage consumers to make better choices and maintain eating satisfaction without sacrificing nutritional gains. Consumer responses to current commercially available products can help guide this investigation followed by an evaluation of experimentally produced alternative nutrition products based on initial feedback.

Recent research has expanded traditional knowledge of internal mechanisms associated with the regulation of body energy homeostasis and has identified other crucial contributors (Shin, Zheng, \& Berthoud, 2009). With this understanding, it becomes of interest to investigate brain mechanisms (particularly reward mechanisms associated with food intake) to fully understand the processes by which the human body regulates body energy, and the factors that influence the drivers of food choice, behavior and intake. Therefore, the objectives of this review of literature are (1) to understand traditional sensory evaluation methods of foods and the evolution of methods used by sensory scientists to gain insight into consumers, (2) to investigate brain reward mechanisms as they relate to food reward and the role of emotion in the food experience, and (3) to explore novel methods of sensory evaluation which incorporate the emotion component. 


\section{CHAPTER II}

\section{Literature Review}

In recent years consumer research has begun to make strides in gaining insight into consumer habits and trends. Similarly, the sensory science community has begun to question the drivers and motivations surrounding food choice and eating behaviors, especially in regards to the effectiveness of different methodologies and measurement techniques. In both situations it has become clear that consumers drive product success (Moskowitz, Beckley, \& Resurreccion, 2006) and with this in consideration, information gained from the sensory evaluation of products, food and non-food, has gained increasing attention. As defined by the Sensory Evaluation Division of the Institute of Food Technologists, "sensory evaluation is a scientific discipline to evoke, measure, analyze and interpret reactions to those characteristics of foods and materials as they are perceived by the senses of sight, smell, taste, touch, and hearing" (Anonymous, 1975). Product information gained from the sensory and consumer science discipline is beginning to contribute more substantially to the decision-making process in the business environment (Stone \& Sidel, 2004).

Beginning in the 1940s and 1950s, the food industry embraced the emergent science and explored the importance of product acceptability (Stone \& Sidel, 2004). Growth and development in the area of sensory science has continued over the years especially with the changing marketplace and consumer demands in the food industry. With sensory methods evolving throughout the years, more opportunities lie in the future as companies continue to become receptive to new evaluation methodologies and as the science becomes more integrated with the business environment to effectively deliver 
benefits to companies and the industry as a whole. Many types of sensory evaluation techniques exist with the underlying principle involving receiving feedback from consumers on specified attributes of a given product.

\section{Traditional Sensory Methods}

To fully understand the evolution of the sensory and consumer sciences, traditional methods must first be explained. As indicated by the definition, the goal of sensory evaluation of foods is to measure, analyze and interpret reactions as activated and perceived by the senses. Selection of the appropriate methodology is therefore crucial to accurately assess product attributes of interest and to appropriately address the question at hand. With this in mind, it is important to gain an understanding of the three classes of traditional sensory methods currently practiced, which are discrimination, descriptive and affective. Traditional methodologies have laid the groundwork for the development and improvement of new methodologies and applications.

\section{Discrimination}

Discrimination testing is a class of tests used to determine if there is a perceived difference between two products. This is a fundamental class of tests including: triangle, duo-trio, paired-comparison and directional difference tests all of which yield very valuable information. If a difference is detected, this may warrant further investigation of the product in question to determine the source of the difference (Stone, Blieibaum, \& Thomas, 2012). The triangle, duo-trio and paired comparison tests are the three most commonly used discrimination tests. A brief description of these three tests will provide a more thorough explanation to improve the understanding of the methodology and implementation. 
Paired-Comparison. The paired-comparison test presents the test subjects with two product samples. Subjects are then asked to indicate which sample exhibits more of a given characteristic. For example, subjects may be presented with two chocolate chip cookies and asked to identify the cookie that is most sweet. This is a forced choice test, requiring subjects to make a decision and select one product or the other, with a chance probability of $p=1 / 2$ (Stone et al., 2012).

Duo-Trio. In a duo-trio test, subjects are presented three samples, one of which is labeled as the reference or control. Subjects are instructed to indicate which sample is most similar to the reference. This method may be considered similar to conducting two paired-comparison tests in which each sample is compared separately to the reference sample. The probability associated with this test mirrors other two-product tests with a chance probability of $p=1 / 2$ (Stone et al., 2012).

Triangle. Of the three most common discrimination tests, the triangle test is the most well-known and practiced. This test presents the subjects with three samples and the task of selecting the one sample that is different (or identifying which two samples are most similar). This method is considered to be more sensitive than the other two methods, with a chance probability of $p=1 / 3$. Similarly to duo-trio tests, triangle tests may be considered similar to conducting three paired-comparison tests. This test proves more challenging for subjects as they must evaluate and remember the sensory characteristics of the first two samples before evaluating the third (Stone et al., 2012).

\section{Descriptive Analysis}

Descriptive analysis of food products is another common method and one of the most advanced. This testing method requires a small panel of about 10-12 subjects who 
work to develop and convey word descriptions of products to sensory professionals that can be used to guide development in products as related to the sensory attributes influencing preference. Researchers have focused their attention on the many methods of descriptive analysis through the continuous development. In summary, descriptive analysis is defined as follows:

... a sensory methodology that provided quantitative descriptions of products, obtained from the perceptions of a group of qualified subjects. It is a complete sensory description, taking into account all sensations that are perceived-visual, auditory, olfactory, kinesthetic, etc.- when the product is evaluated... The evaluation is defined in part by the product characteristics as determined by the subjects and in part by the nature of the problem (Stone et al., 2012).

Several descriptive analysis methods exist which represent different approaches and philosophies, these include: the Flavor Profile Method, Texture Profile Method, Quantitative Descriptive Analysis® (QDA), the Spectrum ${ }^{\mathrm{TM}}$ method, Quantitative Flavor Profiling, Free-Choice Profiling, and other generic approaches (Murray, Delahunty, \& Baxter, 2001). Methods of particular interest will be briefly described.

Quantitative Descriptive Analysis (QDA®). Descriptive analysis encompasses both qualitative and quantitative methods. Upon identifying weaknesses with qualitative approaches, interest peaked in the use of quantitative methods. Developed in the 1970s, Quantitative Descriptive Analysis (QDA®), created the opportunity to overcome perceived disadvantages of previously used methods (Flavor Profile and Texture Profile methods)(Murray et al., 2001; Stone et al., 2012). QDA® requires a thoroughly trained 
panel of subjects to assess and describe all sensory properties of a product. Subjects are intensively screened using discrimination type testing and are selected carefully based on the objectives of the project (Society of Sensory Professionals, 2010; Stone \& Sidel, 2004).

A panel leader facilitates the training process without active participation or interference in an effort to avoid bias (Murray et al., 2001). The trained panel is then required to develop appropriate, non-technical language to scale the newly defined attributes using an unstructured line scale. Training requires approximately 10-15 hours for panelists to understand the product attributes. To increase the reliability and validity of responses, $\mathrm{QDA} \circledast$ relies on a repeated measures design which is often analyzed using Analysis of Variance (ANOVA). A spider diagram is often used to display the results (Figure 1).

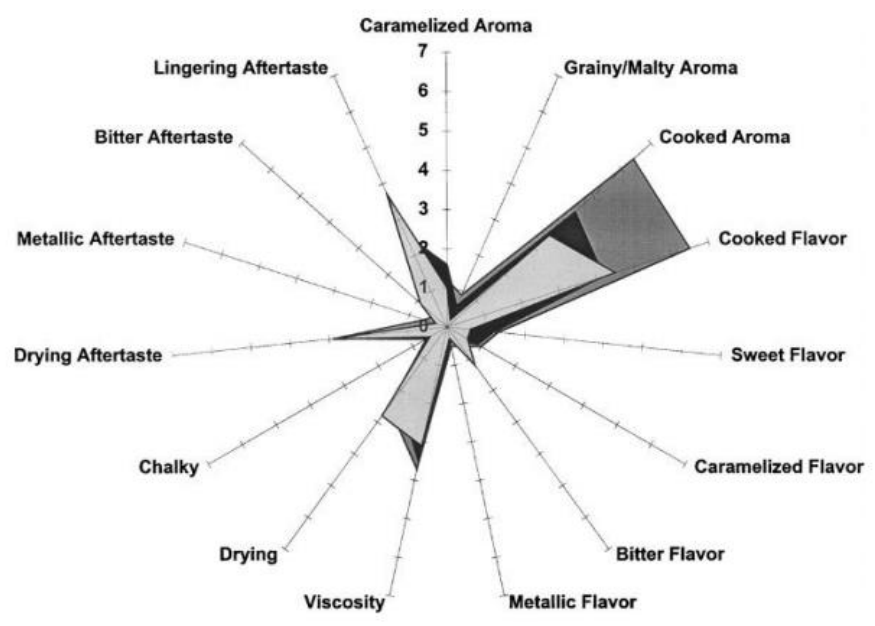

Figure 1. Graphical representation of the sensory profiles of reduced fat milk stored at $6^{\circ} \mathrm{C}$. Individual attributes are positioned like the spokes of a wheel around a center (zero, or not detected) point, with the spokes representing attribute intensity scales, with higher (more intense) values radiating outward (excerpted from Chapman, Lawless, \& Boor, 2001). 
One limitation of QDA® is the inability to compare results across laboratories and between panelists (Murray et al., 2001); however, training panelists is less time intensive than other methods such as the Flavor Profile Method and Spectrum ${ }^{\mathbf{T M}}$.

The Spectrum ${ }^{\mathrm{TM}}$ Method. The Spectrum ${ }^{\mathrm{TM}}$ Method is another form of descriptive analysis and was developed in the 70s by Gail Vance Civille to further adapt the Flavor Profile Method and Texture Profile Method. The goal of this testing methodology is to examine the entire "spectrum" of product attributes using reference lists, trained panels and scaling procedures (Murray et al., 2001). Similar to the QDA® methodology, panelists generate the terminology; however, Spectrum ${ }^{\mathbf{T M}}$ allows one panel to adopt the language developed by another. This process is much more time intensive, requiring approximately 15-20 hours for language development, 10-20 hours for familiarization with the measurement tool, 15-40 hours to practice, 10-15 hours to refine understanding of small product differences, and 15-40 hours for final calibration. The scales used are considered absolute so that for example, an intensity level of 5 is equal across all attribute scales which may make the calibration of most attributes feasible (Murray et al., 2001). With this in consideration, the outcomes are deemed worthy of the large time and financial investment.

Qualitative Multivariate Analysis. As discussed previously, descriptive analysis methods can be either qualitative or quantitative. The integration and combination of methods has shown to be successful to achieve a greater understanding of consumers(Drake, Lopetcharat, \& Drake, 2009) . Of such methods, Qualitative Multivariate Analysis (QMA), combines home-use testing, group discussion, and product mapping. Invented by Jacqueline Beckley, QMA is designed to take advantage of 
qualitative tools while avoiding the potential biases incurred from the similar conventional methods (Beckley, Paredes, \& Lopetcharat, 2012).

This method is not strictly a descriptive method and can be better classified as relating to 'new consumer techniques,' because it uses a series of tests for product optimization. With a variety of data being collected from consumers (usually about 10-15 subjects), this method allows researchers to gain more insight into consumers' wants and needs while avoiding the researcher's interference. It then becomes possible to discover and better understand the relationship between the consumer's values, the product and the product experience as perceived by the consumers.

\section{Affective Testing}

The third class of traditional sensory methods is affective testing and is a crucial component in any sensory program. Depending on the objectives of a given project, this class is also referred to as acceptance, preference, consumer or guidance testing. In the product development process, affective testing is often conducted after analytical testing such as descriptive analysis and discrimination tests (Stone et al., 2012). In general, acceptance testing measures a consumer's liking or preference of a product. Products can be directly compared to each other to identify which one is preferred or can be measured indirectly by determining which product scores significantly higher compared to other products tested individually. Acceptance testing utilizes scaled measurements to determine the degree of liking while preference methods produce ordinal data that only applies to the tested sample set (Hein, Jaeger, Carr, \& Delahunty, 2008; Lim, 2011).

Paired-Comparison. As discussed previously, this testing method can be used to discriminate between products. Additionally, this test can ask subjects to indicate his/her 
preference when presented a pair or samples. A "no preference" option may be made available to subjects or "like both equally" and "dislike both equally" may also be choices. Regardless, samples are presented in a random order across subjects. Although no magnitude of preference can be determined from paired-comparison data, this method is greatly utilized by marketing research (Stone et al., 2012).

Hedonic Scaling. Most commonly, a 9-point hedonic scale has been used to evaluate food products and measure consumer acceptance. This is a balanced bipolar scale with a neutral center, four negative, and four positive categories (Lim, 2011). Each point on the scale is labeled with short phrase descriptors to clearly distinguish categories as they lay on the continuum (Peryam \& Pilgrim, 1957). Figure 2 exemplifies a typical hedonic scale used to evaluate food.

Overall, how much do you like or dislike sample 487 ?

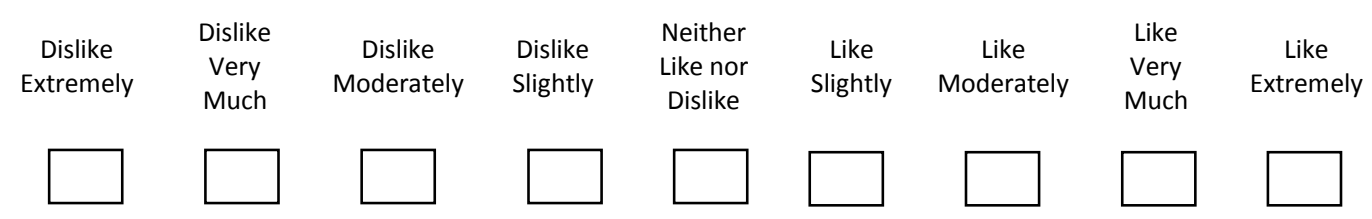

Figure 2. Example of a 9-point hedonic scale

The descriptive labels are presented to give subjects guidance in responding accurately and also to help researchers interpret the data accordingly. Since the development of the 9-point hedonic scale and introduction to the food industry as the "advanced taste-test method" in 1952 (Peryam \& Girardot, 1952), the history of sensory evaluation in the industry has been deeply rooted in hedonics. In fact, this scale has been used in its original form since its development when it quickly became the method of choice in industry, government and academic research (Lim, 2011). Use of this testing 
method has laid the foundation for further method development with a variety of applications.

\section{Evolution of Sensory Methods}

Traditional sensory methods employed all aim to gain feedback from consumers. It must be understood that the sensory and hedonic experience cannot be directly measured; therefore, researchers must use the appropriate method and measurement tool in order to interpret the quantitative or qualitative data provided which represents those experiences (Lim, 2011). As new sensory evaluation methods have been developed over time, it is apparent that they are deeply rooted in hedonics. The hedonic scale continues to be one of the primary measurement tools implemented as part of, in addition to, or as a means of validating these new methods (Cardello et al., 2012; de Wijk, Kooijman,

Verhoeven, Holthuysen, \& de Graaf, 2012; King, Meiselman, \& Carr, 2010; King, Meiselman, \& Thomas Carr, 2013; Ng, Chaya, \& Hort, 2013).

\section{The Role of the Hedonic Scale}

The hedonic scale used in affective testing can provide valuable product/attribute specific data for product developers and has proven to be simple, widely accepted, and very effective in predicting acceptance and understanding hedonic differences between products (King et al., 2010; Lim, 2011). As discussed by Lim (2011) the limitations include that the scale has: unequal scale intervals, lack of a zero point, inherently provides only ordinal data, a limited number of response choices and a tendency exists for consumers to avoid end-points. Despite these limitations, the hedonic scale still functions as an industry standard and is used in conjunction with other methods to receive a more comprehensive perspective of consumer acceptance. However, as the food 
industry continues to grow and the marketplace becomes saturated with similar products, consumer researchers and sensory scientists are striving to explore the minds of consumers to reveal greater distinctions between products and ultimately deliver multidimensionally desirable products to consumers. In order to receive actionable feedback from consumers, researchers must begin by asking the right questions with an appropriate measurement tool.

\section{Limitations of Traditional Methods}

Lim (2011) suggests that the simplest conceptualization of sensory and hedonic measurement involves a two-stage process (Figure 3).

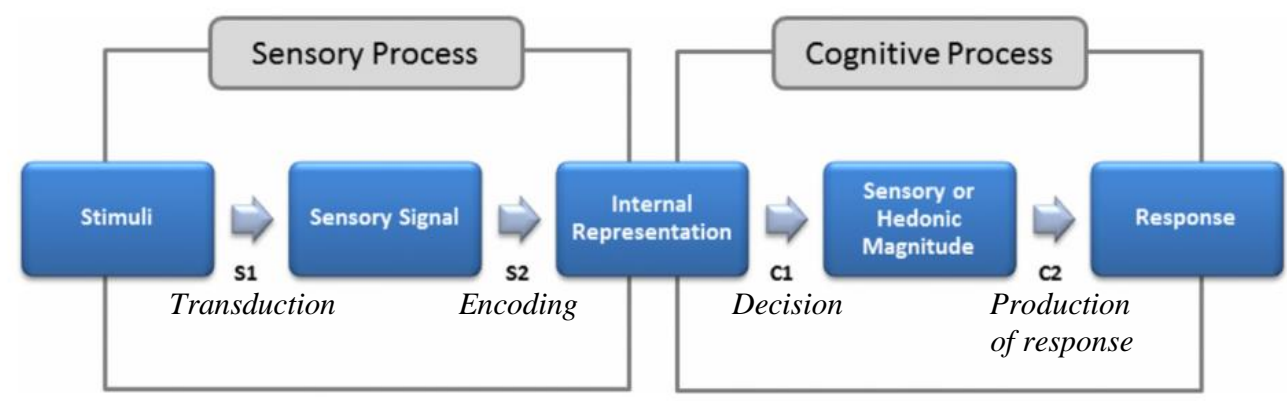

Figure 3. A simple illustration of the stimulus-response model (adapted from Lim, 2011).

As shown in Figure 3, the first stage of processing sensory information involves the transduction (S1) and encoding (S2) of a stimulus, followed by deciding how to respond (C1) and then producing that response (C2) (Lim, 2011). This model relies heavily on the active engagement of the cognitive decision making process when responding to a sensory stimulus. Traditional sensory methods attempt to measure that response; however, other factors driving the response are not captured when using traditional sensory methods and should be accounted for. 
As sensory information is processed, the mind begins to assign meaning and an identity to the object through learned experiences and associations (Thomson, Crocker, \& Marketo, 2010). This results in the creation of conceptualizations. The response to a sensory stimulus can now be seen as the combination of the reaction to the object (or product at hand) and the conceptualizations associated with it. The sensory experience from the exposure of the given product is linked to the conceptualization. Thomson et al. (2010) identifies and illustrates the three broad categories of conceptualizations: functional, emotional and abstract (Figure 4).

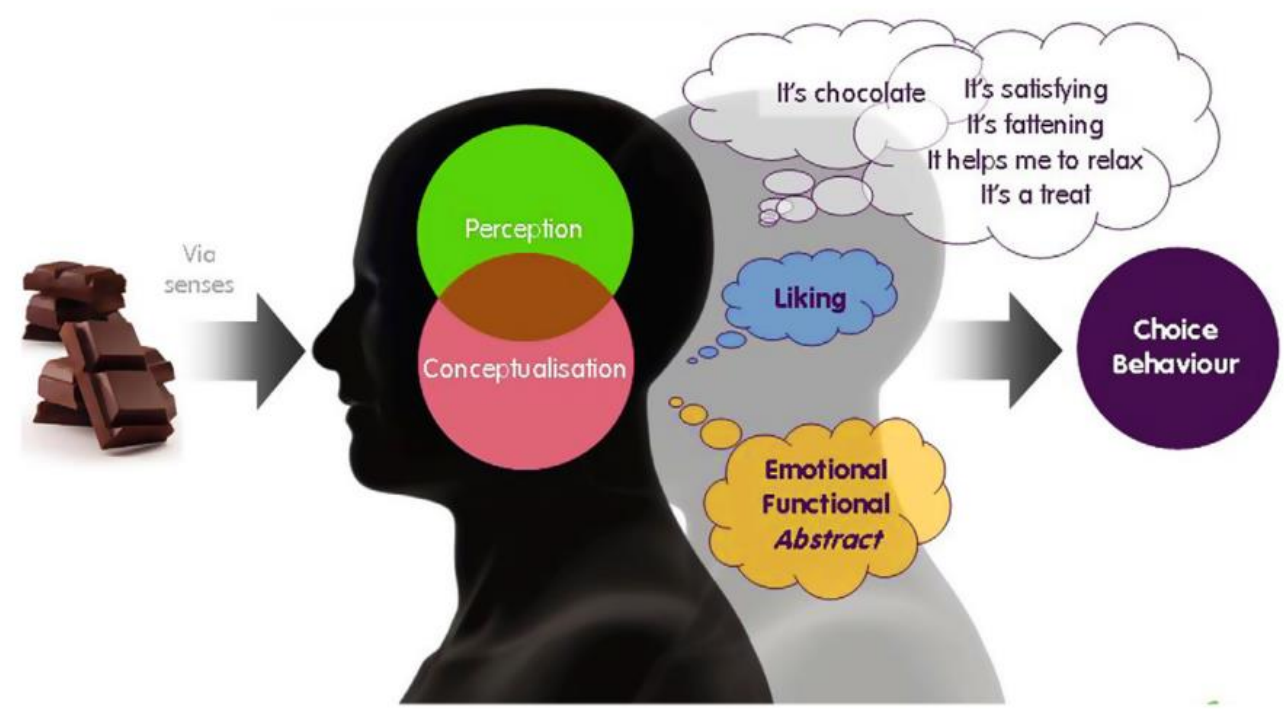

Figure 4. Perception and conceptualization (excerpted from Thomson et al., 2010).

Figure 4 demonstrates the many factors that determine choice behavior. In addition to the factors present in the stimulus-response model, many non-cognitive or subconscious processes contribute to choice behavior, but are not as apparently intuitive or easily accessed by researchers. This poses the challenging task of developing methods to measure and better understand these learned conceptualizations and factors driving consumption and choice behavior. 
Investigating the role of emotion (Figure 4) in addition to product liking may be of particular value to deepen the current understanding of drivers of consumption and/or liking. Gaining a deeper insight may be executed effectively with a more holistic evaluative approach, accounting for physiological and psychological characteristics that affect food intake and choice behavior.

\section{Food Intake Regulation}

Recent research has expanded traditional knowledge of internal mechanisms associated with the regulation of body energy homeostasis and has identified other crucial contributors (Shin et al., 2009). With this in mind, it becomes of interest to investigate brain mechanisms (particularly reward mechanisms associated with food intake) to fully understand the processes by which our body regulates (homeostatically and nonhomostatically) body energy, and drives food choice, behavior and intake.

The consumption of food for energy is an inherent need for all mammals. Traditionally, the mechanisms for regulating feeding were concerned with only the hypothalamic neural pathways and ventromedial nucleus (Saper et al., 2002; Shin et al., 2009; Zheng and Berthoud, 2007). Research within the last ten years, however, has realized a more complex system also involving the engagement of the caudal brainstem, the senses and the cortico-limbic system (Shin et al., 2009; Zheng and Berthoud, 2007). With the involvement of these combined systems identified, it is now generally accepted that cognitive, hedonic and emotional neural processes are also crucial to energy balance (Figure 5, Zheng and Berthoud, 2007) and thus introduces a distinction between homeostatic and non-homeostatic regulation (Shin et al., 2009; Zheng and Berthoud, 2007). 


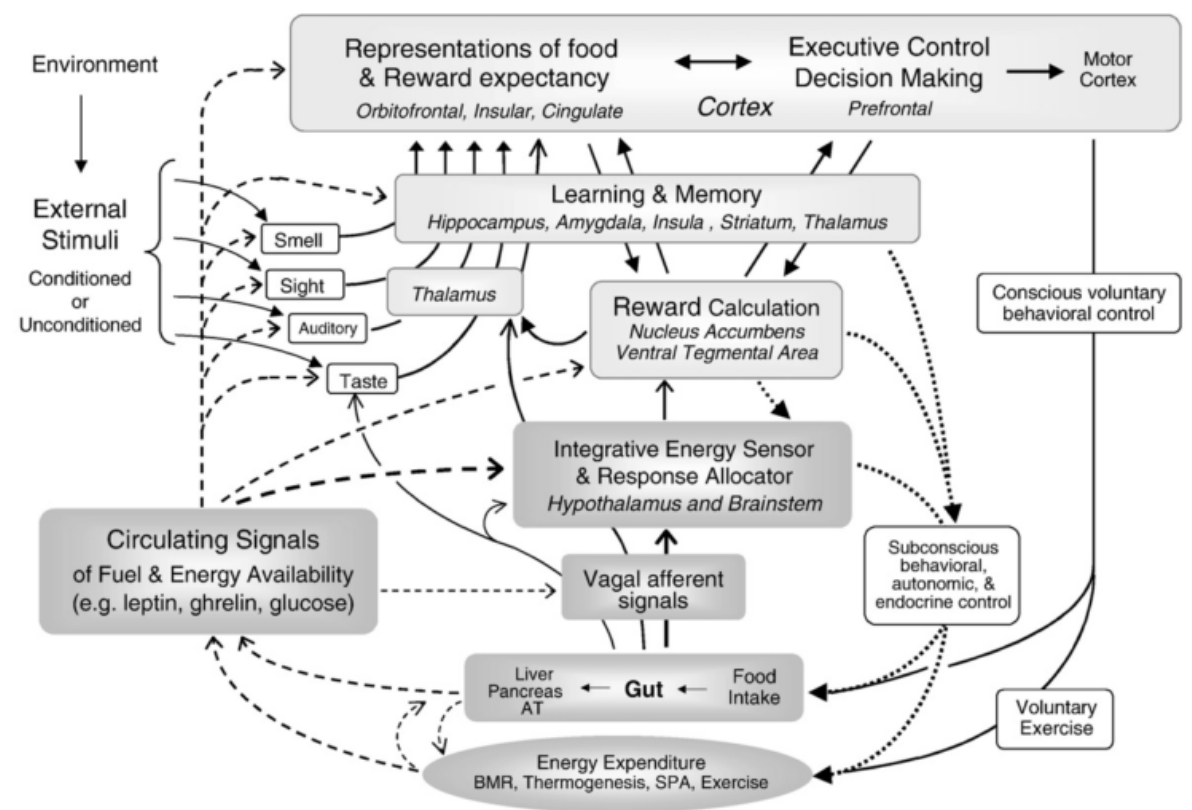

Figure 5. Highly schematic diagram showing neural systems and flow of information involved in the control of food intake and regulation of energy balance. The traditional regulatory circuitry using neural and hormonal feedback from the internal milieu acting on hypothalamus and brainstem is shown on the bottom (dark grey boxes). Sensory and cortico-limbic brain areas used for processing information from the environment are shown in the upper half of the diagram (light gray boxes). The extensive influence of circulating and neural internal feedback signals on sensory processing and cortico-limbic systems concerned with reward, emotion, learning and memory is emphasized with broken line/open arrows (excerpted from Shin et al., 2009).

Figure 5 depicts both homeostatic and non-homeostatic systems involved in food intake and energy balance. For the purpose of this review, the two systems will be briefly investigated to adequately explain the neural processes that contribute to food choice and intake, however, as shown in Figure 5, it should be understood that these two systems are completely intertwined.

\section{Traditional View of Homeostatic Regulation}

Past research has proposed that over long periods of time, an individual's body weight is maintained at a stable point and regulated by a feedback mechanism that occurs in the brain. This is often referred to as the body weight set point theory (Berthoud, 2002; 
Harris, 1990; Shin et al., 2009; Woods, Schwartz, Baskin, \& Seeley, 2000). There are three main components of this system: (1) feedback signals, (2) neural integration, and (3) effector pathways (Shin et al., 2009). As foods are ingested, the body responds to the different food components and nutrients accordingly. Mechano- and chemo-sensors detect the food components and send neural and/or hormonal signals to the central controller in the hypothalamus. This action, in turn, triggers the release of hormones used in the regulation of metabolites (Harris, 1990; Shin et al., 2009). The arcuate nucleus, located in the mediobasal hypothalamus, integrates the information and determines a behavioral, autonomic and/or endocrine response executed through an effector pathway to modify energy balance (Shin et al., 2009). These processes are innate and involuntarily responses carried out to maintain homeostasis.

In addition to the metabolic information carried to the mediobasal hypothalamus, neurons in the lateral hypothalamus receive information from areas in the brain associated with learning and memory, and with the vagal and visceral sensory input (Shin et al., 2009). With the continued extensive research in this area, the discovery of new information (particularly the discovery of leptin, a hormone secreted from adipose tissue) has contributed to a better understanding of the aforementioned system. This research has not negated the feedback control system describing the homeostatic regulation of body weight; however, has recognized that the system involves much more complex interactions. Now, it is generally accepted that multiple other factors (non-homeostatic) also influence the regulation of food intake and energy balance; however, the set point theory is still used as a reference (Berthoud, 2002; Harris, 1990; Shin et al., 2009; Zheng and Berthoud, 2007). 


\section{Non-homeostatic Regulation}

In addition to the hormonal regulators of hunger and satiety, brain reward systems also contribute to food intake behavior. The integration of the non-metabolic controls of eating are primarily processed in the prefrontal cortex, amygdala, and ventral striatum (Figure 5, Berthoud, 2006). These controls include cognitive, hedonic, and emotional neural processes which require a much more detailed investigation to effectively evaluate the links between the rewarding value of food and the emotional responses through the eating experience as they relate to sensory characteristics of foods.

\section{Food Reward}

Initiating the consumption of a food item first requires a conscious, cognitive decision to do so. Berridge et al. (2010) defines food reward as "a composite process that contains "liking" (hedonic impact), "wanting" (incentive motivation), and learning (associations and predictions) as major components." The food reward is an incentive process and is primarily focused on taste, smell, sight and the feel of food (Berridge, 1996). Consumption of palatable food items, chocolate, a high sugar, high fat food for example, has been associated with mood elevation (Macht \& Mueller, 2007) and such emotional responses have reinforced mechanisms, which encourage beneficial stimuli and suppress potentially harmful behaviors (Shin et al., 2009). Thus, through experience by learned responses, humans have created a rewarding value associated with the respective food components. These responses involve the activation of the corticolimbic and mesoaccumbens brain circuits. Figure 6 highlights the regions in the brain that are involved in these processes. 


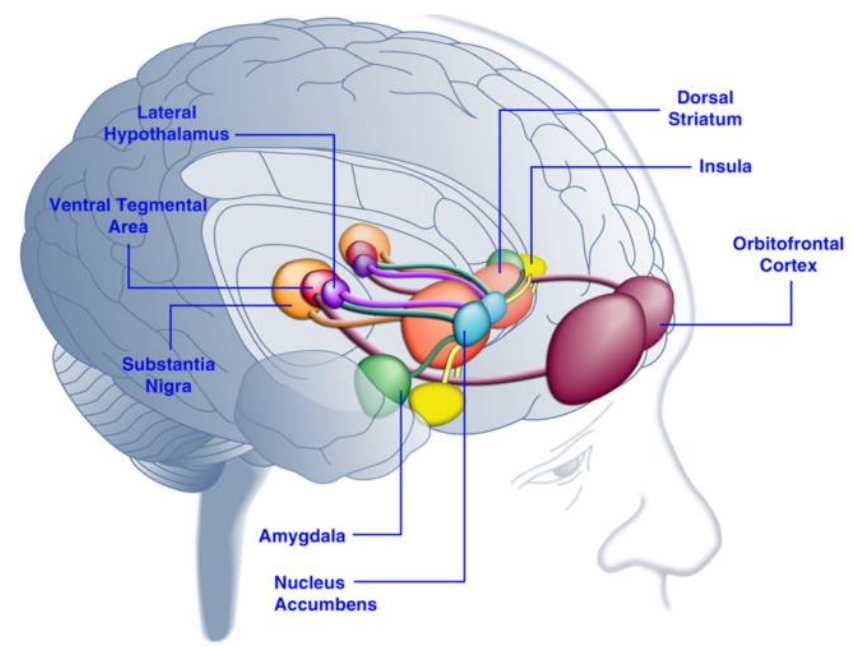

Figure 6. Areas of the human brain activated in response to palatable food or foodassociation cues (excerpted from Kenny, 2011).

While the insula processes information regarding the evaluation of taste, research indicates that the orbitofrontal cortex and amygdala process information associated to the rewarding value of food (Holland and Gallagher, 2004; Kenny, 2011; Sescousse et al., 2010). Regulating information regarding the motivational and incentive qualities of foods are the nucleus accumbens and dorsal striatum, which receive information from the ventral tegmental area and substantia nigra. The lateral hypothalamus also plays a crucial role by directing food-seeking behavior. These areas of the brain work collaboratively in learning the hedonic attributes of food with a focused effort on obtaining food rewards by assessing the incentive value of environmental stimuli (Kenny, 2011).

\section{Components of Food Reward}

The reward processes are not limited to the physical taste stimulus; however, is also comprised of the individual's physiological state and previous experiences (Berridge, 1996). The identification of the three distinct components of reward, "liking," "wanting," and learning (Berridge, 1996, 2009; Berridge et al., 2009; Finlayson et al., 
2007) are of significant research interest to gain more insight in food reward as it correlates to food choice and eating behavior. These three psychological components of food reward often occur together; however, each has separable brain systems, which allows a degree of disassociation. A better understanding of the relationship between "liking" and "wanting" and their contribution to the reward process can give direction to necessary interventions of food consumption, especially for given populations.

"Liking." The "liking" component in food reward is generally defined as the hedonic reaction to the pleasure of a reward and is generated by the subcortical brain systems (Berridge, Ho, Richard, \& DiFeliceantonio, 2010; Berridge, 2009). As described briefly above, many sites activated by food pleasure including: the orbitofrontal cortex (OFC), anterior cingulate cortex, anterior insula cortex, ventral pallidum, nucleus accumbens, amygdala, and some lower brainstem systems (Berridge et al., 2010).

"Wanting." On the other hand, "wanting" is the motivational component or incentive salience of reward, which is triggered by reward-related cues. Incentive salience is attributed to rewards and their predictive cues; the cues then become triggers of "wanting" (Berridge, 2009). This motivational component promotes the approach to and the consumption of the food item that has been assigned the rewarding value (Berridge et al., 2009). This definition of "wanting" is much different than the commonly used word. The idea of "wanting" or incentive salience, depends on cues and physical reward stimuli and disregards cognitive expectations of future outcomes and may not be accessible to conscious awareness. The degree to which a cue influences "wanting" depends on the state of the brain and previous experience with the food reward, which in some cases may be a resultant of hedonic attributes (Berridge et al., 2010; Peciña \& 
Smith, 2010). Berridge et al. (2010) indicates that these mechanisms are located in the nucleus accumbens, striatum, and amygdala.

Dissecting Liking from Wanting. Although "liking" and "wanting" often occur simultaneously, they are psychologically and neurobiologically distinguishable (Berridge, 2009). In fact, it is possible that the brain systems of "wanting" can motivate consumption behavior regardless of the hedonic "liking" component; that is, an increase in consumption can be triggered by "wanting" even if the hedonic "liking" of the food does not also increase (Berridge et al., 2010). In effect, "wanting" has a greater influence on food intake. A stimulus or reward-related cue makes the reward highly "wanted" by motivating appetitive behavior. Methods of measurement of the two components have been investigated (Finlayson, King, \& Blundell, 2008); however, the challenge of completely dissecting the two still exists.

Considering the research in the past ten years, it is evident that these brain mechanisms influence and have implications for an array of issues involving food: restrained eating, food addiction, overeating and other related eating disorders (Berridge, 1996; Berridge et al., 2010; Finlayson et al., 2008; Kenny, 2011; Peciña \& Smith, 2010). Despite inherent homeostatic body weight regulation mechanisms, complex food reward systems exist which may override such metabolic controls. Current research provides new insights and future directions for understanding how the environment can affect physiological and psychological controls of appetite and homeostatic body regulation. A deeper understanding of these mechanisms may serve as a link to better understanding the psychological involvement in the factors determining food choice and behavior. This information can also help identify and define the relationship between sensory 
characteristic of foods, which may influence both "liking" and "wanting." Additionally, other psychological factors have been identified, such as emotion, which may also directly influence consumer's choices and the perceived eating experience. These components should be further evaluated, especially in the context of sensory and consumer science where product acceptability is most commonly determined through a series of hedonic ('liking') attribute questions, which may not effectively capture the incentive salience value associated with the product in question.

\section{Emotion}

As discussed above, physiological and psychological factors influence the consumption experience. Emotion and mood have been identified as interacting with food choice in either strong or subtle ways (Gibson, 2006) and such stand out as a psychological aspects involved in processing information regarding food intake. Research conducted for the development of the Food Choice Questionnaire determined nine factors as motives underlying the selection of food: health, mood, convenience, sensory appeal, natural content, price, weight control, familiarity and ethical concern (Steptoe, Pollard, \& Wardle, 2013). The measurement of affective states has primarily been of interest in the clinical psychology field of study; however, identification of mood as a factor contributing to food choice supports the ongoing consumer science research of how to measure affective states in the consumption experience (Richins, 1997).

\section{Working Definition}

At this point, it is important to understand the distinction between mood and emotion. Defining "emotion" has been a well-known controversy and to date, no one definition of emotion has been agreed upon in any discipline (Mulligan \& Scherer, 2012; 
Scherer, 2005). Mulligan and Scherer (2012) have developed a partial inventory of the main elements of emotion as part of a working definition. The proposed working definition is as follows:

" $x$ is an emotion only if

- $x$ is an affective episode

- $x$ has the property of intentionality

- $x$ contains bodily changes (arousal, expression, etc.) that are felt

- $x$ contains a perceptual or intellectual episode, $y$, which has the property of intentionality

- the intentionality of $x$ is inherited from the intentionality of $y$

- $x$ is triggered by at least one appraisal

- $x$ is guided by at least one appraisal" (Mulligan \& Scherer, 2012).

As described in the above definition, "an affective episode" implies that emotions are short-term and have a beginning and end, whereas moods may persist longer than several minutes in the absence of obvious stimulus (Gibson, 2006; Mulligan \& Scherer, 2012). Both mood and emotion may influence food choice via physiological effects, or, mood and emotion may be an outcome of food choice (Gibson, 2006). In addition to moodpreferences, attitudes, affect disposition and interpersonal stances are other affective phenomena that have been identified by Scherer (2005); the semantic overlap of these terms creates confusion, however, dissecting the features of emotion attempts to more clearly distinguish it from the other terms (Mulligan \& Scherer, 2012). 


\section{Distinguishing Features of Affective Phenomena}

Many features of emotions should be considered to effectively differentiate the affective phenomena including event focus, intrinsic appraisal, transactional appraisal, response synchronization, rapidity of change, behavioral impact, intensity and duration. Each feature will be briefly explained (based on Scherer, 2005) to better clarify how the affective phenomena are distinguished.

Event focus describes the need for emotions to be anchored or in reference to an object or event. Given the above definition, emotions have the property of intentionality; in other words, emotions are generally elicited by stimulus events, whether it is an object (such as food) or event. The object or event then triggers an appraisal, which guides the response and resulting emotion (Mulligan \& Scherer, 2012; Scherer, 2005).

Intrinsic and transactional appraisals evaluate the feature of the object or person. Scherer (2005) explains that intrinsic appraisal of emotions occur independently from present needs and goals and relate to genetic (i.e. sweet tastes) and learned preferences; whereas transactional appraisals evaluate the outcome of an event and how it relates to the appraiser's salient needs, desires, and/or goals.

Response synchronization is emphasized as one of the most important features of emotions (Scherer, 2005). As indicated by the working definition explained above, emotions are triggered by events and thus guide a response; response synchronization refers to how the response corresponds and the process by which an organism coordinates the response with the appraisal of the event. This also relates to the rapidity of change. The appraisal of events can change rapidly as the appraiser uses new information to reevaluate events. As a result, the emotional response is likely to change rapidly. 
Behavioral impact of emotions refers to the effect that emotion-consequences have on behavior (Scherer, 2005). This behavioral component can have implications for communication and social interactions as it relates to the motor expression component of emotion. The intensity of emotions is also very important distinguishing characteristic, considering the role that emotions play in behavioral adaptation (Scherer, 2005). With the high intensity and quick response synchronization, the duration of emotions is relatively short. Conversely, moods can last much longer because they have little behavioral impact. Using this design feature approach, Table 1 summarizes the distinguishing characteristics of the aforementioned phenomena. 
Table 1. Design feature differentiation of different types of affective phenomena (excerpted from Scherer, 2005).

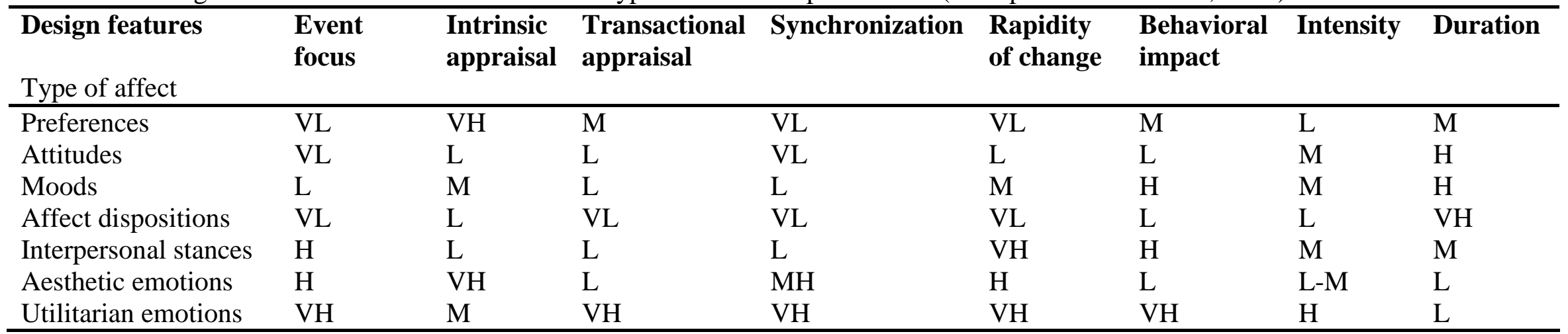

Note: $\mathrm{VL}=$ very low, $\mathrm{L}=$ low, $\mathrm{M}=$ medium, $\mathrm{H}=$ high, $\mathrm{VH}=$ very high.

Design feature definitions

Event focus: the need for an object or event to anchor/ be in reference to

Intrinsic appraisal: evaluation of the feature of the object independent of present needs and/or goals

Extrinsic appraisal: evaluation of an outcome related to the appraiser's needs, desires and/or goals

Synchronization: coordination of response and appraisal of the event

Rapidity of change: the likeliness of the response to change rapidly

Behavioral impact: the effect that the affect-consequence has on behavior

Intensity: degree/extent that the affective phenomenon is experienced

Duration: the length of time the affective phenomenon is experienced (relative to each other) 
As indicated in Table 1, Scherer (2005) finds it necessary to distinguish between different types of emotions. In this case, utilitarian emotions refer to emotions that correspond to events that may have consequences impacting one's wellbeing; examples of these emotions include anger, fear, joy, disgust, sadness, shame and guilt (Scherer, 2005). Most emotion research focuses on these emotions. On the other hand, aesthetic emotions are produced by an appreciation of an object's intrinsic qualities. Examples include being moved or awed, being full of wonder, admiration, bliss, ecstasy, fascination, harmony, rapture and solemnity (Scherer, 2005).

\section{Emotion and Food Experience}

With the basic understanding of emotion and its defining features, the relationship between food and emotion can now be examined. To begin, the role of the orbitofrontal cortex in food reward has been defined and briefly discussed. Given that taste and somatosensory information are sent to the orbitofrontal cortex and emotion results from the appraisal of a stimulus, this part of the brain is crucial in emotion and decisionmaking processes with respect to food (Rolls, 2006). Figure 7 depicts the sensory information processed by the orbitofrontal cortex, which contributes to the emotion either preceding the food experience or as an outcome of the experience. 


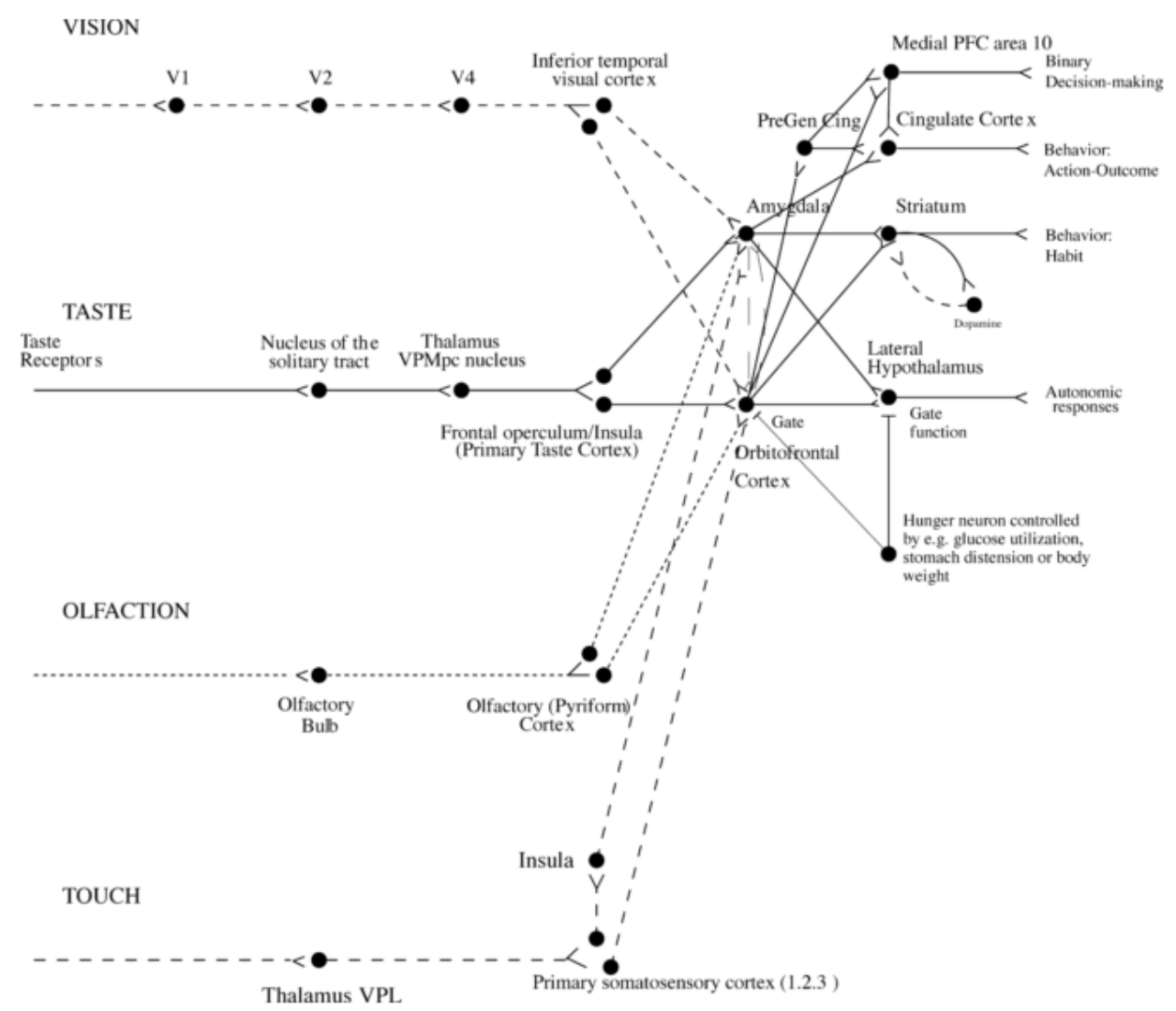

Figure 7. Schematic diagram showing some of the gustatory, olfactory, visual and somatosensory pathways to the orbitofrontal cortex, and some of the outputs of the orbitofrontal cortex in primates. The secondary taste cortex and the secondary olfactory cortex are within the orbitofrontal cortex. V1—primary visual cortex, V4-visual cortical area V4 (excerpted from Rolls, 2006).

Recalling that emotion has a behavioral impact, reward and punishment evaluation of a given stimuli may produce learned changes in a behavior either to perform an action to obtain the reward, or to avoid the punishment (Rolls, 2006). Macht (2008) has identified several factors that contribute to emotion-induced changes of eating. With this information, the effects of emotions on eating were organized into the following classes:

1. "Emotions aroused by food stimuli affect food choice. 
2. Emotions high in arousal or intensity suppress eating due to incompatible emotional responses.

3. Emotions moderate in arousal or intensity affect eating depending on motivations to eat:

a. In restrained eating, negative and positive emotions enhance food intake due to impairment of cognitive control.

b. In emotional eating, negative emotions elicit the tendency to be regulated by eating and, as a consequence, enhance intake of sweet and high-fat foods.

c. In normal eating, emotions affect eating in congruence with their cognitive and motivational features" (Macht, 2008)

This five-way model demonstrates that emotions may influence or may be an outcome of psychological, physiological or biological states, which can severely impact food intake and choice behavior. To illustrate this model, Macht (2008) created a flow diagram. Figure 8 illustrates the model discussed above and the impact on eating.

Studies aiming to understand the relationship between food, eating behavior, characteristic of an individual, social and physical environment and emotion have used a variety of methods (Macht, Meininger, \& Roth, 2005); Desmet and Schifferstein (2008) divide the research into two categories: studying the effect of emotion on eating behavior versus studying the effect of eating behavior on emotion. For the purpose of the review, only the food-induced emotion class will be further discussed (see highlighted section in Figure 8). 


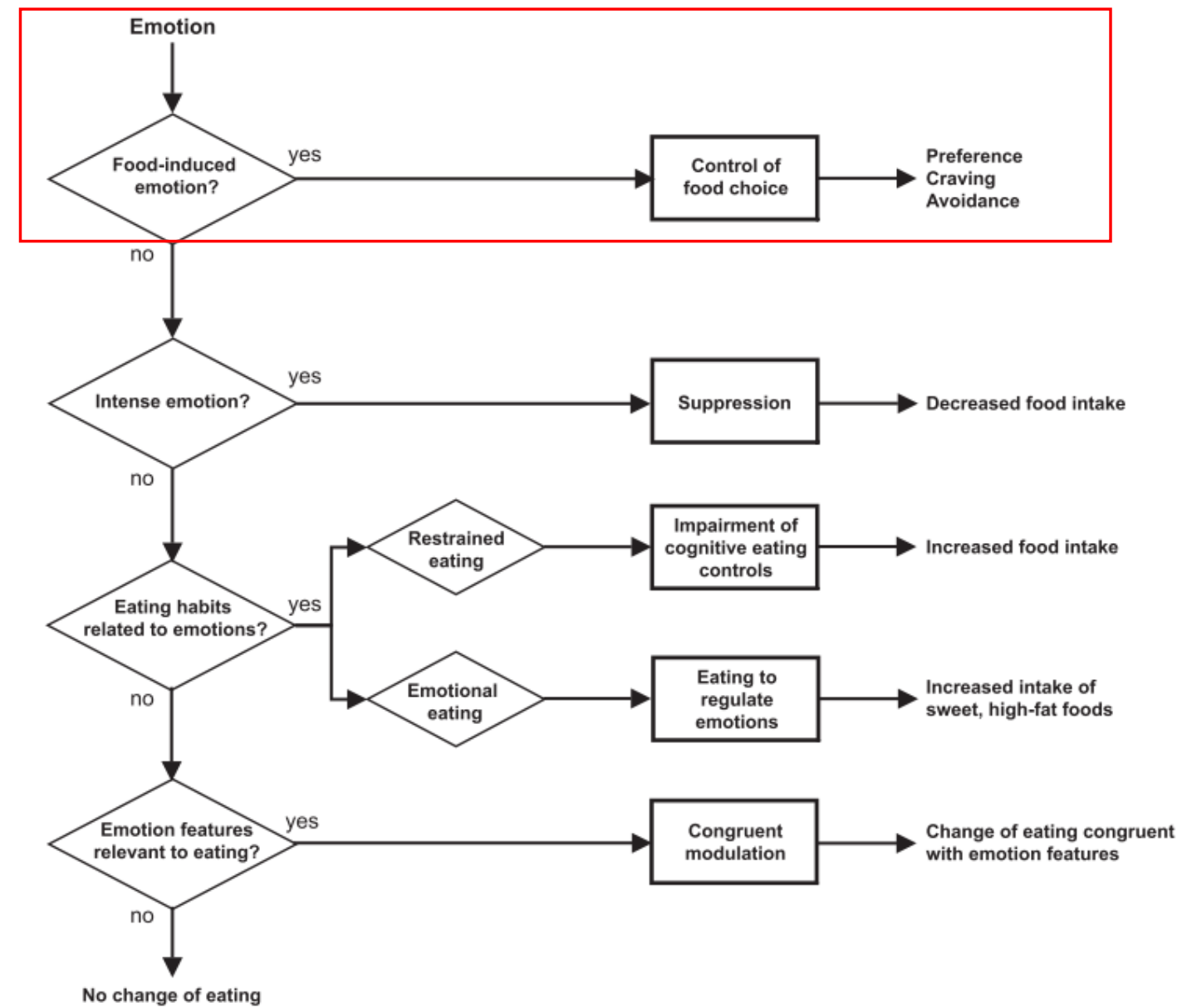

Figure 8. A flow diagram to predict basic classes of emotion-induced changes of eating (excerpted from Macht, 2008). The outlined area represents the main focus of this review.

Food-Induced Emotions. Research interested in food-induced emotions generally focuses on the effect of sensory attributes of food on people's emotions or affective states (Desmet \& Schifferstein, 2008). To address the ambiguity in structure and content of emotions examined in the consumption experience, Laros and Steenkamp (2005) have proposed a hierarchal model of consumer emotions. This model uses three levels to specify the emotions: (1) positive and negative affect, (2) basic emotions (four positive and four negative), and (3) specific emotions (Laros \& Steenkamp, 2005). Forty- 
two specific emotions were considered based on the consumption emotion set (CES) developed by Richins (1997) as a set of descriptors representing the most frequently experienced emotions in consumption situations (Laros \& Steenkamp, 2005; Richins, 1997).

Desmet and Schifferstein (2008) aimed to further understand the emotions that healthy people experience in response to eating and tasting food in everyday life and the types of internal and external conditions that are responsible for the emotions. The authors conducted two studies in which participants were asked to indicate the emotions experienced in everyday interactions with food, followed by reporting the intensity of each emotion experienced after tasting several food samples. Results from the two studies produced five distinct sources of food emotion:

1. sensory properties such as "I was pleasantly surprised by the taste of an exotic fruit,"

2. experienced consequences such as "I was stimulated after drinking coffee,"

3. associated consequences such as "I hope to stay healthy by eating fresh vegetables,"

4. personal or social meanings such as "I was bored by the food that reminded me of boring family lunches," and

5. behavior of agents involved such as "I was proud because my friends complimented me on my cooking” (Desmet \& Schifferstein, 2008).

The authors indicated that these five sources of food emotion may not account for all emotions experienced with all food products and expressed the need for further research. As these studies contribute to building the framework for understanding emotion in the 
food experience, it is evident that methods of measurement need to be validated and employed across many food products and food forms to truly identify the drivers of food choice and how the food effects a person's emotion.

The progression of methods used to measure emotion will be reviewed. Current emotion methodologies continue to strive toward understanding consumers. Emotion is embedded in the food experience and understanding its role in food choice presents opportunities for food manufacturers to reach and/or understand consumer choices in a more dynamic way.

\section{Current Emotion Methodologies}

The measurement of emotions in a commercial context has recently caught the attention of consumer researchers and sensory science professionals. As a result, many new methods have been developed, which strive to measure emotional responses through the food experience. The measurement of emotion is typically conducted in one of three ways: self-report questionnaires, autonomic measurements, and/or brain imaging techniques (Ng et al., 2013). Most commonly, self-report questionnaires are used in consumer testing when subjects are presented with a given food product. Many of these novel sensory methods are still in their infancy of the development process and have not undergone intensive validation-type studies. A brief review of these methodologies will provide a clear understanding of the merits of each and the opportunities for industry applications.

\section{Product Emotion Measurement Instrument (PrEmo)}

Desmet, Hekkert, and Jacobs (2000) recognized the importance of emotions involved in the eating experience and realized that the emotions elicited from product 
appearance are not clearly distinguished from emotions elicited by the total consumption experience. As a result, Desmet et al. (2000) developed the PrEmo method aimed to address two main needs: (1) a non-verbal measurement instrument and (2) a method to measure mixed emotions, elicited by product appearance, at a low intensity. PrEmo is a non-verbal, self-running (computer guided), self-report instrument that measures 7 positive emotions (desire, pleasant surprise, inspiration, amusement, admiration, satisfaction, fascination) and 7 negative emotions (indignation, contempt, disgust, unpleasant surprise, dissatisfaction, disappointment, boredom) using expressive cartoon depictions. As shown in Figure 9, each animation depicts one of the 14 emotions.

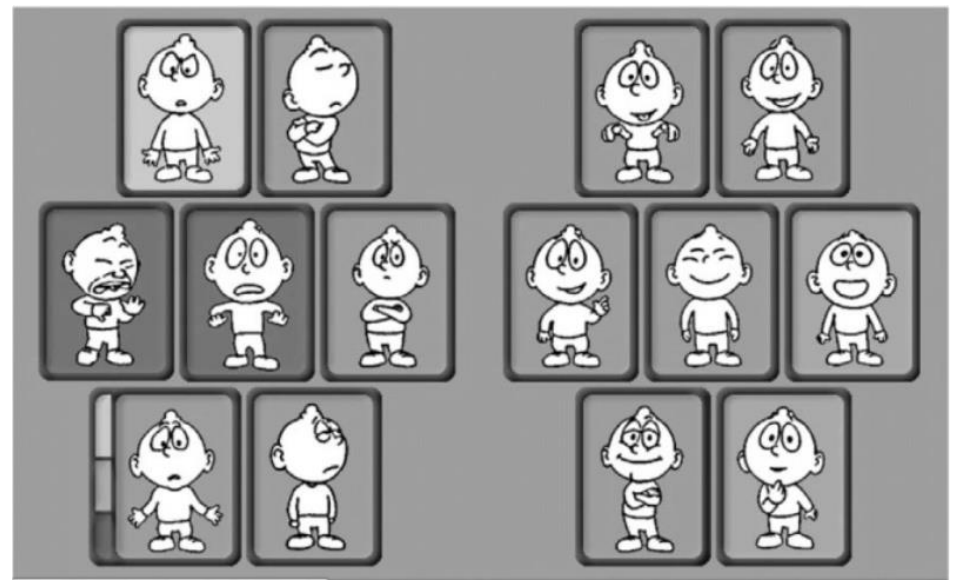

Figure 9. PrEmo animations (excerpted from Desmet, 2005).

Each animation is accompanied by a three-point rating scale which appears once the subject has clicked on the image: "I do feel the emotion," "to some extent I feel the emotion," and "I do not feel the emotion expressed by this animation" (Desmet, 2005). During a testing session, the subject is presented with a picture of a product and prompted to indicate his/her emotional response evoked by the product by selecting one or more of the animations shown on the interface. 
Development of the cartoon animations operates under the assumption that emotional expressions are universal and can be recognized reliably (Desmet, Hekkert, \& Jacobs, 2000; Desmet, 2005; Ekman \& Friesen, 1986; Ekman, 1994). Ekman and Friesen (1986) report that basic emotions, such as anger, fear, and happiness, have unique facial expressions recognized pan-culturally. The PrEmo method measures emotions beyond the basic ones identified by Ekman and Friesin (1986). To address the subtleties of the other emotions, the animations produced for the PrEmo method were carefully designed to portray total body expression, movement and vocal expression (Desmet, 2005).

PrEmo presents many opportunities for its application in consumer testing. While verbal instruments to measure emotions exist, one of the main criticisms and disadvantages of these methods is the difficulty of applying it between cultures, as emotion words often do not translate easily. Utilizing a non-verbal instrument, such as PrEmo, provides a unique language independent method that can be applied crossculturally (Desmet et al., 2000; Desmet, 2005). Additionally, this method allows a subject to report combinations of distinct emotions without asking the subjects to articulate their emotions. Conversely, one important consideration that must be made when applying this method is the appropriateness of the 14 emotions. If the presented emotions do not adequately represent the product of interest, the animations should be modified. Furthermore, this method was developed with the intention of measuring emotions elicited by product design based on appearance. More research is necessary to determine if this method can be applied to other stimuli, activating more than one sense. This method though exhibits huge potential for design researchers, which may ultimately be communicated and translated to product developers in the food industry. 


\section{The Geneva Emotion and Odor Scale (GEOS) and ScentMove ${ }^{\mathrm{TM}}$}

Odor has been generally recognized as a powerful elicitor of emotions and recent research has explored ways in which to measure the feelings induced by odors (Chrea et al., 2009; Delplanque et al., 2012; Porcherot et al., 2010, 2012). Due to the role that odor plays in the sensory perception of foods during the consumption experience, it seems necessary to briefly review these methods. As with PrEmo, current emotion and odor scales only apply to one of the five senses. Capturing this information may be crucial though to better understand how emotional responses are evoked by sensory characteristics and ultimately what impact these properties have on the eating experience.

The Geneva Emotion and Odor Scale was developed to verbally measure the subjective affective experience elicited by everyday odors (Chrea et al., 2009) and further refined to be called ScentMove ${ }^{\mathrm{TM}}$ (Porcherot et al., 2010, 2012). Results from two consumer-testing studies followed by a series of exploratory factor analyses generated 36 affective terms based on six factors:

1. Happiness/Well-Being: Pleasant, well-being, pleasantly surprised, happiness attracted, feeling awe

2. Awe/Sensuality: Desire, sensual, in love, romantic, sexy, admiration, excited

3. Disgust/Irritation: Unpleasant, disgusted, unpleasantly surprised, sickening, dissatisfaction, dirty, irritated, angry

4. Soothing/Peacefulness: Relaxed, soothed, serene, reassured, light

5. Energizing/Cooling: Revitalized, clean, refreshed, invigorated, stimulated, energetic, shivering

6. Sensory pleasure: Nostalgic, amusement, salivating (mouthwatering) 
The two studies mentioned were conducted in French and translated to English for the purpose of reporting the findings. Chrea et al. (2009) indicated that this model is not representative of all odor-elicited feelings, however this model lays the groundwork for future testing with everyday odors and provides a basis in which to measure a person's affective experience. Despite the understanding that odors have a powerful effect on emotion, no systematic, empirically derived taxonomy of olfactory-induced emotions (Porcherot et al., 2010) had been utilized until this method was developed.

The GEOS method has been compared to terms derived from the basic emotions and tridimensional (PAD; Pleasure, Arousal, and Dominance) approaches based on the "intensity of reported feelings, the inter-rater agreement in using the different sets of terms, and the ability of the sets to discriminate the feelings" (Delplanque et al., 2012). Results from this study indicated that the GEOS method outperformed the other two approaches suggesting that olfactory-specific terms are necessary to capture the feelings evoked by the given odor.

Since its development, researchers have worked to adapt the GEOS to suit commercial and development needs by evaluating odors beyond the everyday odors; for example, fragrances and flavored products (Porcherot et al., 2010). Accordingly, Porcherot et al. (2010) created the ScentMove ${ }^{\mathrm{TM}}$ questionnaire by reducing the number of terms from 36 to 18 , six factors each with the three most representative terms:

1. "Happiness-Well-being-Pleasantly surprised"

2. "Romantic-Desire-In love"

3. "Disgusted-Irritated-Unpleasantly surprised" 


\section{4. "Relaxed-Serene-Reassured"}

5. "Nostalgic-Amusement-Mouthwatering"

6. "Energetic-Invigorated-Clean"

The studies used to optimize the GEOS have indicated that the ScentMove ${ }^{\text {TM }}$ produces similar results to the GEOS and can therefore be used to evaluate fragrances beyond everyday odors (Porcherot et al., 2010, 2012). Special care should be taken when using this method though. The researchers suggest that context and testing environment may have an effect on the emotion responses. The idea that a particular context may be necessary to elicit certain emotions has not yet been tested, but if the testing is contextualized, it would be difficult to determine whether or not the emotion can be attributed to the situation or the odor (Delplanque et al., 2012). Additionally, as with most sensory testing, it is important to understand the demographic being tested. If the participants are not consumers of the products it may affect the generalizability of the data collected. Similarly to the other emotion methods, this data provides information beyond product acceptance, which may help distinguish products with similar liking scores.

\section{The EsSense Profile ${ }^{\circledR}$}

The EsSense Profile®, an emotion-specific measurement tool, was developed by King and Meiselman (2010) to test foods with consumers in person or via the internet. This method goes beyond appearance and odor by encompassing the whole product experience. The EsSence Profile ${ }^{\circledR}$ questionnaire uses a list of 39 emotions (Table 2) found to be most appropriate in a food context (King et al., 2010; King \& Meiselman, 
2010). These terms were determined based on previous research and rigorous consumer testing - a series of central location tests, internet surveys, and home use tests (King \& Meiselman, 2010).

Table 2. List of emotions used in the EsSense Profile ${ }^{\circledR}$ questionnaire (excerpted from King \& Miselman, 2010).

\begin{tabular}{|l|l|l|}
\hline Active & Glad & Pleased \\
Adventurous & Good & Polite \\
Affectionate & Good-natured & Quiet \\
Aggressive & Guilty & Satisfied \\
Bored & Happy & Secure \\
Calm & Interested & Steady \\
Daring & Joyful & Tame \\
Disgusted & Loving & Tender \\
Eager & Merry & Understanding \\
Energetic & Mild & Warm \\
Enthusiastic & Nostalgic & Whole \\
Free & Peaceful & Wild \\
Friendly & Pleasant & Worried \\
\hline
\end{tabular}

This method has shown huge advances in consumer and sensory testing as it provides valuable information to support and guide product developers. Additionally, the EsSense Profile® is incorporated with traditional sensory testing methods which allows greater flexibility in the design of product-specific questionnaires. Hedonic, "just about right" scales or other types of questions may appear with this emotion measurement as a holistic approach to understanding consumer perception. King et al. (2010) suggest that the 39 emotions may also be modified as necessary for specific food categories.

Implementation of this questionnaire also offers flexibility. The emotions may be displayed in a check- all-that-apply (CATA) format and/or scaled. The decision to use either of these approaches depends on the objective of the study. Scaling the emotions may provide more information especially when comparing products with small 
differences (King et al., 2013). As discussed by King and Meiselman (2010), emotions (in comparison to moods) are brief, intense and occur in reference to a stimulus or event; therefore they recommend that emotion measurements occur during the presentation of the stimulus or immediately after. Emotion measurements can also be taken prior to introducing the stimulus to the subject.

Consumer testing aimed to evaluate this method has shown that subjects found the EsSense Profile® questionnaire to be an easy and intuitive task (Jaeger, Cardello, \& Schutz, 2013). This is promising considering the actionable data provided. Ultimately, King et al. (2010) have demonstrated the applicability of using consumer emotions and product acceptability ratings to effectively link marketing efforts with product development. Replicating these studies though is necessary to really understand the meaning of the responses recorded using this method. During the evaluation of this method, subjects also indicated that the task at hand was strange and expressed that the emotions presented in the questionnaire did not align with what was felt, thus leading to questions regarding why the stimulus would produce those emotions (Jaeger et al., 2013).

Refinement of this method may be necessary before the questionnaire can be effective in producing meaningful results as the method intends. The developers of this method have already begun to address some of the logistical questions of concern including: questionnaire format, product context, time of day, and number of products to be evaluated in one session (King et al., 2013). Applying this new method in a product development context requires careful consideration and selection of an appropriate testing approach. 


\section{EmoSemio}

In an effort to solve some of the limitations identified with current approaches, the EmoSemio method was recently developed (Spinelli, Masi, Dinnella, Zoboli, \& Monteleone, 2013). Spinelli et al. (2013) aimed to address the following with this new method: (1) design an efficient and repeatable procedure to develop product categoryspecific questionnaires based on consumer input, (2) determine if complete sentences produce more reliable results compared to the use of only adjectives when measuring emotions using a questionnaire, (3) evaluate the performance of the EsSense Profile ${ }^{\circledR}$ questionnaire against EmoSemio in a cross-cultural study, and (4) implement the new method to investigate the link between emotions and drivers of liking.

Developing the product-specific questionnaire involved one-on-one interviews with consumers to collect information on the personal constructs associated with the product at hand. For this study, the authors chose chocolate and hazelnut spreads as the product of interest. Spinelli et al. (2013) conducted the interviews using a modified Repertory Grid Method (RGM), which has been shown to be effective in collecting data on consumer perception of food products. Semiotic methodology was then used to analyze consumer responses regarding their experience with the product from the one-onone interviews. The researchers separated the words or expressions into "semantic categories" which grouped similar words or phrases together. Twenty-three semantic categories, 16 positive and 7 negative, were chosen and transformed into sentences. The sentences were meant to provide a context for the emotion word, to better clarify the meaning of the emotion, and to reduce ambiguity. Table 3 shows the 23 words and their respective sentences. 
Table 3. EmoSemio questionnaire for chocolate and/or hazelnut spreads (excerpted from Spinelli et al., 2013).

\begin{tabular}{|c|c|c|}
\hline & EmoSemio Questionnaire Real Sentences & $\begin{array}{l}\text { EmoSemio } \\
\text { Questionnaire Labels }\end{array}$ \\
\hline 1. & It is an anti-stress: it cams me, it soothes me, it reassures me & Anti-stress \\
\hline 2. & It relaxes me and make me feel carefree & Relaxed \\
\hline 3. & I associate it with amusement and fun & Amused \\
\hline 4. & It makes me feel full of energy and reinvigorated & Energetic \\
\hline 5. & It makes me merry & Merry \\
\hline 6. & It makes me happy & Happy \\
\hline 7. & It satisfies me & Satisfied \\
\hline 8. & It gratifies me, rewards me & Gratified \\
\hline 9. & It makes me feel tender and affectionate & Tender \\
\hline 10. & It makes me feel cuddled and loved & Cuddled \\
\hline 11. & It communicates sensuality, it charms me & Sensual \\
\hline 12. & It communicates security & Secure \\
\hline 13. & I associate it to happy memories of childhood & Happy memory \\
\hline 14. & It makes me feel good and generous & Generous \\
\hline 15. & It surprises me & Surprised \\
\hline 16. & It makes me curious & Curious \\
\hline 17. & It makes me feel indifferent & Indifferent \\
\hline 18. & It bores me & Bored \\
\hline 19. & It makes me feel neglected, without any care for me & Neglected \\
\hline 20. & It makes me feel sad & $\mathrm{Sad}$ \\
\hline 21. & It disappoints me & Disappointed \\
\hline 22. & It makes me feel guilty & Guilty \\
\hline 23. & It annoys me, it makes me nervous & Annoyed \\
\hline
\end{tabular}

Although EmoSemio and the EsSense Profile ${ }^{\circledR}$ do not include the same emotion words, the two questionnaires were compared. Creators of the EmoSemio method reported that the EmoSemio method outperformed the list of adjectives used by the EsSense Profile® when evaluating six chocolate hazelnut spreads (Spinelli et al., 2013). Although these results may be true in the case for this product category the following considerations must be kept in mind: (1) the EsSense Profile ${ }^{\circledR}$ questionnaire was translated from English into Italian, while the EmoSemio method was developed in Italian with native speaking consumers, (2) the EmoSemio questionnaire was specifically developed for chocolate hazelnut spreads, while the EsSense Profile ${ }^{\circledR}$ was developed for a broad range of products with the creators indicating that the emotions may need to be 
expanded or modified for product-specific applications (King et al., 2010), and (3) six products were tested despite the researchers acknowledging that the EsSense Profile $®$ is not suggested when testing more than two samples (King et al., 2013; Spinelli et al., 2013).

This new method presents many opportunities for specific product categories that may be of interest. Spinelli et al. (2013) suggests that 25, 30-minute preliminary interviews are sufficient to develop an EmoSemio questionnaire; however, caution should be taken when translating the questionnaire for use in cross-cultural studies as a direct translation may not effectively convey what the researchers intend when compare to the primary language used during the questionnaire development. As with the other methods discussed, further studies and method refinement may be necessary before the method can be used as a standard tool for sensory science professionals.

\section{Best-Worst Scaling}

This scaling method is less frequently used in sensory evaluation, however, has recently been applied in an innovative way as another emotion measurement tool. Bestworst scaling falls under the discrimination class of sensory tests where consumers are asked to choose the best liked and worst liked products of the products presented to them (Jaeger \& Cardello, 2009). This method has been compared to several acceptance and

preference testing methods such as the labeled affective magnitude scale (LAM), 9-point hedonic scale, unstructured line scales, and preference ranking. The results from these studies have indicated that best-worst scaling is simple for consumers to use and may be more sensitive to detecting product differences in a laboratory setting (Hein et al., 2008; Jaeger \& Cardello, 2009). 
Thomson et al. (2010) applied best-worst scaling as a means of conceptual profiling - an innovative way to link sensory characteristics to emotions. The protocol involved creating several sets of four or five emotion words (quads or quins, respectively); consumers would then be asked to decide which quad or quin he/she feels most closely relates to the food experience at hand and identify which quad or quin he/she feels is least related. In an example using dark chocolate, a lexicon of 24 emotion words was developed. Consumers were presented with 16 sets of quins for each chocolate sample tested and asked to identify which quin "most readily and least readily came to mind as a consequence" of eating the sample at hand (Thomson et al., 2010). The researchers suggest that due to the sensitivity of best-worst scaling (when properly implemented), it can clearly discriminate between conceptual profiles with a relatively small sample size. This is very advantageous and presents an opportunity for companies to efficiently collect data on the conceptualizations projected by their product.

Additionally, the unique application of this method contributes substantially to gaining a better understanding of how the sensory profile of a product can align with branding in relation in the emotional conceptualizations.

\section{Facial Scaling}

King and Meiselman (2010) have identified three systems utilized to measure emotions through facial scaling: Noldus FaceReader, Emotionomics, and PrEmo. A brief description of each will be provided to further demonstrate the progression and innovation through the evolution of sensory science and the efforts being made to address emerging research questions. 
Noldus FaceReader is a sophisticated software designed to analyze facial expressions indicative of seven main emotions: happy, sad, angry, surprised, scared, disgusted and neutral. Video recordings of consumers can be taken during sensory testing, uploaded to the program and analyzed frame-by-frame. Facial readings are classified from 0 - emotion not present at all, to 1 - maximum intensity of the given emotion. The use of this technology is fairly new to the addition of sensory evaluation methods (Garcia-Burgos \& Zamora, 2013; Zeinstra, Koelen, Colindres, Kok, \& de Graaf, 2009) but provides valuable information and may be suitable in better assessing food preferences when combined with traditional sensory methods, especially when working with a school-aged target demographic. Additionally, FaceReader can be implemented to validated self-report questionnaires to understand if the questionnaire is effective in accurately measuring emotions of panelists. Are the panelists actually feeling and expressing what they indicate they are?

Emotionomics operates in a similar manner to FaceReader. Videos can be analyzed based on the seven core emotions which Dan Hill, the creator, identifies as happiness, surprise, fear, anger, sadness, disgust, and contempt (Hill, 2007). These emotions align with FaceReader, however, Emotionomics detects contempt and not scared and vice versa. Both software programs have the capability of measuring and analyzing 7 emotions, one of which is positive. Of the methods discussed, facial scaling tests a much shorter list of emotions. This may be due to software limitations or the idea that the basic emotions are universal and therefore measureable. Regardless, these advances allow for broader applications of emotion testing. 
As mentioned, King and Meiselman (2010) suggest that PrEmo is a facial scaling method. The images used in the PrEmo method do rely on the animation of facial expressions; however, during testing subjects select the image that they most relate to whereas the facial scaling technology analyzes a direct measurement of the panelist's emotional responses determine by the facial expression exhibited. For that reason, PrEmo was discussed in detail above.

\section{Image Measurement of Emotions and Texture}

Congruent with this research, a team of researchers at California Polytechnic State University developed the Image Measurement of Emotions and Texture (IMET) method (Collinsworth, Lammert, Martinez, Leidheiser, et al., 2014). This method utilizes selfselected emotion images and pictorial representations of texture attributes to measure consumer perception of product acceptability and resulting emotional responses. Emotions were selected based on previous research and frequency of selection during testing with similar product categories (Collinsworth, Lammert, Martinez, Arnold, et al., 2014; Collinsworth, Lammert, Martinez, Leidheiser, et al., 2014).

Prior to evaluating a product, subjects are asked to complete a "homework" assignment and given detailed instructions. Each subject is required to find images, which represent the emotions selected for testing. The seven emotions identified for the most current testing included: excited, sociable, self-confident, fatigued, judgmental, raging, and sad, scaled from "slightly" (level 1) to "extremely" (level 5); a "not at all" option was also included for each emotion. Subjects attach their images to a poster board, resulting in 35 images: one image for each of the seven emotions at each of the five levels of 
intensity. Figure 10 shows an example of an emotion poster board created by a participant and brought to testing with them.

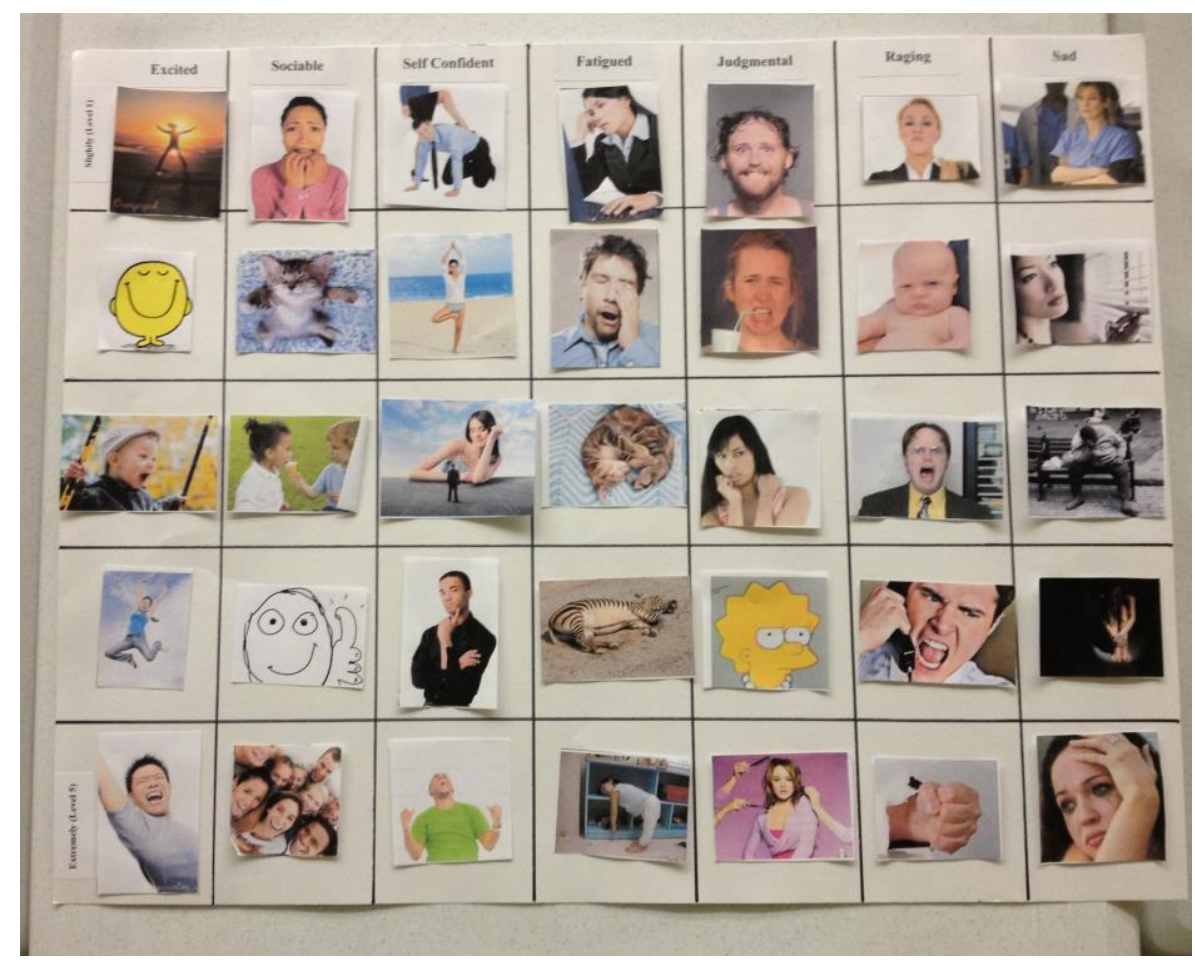

Figure 10. Example of an emotion poster board created by a participant and used during testing as part of the IMET method

During testing, subjects are asked use their emotion poster board as a reference and to indicate his/her initial emotional state in a CATA format before and after consuming each sample. Hedonic and texture rating questions are also asked during and at the end of consumption to capture the entire eating experience. A texture image card is provided to panelists with images of several texture attributes (Appendix D) and the corresponding levels. The following texture attributes (of most recent interest) included in the texture image card are: bite location, break resistance, fibrousity, shear, stickiness, surface deviation, grittiness, crumble, soft, sponginess, rubbery, sandy, and waxiness. 
These attributes are evaluated using a 3,5 or 7-point scale depending on the attribute, with the higher end of the scale indicating an increase in the perceived level of the given attribute. Similar to the EsSense Profile®, the IMET method allows for flexibility during questionnaire deign and can be modified to better assess the product of interest.

The IMET method addresses several issues that are neglected by the previously discussed emotion measurement techniques. First, the consumers use self-selected emotion images, which are relevant and relatable, to gauge their perception of their emotional state; predefined texture images are used to uniformly and accurately measure the texture attributes. The PrEmo method utilizes images in the form of animations; however, these images are not self-selected and therefore may not resonant with the consumer to the same extent. Secondly, the IMET method measures initial emotion. The aforementioned methods fail to take this measurement and as a result cannot measure the emotional change through the eating experience. Finally, hedonic and texture measurements are taken through the eating experience. Although questionnaire length may have an effect on the consistency and validity of the scores, and/or contribute to panelist fatigue, collecting data at multiple time points during the eating experience may yield information that is not currently being captured with the other measurement tools.

Measuring emotions in the eating experience and calling on food manufactures to act upon consumer feedback, can contribute positively to the current health initiatives to raise a healthier generation of kids ("Let's Move," 2014) by providing healthier alternatives with desirable sensory attributes and encouraging consumption of those healthier food products. 


\section{Decreasing Sodium Consumption}

The Dietary Guidelines for Americans, 2010, emphasizes three major goals: (1) weight management with physical activity, (2) consume more nutrient dense foods and (3) reduce consumption of foods high in sodium (in the form of $\mathrm{NaCl}$; salt), saturate fats, trans fats, cholesterol, added sugars, and refined grains. An increased sodium intake is correlated with increased blood pressure. Adults and children are encouraged to maintain blood pressure in the normal range as it reduces an individual's risk of many diseases such as cardiovascular disease, congestive heart failure, and kidney disease (U.S. Department of Agriculture \& U.S. Department of Health and Human Services, 2010). Unfortunately, Americans consume much more sodium than is needed to maintain normal bodily functions. The 2010 Dietary Guidelines recommend reducing sodium intake to less than 2,300 $\mathrm{mg}$ per day and even further to $1,500 \mathrm{mg}$ per day for most of the population. Figure 11 illustrates the average daily sodium intake for men and women by age group in 2009-2010, which exemplifies the extremely high rate of sodium consumption. 


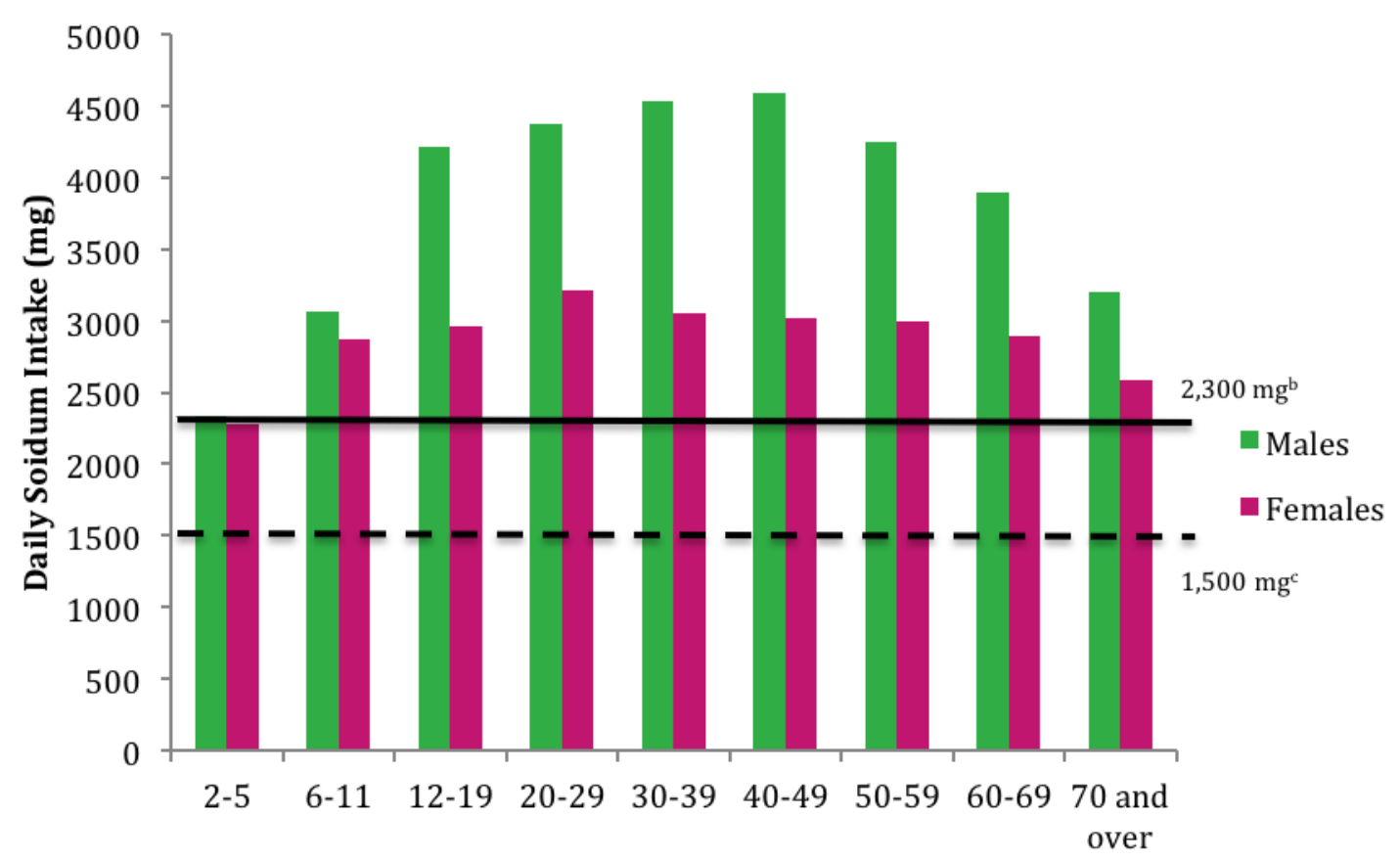

Age Range (years)

Figure 11. Average daily intake of sodium by gender and age group ${ }^{\mathrm{a}}$ ${ }^{a}$ Data from USDA ARS, What We Eat in America, NHANES 2009-2010 (USDA Agricultural Research Service, 2010)

${ }^{\mathrm{b}}$ Tolerable Upper Intake Level as recommended by the Institute of Medicine (Centers for Disease Control and Prevention, 2011)

${ }^{\mathrm{c}}$ Recommended Adequate Intake Level as recommended by the Institute of Medicine (Centers for Disease Control and Prevention, 2011)

Considering this effort to decrease sodium consumption, foods that contain a high amount of salt $(\mathrm{NaCl})$ have been especially targeted to create alternative products that are more healthful and follow suit with the Dietary Guidelines. The following ten food items contribute to more than $40 \%$ of sodium in the diet: breads and rolls, cold cuts and cured meats, pizza, poultry, soups, sandwiches, cheese, pasta dishes, meat dishes, snacks (Centers for Disease Control and Prevention, 2012b). Of these food items, cheese contributes to high sodium in the diet since it is quite frequently consumed with mixed meals and in combination with the other top sources of sodium in the diet. Table 4 lists 
commonly consumed cheeses, the sodium content and the amount (in pounds) consumed per capita.

Table 4. Serving size, percent water, sodium per serving, and per capita consumption of commonly consumed cheeses

\begin{tabular}{|c|c|c|c|c|c|}
\hline Cheese & $\begin{array}{l}\text { NDB } \\
\text { No. }^{a}\end{array}$ & $\begin{array}{l}\text { Serving } \\
\text { Size }(g)^{a}\end{array}$ & $\%$ Water $^{\mathrm{a}}$ & $\begin{array}{c}\text { mg } \\
\mathrm{Na} / \text { serving }^{\mathrm{a}}\end{array}$ & $\begin{array}{l}2011 \text { Per capita } \\
\text { consumption } \\
\text { (lb) }\end{array}$ \\
\hline $\begin{array}{l}\text { Mozzarella } \\
\text { (low moisture, part }\end{array}$ & 01029 & 28.35 & 47 & 185 & \\
\hline $\begin{array}{l}\text { skim) } \\
\text { Mozzarella } \\
\text { (low moisture, whole } \\
\text { milk) }\end{array}$ & 01027 & 28.35 & 48 & 201 & $11.51^{\mathrm{c}}$ \\
\hline Cheddar & 01009 & 28.35 & 37 & 176 & 9.43 \\
\hline Provolone & 01035 & 28.35 & 41 & 248 & 1.14 \\
\hline Blue Cheese & 01004 & 28.35 & 42 & 325 & 0.31 \\
\hline Parmesan & 01033 & 28.35 & 29 & 390 & 1.01 \\
\hline Swiss & 01040 & 28.35 & 37 & 20 & 1.15 \\
\hline
\end{tabular}

${ }^{a}$ Data from USDA Nutrient Database for Standard Reference (USDA Agricultural Research Service, 2013)

${ }^{\mathrm{b}}$ Data from USDA Economic Research Services: Dairy Data (USDA Economic Research Service, 2013)

${ }^{\mathrm{c}}$ Represents per capita consumption data for all mozzarella cheeses

Salt addition to cheese is inherent to the cheese making process. Given that mozzarella cheese is the most commonly consumed cheese and one serving contains more than $1 / 12$ of the targeted daily consumption, sodium reduction is mozzarella cheese has been a primary investigation and the focus for this research.

\section{Decreasing Sodium in Cheese}

Sodium chloride $(\mathrm{NaCl}$; salt) plays many crucial roles in the manufacturing and aging of cheese, thus reducing $\mathrm{NaCl}$ in cheese has been a challenge in the food industry. The role of $\mathrm{NaCl}$ and efforts made toward reducing $\mathrm{NaCl}$ in cheese has been researched and reviewed by many (Ayyash \& Shah, 2011b; Ayyash, Sherkat, \& Shah, 2013; Cruz et 
al., 2011; Faccia, Mastromatteo, Conte, \& Del Nobile, 2012; M. E. Johnson, Kapoor, Mcmahon, Mccoy, \& Narasimmon, 2009; McMahon \& Oberg, 1998; Paulson, Mcmahon, \& Oberg, 1998; Rulikowska et al., 2013). Johnson et al. (2009) have identified six main roles that salt plays in cheese: (1) encouraging syneresis and final moisture control, (2) support of starter bacteria, (3) influences other organisms contributing to flavor development during ripening, (4) control of enzymatic activity, (5) control of texture in the final cheese and (6) contributes to the expected taste and flavor of the cheese. Additionally, the salt to moisture ratio controls the growth of microorganisms and contributes to the cheese's safety (from a microbiological standpoint) and shelf life (Cruz et al., 2011; M. E. Johnson et al., 2009).

Reducing sodium chloride in cheese presents two main concerns. First, the reduction of $\mathrm{NaCl}$ may change the flavor profile of the cheese. This will directly affect consumer acceptance and may be a deterrent for consumption. If such products are avoided, it negates the main goal in reducing the sodium content. Secondly, controlling microbial and enzymatic activity will present new challenges in regards to the safety and stability of the cheese. These factors must be considered in creating a low sodium cheese.

\section{Properties of Low Sodium Cheese}

Replacing or partially substituting $\mathrm{NaCl}$ with other chemicals has been successful in some milder cheeses. The effect of different $\mathrm{NaCl}$ concentrations in combination with other compounds will be briefly discussed with a focus on mozzarella cheese.

Cruz et al. (2011) provides an excellent review of processing with reduction and substitution of $\mathrm{NaCl}$ in a variety of cheeses. With a specific interest in mozzarella cheese, Ayyash and Shah (2011b) examined the effect of $\mathrm{NaCl}$ substitution with $\mathrm{KCl}$ 
(potassium chloride) on the chemical compositions, organic acids profile, and functional properties of low-moisture mozzarella cheese. Their findings suggested that the substitution of $\mathrm{NaCl}$ with $\mathrm{KCl}$ might not affect the chemical composition. Additionally, the cheeses salted with $1 \mathrm{NaCl}: 1 \mathrm{KCl}$ and $1 \mathrm{NaCl}: 3 \mathrm{KCl}$ showed significantly higher meltability and browning compared to the $\mathrm{NaCl}$ (only) control (Ayyash \& Shah, 2011b). In a similar experiment conducted by the same researchers, findings indicated that $\mathrm{NaCl}$ or $\mathrm{NaCl} / \mathrm{KCl}$ mixtures had similar effects on the texture and microstructure of the low moisture mozzarella (Ayyash et al., 2013). This research also suggested $\mathrm{KCl}$ as an alternative to $\mathrm{NaCl}$ in low moisture mozzarella cheese with $\mathrm{NaCl} / \mathrm{KCl}$ cheeses having similar sensory properties to the control ( $\mathrm{NaCl}$ only). No significant differences were found in creaminess, bitterness, saltiness, sour-acid and vinegary taste among the experimental cheese (NaCl:KCl, 3:1, 1:1, and 1:3 w/w) (Ayyash et al., 2013). These results are encouraging for manufactures taking part in sodium reduction initiatives. Further research is necessary though to determine appropriate processing methods incorporating the $\mathrm{NaCl}$ substitution that are feasible and can be applied in the industry.

In addition to understanding processing interactions of the cheese components and how they affect functionality and chemical composition, it is crucial to gain a better understanding of the consumers. Consumer acceptance of cheeses lower in sodium is necessary in order to move forward.

\section{Objectives of Thesis Work}

A paradigm shift in the food industry is necessary to help combat national health epidemics; sensory scientists are actively working with consumers and product 
developers to achieve success in new and healthful products. Ultimately, developing alternative nutrition products that elicit similar responses as their "unhealthy" counterparts can contribute to initiatives aimed at increasing the health of the nation. Effectively, two phases of consumer research experiments were conducted, with a primary emphasis on cheese products, aiming to contribute to the overall grand endeavor of the food industry.

As discussed, emotion and product acceptability measurements may be necessary to really understand the factors driving food choice. Accessing the minds of consumers and gaining actionable feedback requires meticulous questionnaire design and implementation. Execution and validation of such methods is necessary to ensure that the measurement tool aligns appropriately with the variable being measured. Therefore, the two phases of research conducted work toward refining and validating the IMET method as an appropriate tool to implement when striving to understand consumers.

\section{Phase 1: Evaluation of Commercial Convenience Cheeses}

Seven commercially manufactured convenience string cheese varieties with varying sodium and fat contents were evaluated using the scaled IMET method of emotion, hedonic and texture measurements. In line with similar emotion research, this study was conducted to (1) determine the hedonic and texture attributes of different cheeses that affect the end emotional state of a panelist, and (2) determine if initial emotions and hedonics could better represent end product liking than hedonics alone. 


\section{Phase 2: Emotion Calibration and Low Sodium Cheese}

Low moisture part skim mozzarella samples were produced with three different salt/salt substitutes $\left(\mathrm{NaCl}, \mathrm{KCl}\right.$, and Salona $\left.{ }^{\mathrm{TM}}\right)$ at two levels $(100 \%$ and $50 \%)$ with two antimicrobials (CytoGuard ${ }^{\mathbf{T M}}$ LA 20 and NovaGARD®). The IMET method was adapted to include an emotional calibration step between samples intended to more accurately assess the participant's end emotional response following consumption of each sample. The objectives of this study were to (1) determine if the emotion calibration step is effective in creating an emotional baseline between samples, (2) determine differences in product acceptance based on partial $\mathrm{NaCl}$ substitution, and (3) evaluate product preparation procedures during formulation of low sodium cheeses. 


\title{
CHAPTER III
}

\section{Consumer evaluation of commercially produced convenience cheeses using a scaled emotion Image Measurement of Emotion and Texture (IMET) Method}

\begin{abstract}
As the food industry continues to grow and the marketplace becomes saturated with similar products, consumer researchers and sensory scientists are looking to dig deeper into the minds of consumers to reveal greater distinctions between products and ultimately deliver multi-dimensionally desirable products to consumers. This study was conducted to (1) determine the hedonic and texture attributes of different cheeses that affect the end emotional state of a panelist, and (2) determine if initial emotions and hedonics could better represent end product liking than hedonics alone.
\end{abstract}

Seven convenience string cheese varieties with varying sodium and fat contents were evaluated using the Image Measurement of Emotion and Texture (IMET) method. Seven emotions (excited, sociable, self-confident, fatigued, judgmental, raging, and sad) scaled from 1- "slightly" to 5-“extremely" (with 0 representing "not at all”) were used, with each emotion at each level of intensity anchored by self-selected images that subjects chose prior to testing. Using a CATA format, subjects reported his/her emotional state and perception of textural attributes before and at the end of consumption. Hedonic attribute questions were measured using a 9-point hedonic scale and presented to subjects before and at the end of consuming each product. Compusense ${ }^{\circledR}$ at-hand was used for data collection. 
The results indicated: (1) the effect of texture attributes on the end emotional response of consumers depends on the cheese sample and (2) the hedonic principal components were sufficient to predict overall liking.

\section{Highlights}

- Drivers of product related end emotional response were investigated.

- A variety of commercially produced convenience cheeses were evaluated.

- Emotional response, hedonic scores, and textural attributes were measured.

- Emotions were scaled using images with 5 intensities from slightly to extremely.

Keywords: scaled emotions with images; emotion testing; hedonic testing; convenience cheeses 


\section{Introduction}

Traditional sensory methods, such as the hedonic scale used in affective testing, can provide valuable product/attribute specific data for product developers. However, as the food industry continues to grow and the marketplace becomes saturated with similar products, consumer researchers and sensory scientists are striving to explore the minds of consumers; the goal being to reveal greater distinctions between products and ultimately deliver multi-dimensionally desirable products to consumers. In order to receive actionable feedback, researchers must begin by asking the right questions. Gaining a deeper insight may be executed effectively with a more holistic approach, accounting for physiological and psychological characteristics that affect food intake and choice behavior in addition to product liking alone.

It has become clear that an individual's emotional response plays a significant role in food choice, product conceptualization and product identity (Thomson et al., 2010). In recent years, the relationship between food and emotion has been intensely studied (Evers, Adriaanse, de Ridder, \& de Witt Huberts, 2013; Macht, 2008; Shin et al., 2009), which has thus spurred and guided sensory and consumer science researchers through the development of many methods to measure emotional responses through the food experience with a given product. The measurement of emotion is typically conducted in one of three ways: self-report questionnaires, autonomic measurements, and/or brain imaging techniques ( $\mathrm{Ng}$ et al., 2013). Of these, self-report questionnaires are most commonly utilized when conducting consumer research as identified by the success of recently developed methodologies (Jaeger \& Hedderley, 2013; King et al., 2010, 2013; King \& Meiselman, 2010). 
The EsSense Profile®, developed by King and Meiselman (2010) utilizes a detailed list of emotions selected based on previous research and scaled from 1 (not at all) to 5 (extremely). This method has been successful in modeling protocol necessary to measure emotions in a given context. As new methods have been developed, researchers have recognized the need for further exploration (Jaeger \& Hedderley, 2013;

Schifferstein \& Desmet, 2010). Although new measurement methods can be tested alone, the inclusion of hedonic questions can serve as a link between the new and currently utilized methods (King et al., 2010). Additionally, as new methods emerge to identify emotional responses elicited by products, the application of the data must be considered. Including attribute specific questions will allow for a better understanding of the factors driving consumer's emotional responses; specific attribute information can further guide product developers seeking to evoke a given emotion.

In line with this research, the Image Measurement of Emotion and Texture (IMET) method was developed in 2012 (Collinsworth et al., 2013) which uses selfselected emotion images and pictorial representations of textural attributes to gauge consumer perception of product acceptance through the eating experience. Similar to other recently developed methodologies (King et al., 2010; King \& Meiselman, 2010), this method uses scaled emotions. The main distinction between IMET and other methods is that IMET utilizes a shorter, balanced list of emotions and images, which have been shown to resonant with consumers more than words alone (Collinsworth, Lammert, Martinez, Leidheiser, et al., 2014). Additionally, Thomson et al. (2010) has recognized the criticism associated with solely using words in emotion research. One issue being that cognitive processing results in an individual focusing on the literal meaning of the 
emotion word. Often the true meaning of the word is found in the metaphorical interpretation. Using self-selected emotion images allows individuals to more readily access the non-cognitive influences that he/she identifies with the given emotion. This permits a deeper, more meaningful connection to effectively anchor the individual's response choices. To our knowledge no other emotion research (in a food context) has used images as part of the methodology when measuring emotion.

The present study aims to better understand the factors that contribute to a person's emotional state after exposure to a product. Additionally, we seek to understand if combining hedonic and emotion measurements will lead us to obtain a more holistic perspective of consumers, measured by product acceptance. The objectives of the present study were to (1) determine the hedonic and texture attributes of different cheeses that affect the end emotional state of a panelist, and (2) determine if emotions and hedonics could better represent product liking than hedonics alone.

\section{Materials and Methods}

\section{Samples and Preparation}

Seven convenience string cheese varieties were used for consumer acceptance and emotion testing (Table 5). All cheese samples were stored at $42^{\circ} \mathrm{F}$ in their original packaging prior to testing. Twenty minutes before serving to panelists, samples were removed from refrigeration, unwrapped and held at room temperature $\left(72^{\circ} \mathrm{F}\right)$. Full serving sizes of each sample were presented to panelists on 6" diameter paper plates with randomized three-digit codes. Samples were tested in a William's design where sample order was randomized within and across subjects. 
Table 5. Description of seven cheese samples

\begin{tabular}{lll}
\hline Sample Name & \% Fat & \% Sodium \\
Regular Mozzarella 1 (RM1) & 21.4 & 0.68 \\
\hline Regular Mozzarella 2 (RM2) & 20.8 & 0.71 \\
Reduced Fat Mozzarella (RFM) & 16.1 & 0.68 \\
\hline Light Mozzarella (LM) & 10.4 & 0.83 \\
Mozzarella and cheddar (MC1) & 19.0 & 0.67 \\
Mozzarella and cheddar (MC2) & 20.8 & 0.71 \\
Colby Jack (CJ) & 33.3 & 0.63 \\
\hline
\end{tabular}

\section{Subjects}

Testing was conducted in an open lab at California Polytechnic State University, San Luis Obispo, CA and subjects completed the test in approximately 40 minutes. Subject selection and sensory testing procedures were reviewed and approved by the university's human subjects board prior to testing.

Participants for this study were recruited by email; subjects were selected for testing based upon their frequent consumption of cheese and being a non-user of Crest Pro-Health products (due to the active ingredient, cetylpyridinium chloride, which has been shown to alter taste perception) (DeSimone \& Heck, 1991; Food and Drug Administration, 2003; St John \& Hallagan, 2005). A total of 77 subjects participated, which included students, university staff and community members.

\section{Questionnaire and Testing Procedure}

The IMET method (Collinsworth, Lammert, Martinez, Leidheiser, et al., 2014) was used with the following adaptations. Qualifying participants were asked to complete a "homework" assignment prior to testing. Each participant was (1) given a poster board with 35 sections ( 7 emotions $x 5$ levels of intensity) and asked to find and attach one 
image which they found best represented each emotion at each given intensity level and (2) asked to complete the Behavioral Inhibition System (BIS)/Behavioral Activation System (BAS) questionnaire (Carver \& White, 1994), which was available to them online. The data from this questionnaire was analyzed independently and not included in the presented results.

The participants were assigned a username and password to access the testing questionnaire. In congruence with the IMET method, subjects were first asked to indicate his/her initial emotional state in a choose-all-that-apply (CATA) format prior to consuming the sample. The seven emotions included: excited, sociable, self-confident, fatigued, judgmental, raging, and sad, ranging from "slightly" (level 1) to "extremely" (level 5); a "not at all" option was also included for each emotion. Previous research indicated that these emotions were most frequently selected during prior testing (Collinsworth, Lammert, Martinez, Arnold, et al., 2014). All subjects were instructed to use their personal poster board as an anchor or reference. Next, subjects were directed to consume and score hedonic attributes of the sample including: overall liking, flavor, texture, appearance, aroma and aftertaste liking. Texture image cards were provided with images of several texture attributes, the same images for all subjects, and the corresponding levels. After answering the hedonic questions, subjects were prompted to rate his/her perception of the level of each texture attribute, including: bite location, break resistance, fibrousity, shear, stickiness, surface deviation, grittiness, crumble, soft, sponginess, rubbery, sandy, and waxiness. Texture attributes were evaluated using a 3, 5 or 7-point scale depending on the attribute, with the higher end of the scale indicating an increase in the perceived level of the given attribute. 
The hedonic and texture questions were asked at the beginning and end of consuming each sample. After completing the texture component at the end of consumption, subjects were asked to indicate his/her emotional state using the CATA format. Before moving on to the next sample, subjects were given the opportunity to indicate what he/she enjoyed most about the sample. Bottled water and unsalted crackers were supplied and a thirty-second forced break between each sample allowed subjects the opportunity to cleanse his/her palate in an effort to decrease carryover and sensory fatigue. Testing was performed using Compusense ${ }^{\circledR}$ at-hand.

\section{Data Analysis}

Data analyses were performed using JMP® Pro statistical software (JMP, Version 10. SAS Institute Inc., Cary, NC, 1989-2007). P-values $<0.05$ were considered statistically significant. All Multivariate Analyses of Variance (MANOVA) were conducted using SAS® 9.4 (SAS Institute Inc., Cary, NC, 2013). Hedonic and texture attribute scores were averaged (beginning and end) and used in all subsequent analyses.

\section{Effects of Hedonics and Texture on End Emotional Response}

An Analysis of Variance (ANOVA) was performed on the initial emotion scores to determine if the initial emotion differed significantly between samples. No significant differences were found when using Tukey's test to compare the mean scores (data not shown). On average, for each emotion, panelists reported the same emotional intensities prior to tasting each sample.

A series of Multivariate Analyses of Variance (MANOVA) were performed to determine how hedonics and texture affect the end emotional state of a panelist. To understand the relationship between hedonic attributes and the end emotional responses, 
the MANOVA model contained the seven end emotions as the response variables, and the cheese sample, panelist (treated as a random effect), and the five hedonic attributes used as the explanatory variables. This model excluded the overall liking attribute, as the objective was to understand how the specific hedonic attributes affect the end emotion. This analysis was repeated using the thirteen texture attributes, in place of the hedonic attributes. Interactions between each attribute and sample were also investigated.

\section{Effect of Emotions and Hedonics on End Product Liking}

To determine if the combination of emotions and hedonics can better represent product liking than hedonics alone, three ANOVA models were compared. The response variable in all cases was defined as the end overall liking score. This score captures the panelist's overall liking of the product at the end of consumption and is assumed to be the best indicator of product acceptance. The explanatory variables for each of the models are as follows (with all accounting for panelist and cheese type): (1) hedonic attributes, (2) both hedonics and initial emotions, and (3) hedonics, initial emotions, and the interactions between the two.

In line with the objectives, the aim is to check if the addition of emotion measurement better models the overall product liking. Prior to modeling, two principal components analyses (PCA) were carried out to reduce the dimensionality of the seven initial emotions and hedonic attributes. The first two principal components account for $62 \%$ of the variability in the seven initial emotion variables. For the five hedonic attributes, the first two components explained $84 \%$ of the variability (Table 6). 
Table 6. Loading matrix for the initial emotion and hedonic attribute principle components

\begin{tabular}{lcc}
\hline \multicolumn{1}{c}{ Initial Emotion } & PC 1 & PC 2 \\
\hline Excited & 0.73767 & -0.47739 \\
Sociable & 0.73303 & -0.51657 \\
Self Confident & 0.65241 & -0.46163 \\
Fatigued & 0.35574 & 0.44658 \\
Judgmental & 0.42734 & 0.48141 \\
Raging & 0.60658 & 0.54482 \\
Sad & 0.52100 & 0.64667 \\
\hline \multicolumn{1}{c}{ Hedonics } & PC 1 & PC 2 \\
\hline Flavor & 0.85445 & -0.33980 \\
Texture & 0.84058 & -0.30461 \\
Appearance & 0.78338 & 0.59152 \\
Aroma & 0.80214 & -0.22116 \\
Aftertaste & 0.91708 & 0.28395 \\
\hline
\end{tabular}

\section{Results and Discussion}

\section{Effects of Hedonics and Texture on End Emotional Response}

Hedonics. Interactions between the hedonic attributes and cheese samples were not found to be significant. Also, the hedonic main effects were not found to be significant. Only the random effect of panelist was significant (Wilks' MANOVA Lambda, $\mathrm{F}(532,3117.1)=16.98, \mathrm{p}<0.0001)$. This was expected as individuals can widely vary in his/her emotional disposition and perceived emotional responses. Additionally, panelist was found to be significant for each of the 7 end emotions $(\mathrm{p}<0.0001)$.

Texture and Sample Interactions. Textural properties of foods, along with taste and smell, have an important influence on product acceptability (Rolls, Verhagen, \& Kadohisa, 2003); this information is processed in the orbitofrontal cortex (OFC) of the human brain, which also takes part in mediating emotion-based decision making (Ghirri \& Bignetti, 2009; Rolls et al., 2003). As a result, the emotion and texture components are 
deeply connected. Understanding how texture attributes can influence the emotion of a panelist after consuming a product can yield valuable information to help guide manufacturers in the development and processing of their products. This information may also help explain why the hedonic attributes were not found to have an effect on the end emotion of the panelists.

Results from the texture MANOVA indicated that the interaction of the following texture attributes with the sample had a significant effect on the end emotion: shear (Wilks' Lambda, F $(42,1588.8)=1.51$, p=0.0191), soft (Wilks' Lambda, F (42, 1588.8) $=1.51, \mathrm{p}=0.0198)$ and sponginess (Wilks' Lambda, $\mathrm{F}(42,1588.8)=1.41, \mathrm{p}=0.0437)$. The follow up ANOVA showed that these effects were significant for the end sociable, fatigued and raging emotional responses (Table 7).

Table 7. Effect of the interaction of the texture attributes and the sample on the end emotion

\begin{tabular}{cll}
\hline Emotion & Texture Interaction & p value \\
\hline Sociable & Shear x sample & $0.0116^{*}$ \\
& Shear x sample & $0.0004^{*}$ \\
\multirow{2}{*}{ Fatigued } & Soft x sample & $0.0241^{*}$ \\
& Sponginess x sample & $0.0010^{*}$ \\
Raging & Sponginess x sample & $0.0495^{*}$ \\
\hline
\end{tabular}

$* \mathrm{p}<0.05$ is considered statistically significant

These results indicate that the effect of these texture attributes on the end emotional responses depends on the cheese sample. Holding all other variables constant (the means and modes were used for continuous and nominal variables, respectively), interaction plots were created to depict how the perceived levels of each texture attribute would affect the end emotional response after consuming each sample. 
The interaction between shear and cheese sample for the end sociable response is shown in Figure 12. The interaction plot shows that samples RFM, MC1, and MC2 had a similar trend; as the perceived level of shear increased, the end sociable intensity also increased. Both MC1 and MC2 contain mozzarella and cheddar. As a result, it is logical that the two samples would produce similar responses. It is interesting that although the RFM cheese has 3\% less fat, it had a similar trend. This may be in part due to processing, which is promising for manufacturers aiming to deliver a lower fat product without sacrificing the desired attributes.

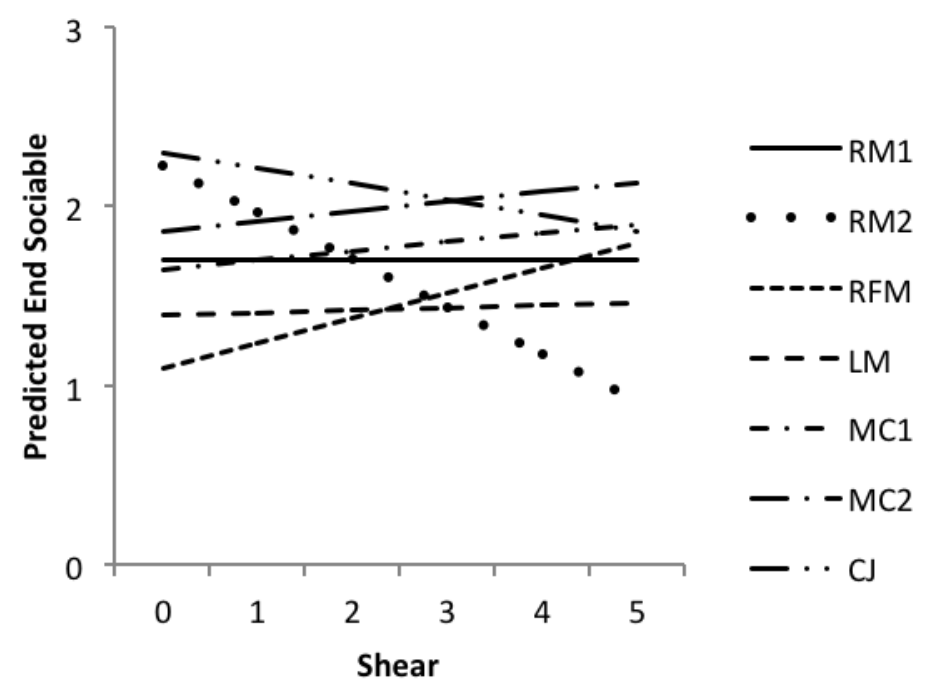

Figure 12. Effect of shear on the predicted end sociable response for each cheese sample

Conversely, as the perceived level of shear increased, the end sociable intensity decreased for sample RM2 and CJ. The RM2 sample has approximately $10 \%$ less fat than the CJ sample, however was perceived similarly. RM1 and LM appear to have little to no changes in the end sociable response regardless of the perceived level of shear. It seems that processing techniques or processing techniques combined with the cheese ingredient interactions may be responsible for the texture properties of these cheeses. 
The sample interaction between shear, soft and sponginess had a significant effect on the end fatigued intensity reported by panelists (Table 7). Similar to the end sociable responses, the RM2 and CJ samples exhibited a similar trend, however in the opposite direction. As the perceived level of shear increased, and the end sociable intensity decreased, the end fatigued response increased (Figure 13). All other cheese samples showed a similar trend with varying slopes.

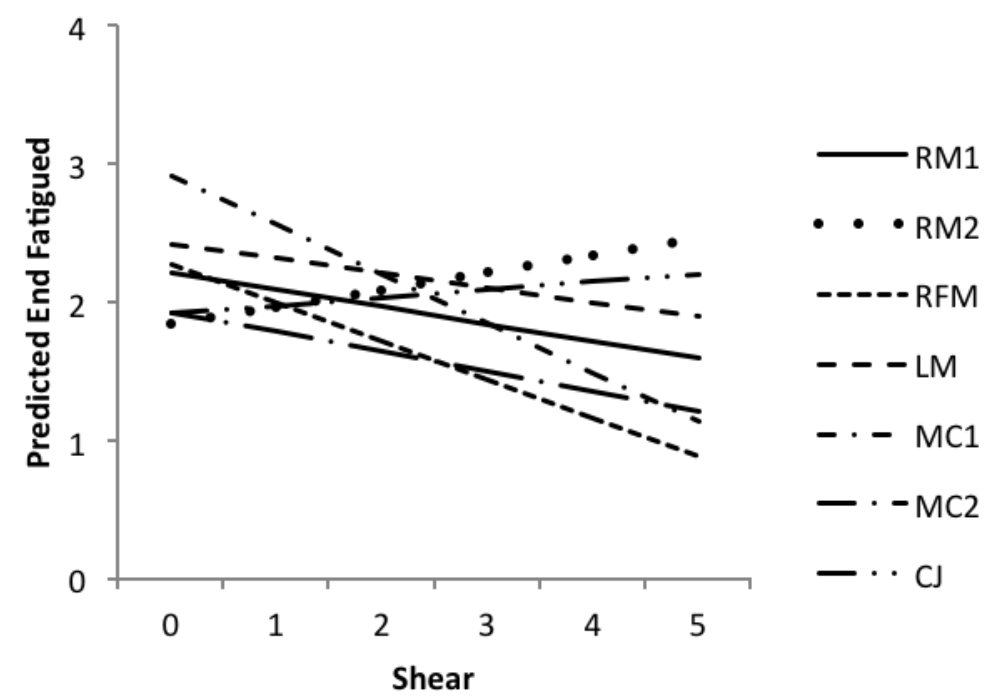

Figure 13. Effect of shear on the predicted end fatigued response for each cheese sample

Interestingly, as the perceived softness of the samples increased, the end fatigued emotional response increased after consuming the RFM and LM samples. Since both samples have a reduced fat content compared to RM and RM2, it was expected that these samples may be perceived similarly. The perception of softness after consuming all other samples seemed to have the opposite effect on the end fatigued response (Figure 14). 


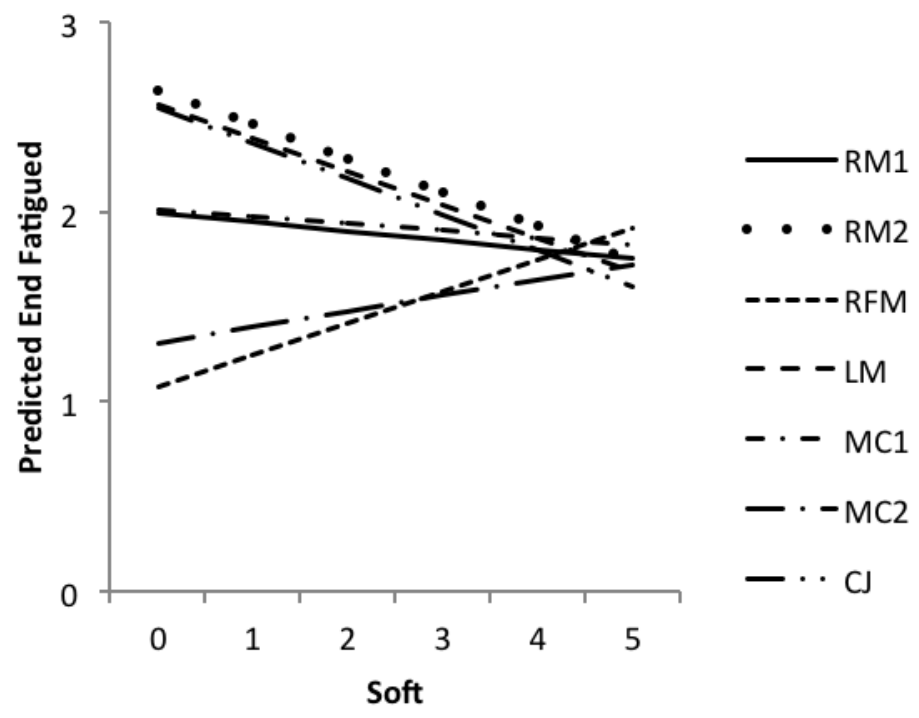

Figure 14. Effect of soft on the predicted end fatigued response for each cheese sample

Looking at the effect of sponginess on the predicted end fatigued emotional response, the MC1 most notably stands out (Figure 15). As the perceived level of sponginess increased, the intensity of the end fatigued response was also predicted to increase with a relatively steep slope compared to the other cheese samples.

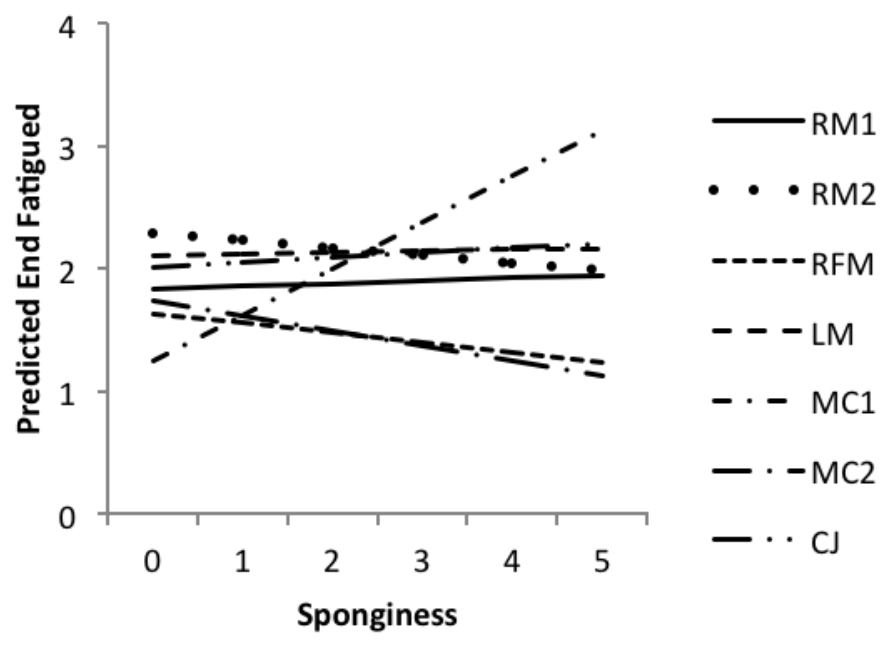

Figure 15. Effect of sponginess on the predicted end fatigued response for each cheese sample 
The interaction between the sample and sponginess texture attribute was also significant for the predicted end raging emotional response. Again, the effect of the texture attribute has the most noticeable change in the end raging response after consuming sample MC1 (Figure 16). As the perceived level of sponginess increased, the end raging response, in addition to the end fatigued response was predicted to increase.

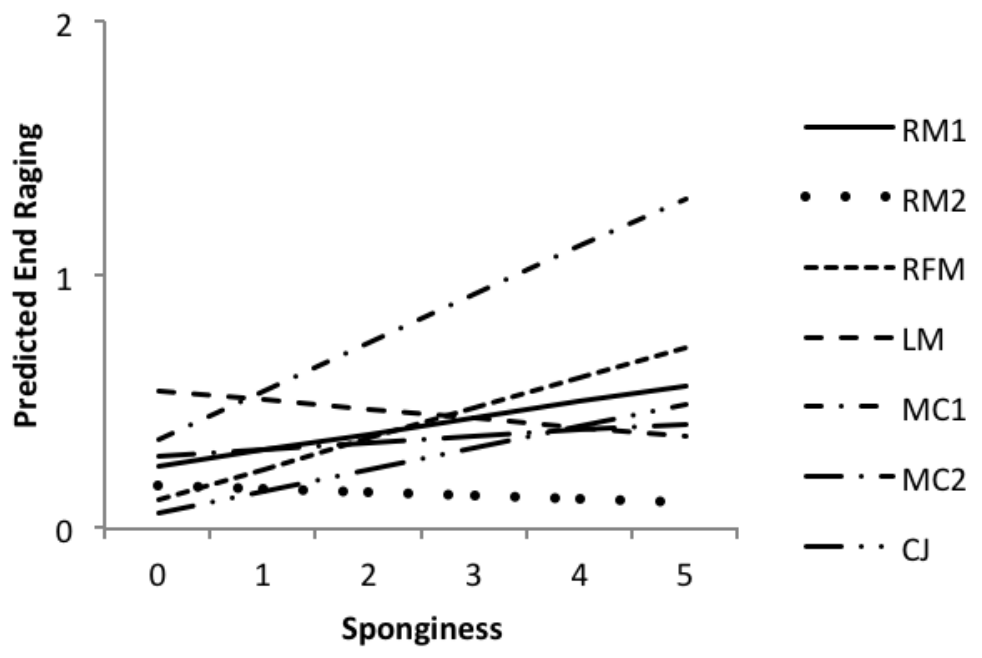

Figure 16. Effect of sponginess on the predicted end raging response for each cheese sample

Caution should be taken in the interpretation of these results as the attributes selected are very product specific, additionally, special attention should be drawn to the scale of each plot. For the aforementioned texture attributes, the effect of each attribute on the end emotional response was completely dependent on the cheese sample. It is clear though that these attributes have an effect on the end emotion and texture should therefore be given special consideration when manufacturing convenience cheeses, especially if the aim is to evoke a certain emotion. 
Texture Main Effects. The initial MANOVA also indicated that the following main effects were significant for at least one of the end emotions: panelist (Wilks' Lambda $\mathrm{F}(532,2371)=14.3, \mathrm{p}<0.0001)$, fibrousity $($ Wilks' Lambda $\mathrm{F}(7,338)=2.73$, $\mathrm{p}=0.0091)$, rubbery (Wilks' Lambda $\mathrm{F}(7,338)=3.33, \mathrm{p}=0.0019)$, and waxy (Wilks' Lamda $\mathrm{F}(7,338)=2.06, \mathrm{p}=0.0474)$. The follow up ANOVAs showed that panelist was significant for all end emotions $(\mathrm{p}<0.0001)$ as well as the texture attributes (Table 8$)$.

Table 8. Effect of texture attributes on end emotional responses

\begin{tabular}{llcc}
\hline Emotion & Significant Term & Direction of Influence & p value \\
\hline Excited & Waxy & + & 0.0307 \\
Sociable & Rubbery & + & 0.0326 \\
Fatigued & Waxy & + & 0.0143 \\
Judgmental & Waxy & + & 0.0279 \\
Raging & Rubbery & - & 0.0027 \\
& Waxy & + & 0.0265 \\
Sad & Fibrousity & - & 0.0051 \\
& Rubbery & - & 0.0240 \\
\hline
\end{tabular}

As shown in Table 8, many of the significant texture attributes had a positive $(+)$ direction of influence. For example, as the perceived waxiness level increased, panelists reported an increased intensity for their excited, fatigued and judgemental end emotional responses. Conversely, as the perceived level of rubbery increased, the end raging and sad intensity decreased.

At this point, it is unclear which factors exactly contribute to the specific texture properties perceived by the panelists, especially when considering the different cheese varieties tested. Different cheese types inherently have a broad range of textural properties. The manufacturing process of cheese involves careful management of milk 
composition, rate and extent of acid development, moisture content, curd manipulation, and maturation conditions (Lucey, Johnson, \& Horne, 2003). Lucey et al. (2003) identifies that the two most important factors influencing the physical properties of cheese (i.e. texture) are the condition of casein molecules in the cheese and the extent of proteolysis. As a result, application of the method at hand and interpretation of results are very specific to the product of interest and the individual manufacturer. Other attributes of interest may have a significant effect on the resulting emotion when testing other food products and food forms. However, results from the present study provide valuable information for cheese processors, especially those manufacturing convenience cheeses. New processing techniques allow for more flexibility in controlling and manipulating the aforementioned factors that should be considered in the cheese making process. It is necessary to create mechanisms that correlate sensory and mechanical measures of these texture attributes (E. A. Foegeding \& Drake, 2007; E. Foegeding, Brown, Drake, \& Daubert, 2003) so that the information can provide manufacturers actionable feedback to create products that cater to the drivers of food choice and foster product conceptualisation. Product developers can also apply this information to new cheese products as they are created.

\section{Effects of Initial Emotions and Hedonics on End Product Liking}

To determine if a model with hedonic and initial emotion measurements better predicts product liking, as measured by the end overall liking score, than hedonics alone, three models were compared. As shown in Table 9, both hedonic principal components in Model 1 are significant predictors of overall liking. Including the initial emotion principal components in Model 2 did not cause a large increase in the adjusted $\mathrm{R}^{2}$. Similarly, 
including the interactions between hedonics and initial emotions (Model 3) did not improve the model more than would be expected by chance alone. When considering the three models, a model including hedonics represented as principal components is sufficient to predict overall liking. Future studies are necessary to validate the conclusions drawn based on this evidence. Additionally, it should be noted that the more complex models do not improve the ability to predict overall liking, however, such models may be necessary when trying to predict a panelist's emotional response or other variables that may of interest in particular situations.

The combination of hedonic and initial emotion measurements provides researchers more detailed information regarding consumers and the target population for a given product. Of course, researchers, manufacturers and product developers can utilize the information as necessary to deliver desirable products that meet consumer demands. 
Table 9. Comparison of three models to determine if hedonics and emotions better predict overall liking than hedonics alone

\begin{tabular}{|c|c|c|c|}
\hline & Model 1 & Model 2 & Model 3 \\
\hline Adjusted $\mathbf{R}^{2}$ & 0.861679 & 0.861621 & 0.860578 \\
\hline SS Model & 2106.3707 & 2107.4806 & 2107.8641 \\
\hline SS Error & 278.3566 & 277.2467 & 276.8632 \\
\hline Panelist & $<0.0001 *$ & $<0.0001 *$ & $<0.0001 *$ \\
\hline Sample & 0.0804 & 0.0727 & 0.0702 \\
\hline PC1 (hedonics) & $<0.0001 *$ & $<0.0001 *$ & $<0.0001 *$ \\
\hline PC2 (hedonics) & $<0.0001 *$ & $<0.0001^{*}$ & $<0.0001 *$ \\
\hline PC1 (emotion initial) & - & 0.6890 & 0.7243 \\
\hline PC2 (emotion initial) & - & 0.1894 & 0.1844 \\
\hline \multicolumn{4}{|l|}{ PC1 (hedonics) * } \\
\hline PC1 (emotion initial) & - & - & 0.5318 \\
\hline \multicolumn{4}{|l|}{ PC1 (hedonics) * } \\
\hline PC2 (emotion initial) & - & - & 0.8141 \\
\hline \multicolumn{4}{|l|}{ PC2 (hedonics) * } \\
\hline PC1 (emotion initial) & - & - & 0.9684 \\
\hline \multicolumn{4}{|l|}{ PC2 (hedonics) * } \\
\hline PC2 (emotion initial) & - & - & 0.6351 \\
\hline
\end{tabular}

${ }^{*} \mathrm{p}<0.05$ is considered statistically significant

\section{Conclusion}

Hedonic scores were not found to have a significant effect on a panelist's end emotional response for the seven commercially produced convenience cheeses tested. The texture/sample interaction of the perceived level of shear, soft, and sponginess significantly affected the end sociable, fatigued and raging emotional responses. These responses were dependent on the cheese sample. Additionally, fibrousity, rubbery and waxy had a significant effect on at least one of the end emotions. These results can provide valuable information to cheese manufacturers aiming to evoke a given emotion or hoping to encourage healthier choices by replicating desirable attributes in alternative nutrition products. The relationship between emotion and texture attributes is not clearly 
defined; however, there is an interesting link since this information is processed in the same region of the brain. Further investigation is necessary to gain a better understanding of how the two are interrelated on a per product basis. Processing techniques should be evaluated closely in order to identify the key steps responsible for textural properties of the final product.

Comparison of the three different models indicated that hedonic principal components were sufficient to predict end overall liking for the cheese samples tested. From a practical standpoint, emotion measurements may not be needed if the research goal is strictly regarding overall liking of a product. The aforementioned results though, clearly demonstrate the importance of other considerations (such as texture measurements) in understanding drivers of end emotion, which ultimately contributes to the overall product experience. This research raises many questions regarding emotion measurement, how it relates to texture and hedonic attribute questions and whether or not the measurement tool is effective in capturing true emotional responses. The research though represents a stepping-stone to help guide future research seeking to effectively dissect, measure and analyze the components involved in the consumption experience. 


\title{
CHAPTER IV
}

\section{Do we need an emotional cleanser? An example using experimentally developed low moisture part skim mozzarella with partial $\mathrm{NaCl}$ substitution}

\begin{abstract}
Mozzarella cheese is the most consumed type of cheese in the U.S., which presents an opportunity for investigating sodium reduction. Determining the attributes of cheese that drive consumption and the emotions that such products may elicit, can guide manufacturers in the production of a low sodium product that is accepted and preferred by the consumers. Incorporating an emotional calibration step during consumer testing may provide researchers a greater understanding of the end emotion elicited by a given product. The objectives of this study were to (1) determine if the emotion calibration step is effective in creating an emotional baseline between samples, (2) determine differences in product acceptance based on partial $\mathrm{NaCl}$ substitution, and (3) evaluate product preparation procedures during formulation of low sodium cheeses.
\end{abstract}

Low moisture part skim mozzarella samples were produced with three different salt/salt substitutes $\left(\mathrm{NaCl}, \mathrm{KCl}\right.$, and Salona $\left.{ }^{\mathrm{TM}}\right)$ at two levels $(100 \%$ and $50 \%)$ with two antimicrobials (CytoGuard ${ }^{\mathbf{T M}}$ LA 20 and NovaGARD®). All samples were evaluated by consumers $(\mathrm{N}=54)$, which involved emotion, hedonic and texture measurements. Subjects were asked his/her emotional state (excited, sociable, self-confident, fatigued, judgmental, raging and sad; scaled from 1- "slightly" to 5-“extremely" (with a 0 -"not at all” option) in a CATA format before and after consuming each sample. Hedonic questions (9-point hedonic scale) and perception of texture were assessed during and at 
the end of consumption. An emotional calibration step was added between samples. All data was collected using Compusense ${ }^{\circledR}$ at-hand.

The results indicated: (1) there was no significant variations in panelists' reported initial emotions between samples, (2) the full sodium and 100\% $\mathrm{KCl}$ samples were consistently liked more compared to the other samples, and (3) special considerations for antimicrobial application should be made during production and preparation of experimentally developed low sodium cheese.

\section{Highlights}

- Experimentally produced LMPS mozzarella was evaluated

- Emotion testing involving an emotion calibration step between samples

- Evaluation of initial emotions between samples

- Cheeses with salt replacers were not as well-liked as the full sodium control

Keywords: emotion testing; emotion calibration; hedonic testing; low sodium mozzarella cheese 


\section{Introduction}

Mozzarella cheese is the most consumed type of cheese in the U.S., reaching a record high of 11.29 pounds per capita in 2010 (International Dairy Foods Association, 2013). One serving of mozzarella (approximately 28 grams) provides $8 \%$ of your Daily Value for sodium. Considering the obesity epidemic and increasing prevalence of hypertension (Centers for Disease Control and Prevention, 2013), there are opportunities to investigate sodium reduction in mozzarella (Ayyash et al., 2013; Cruz et al., 2011). Determining the attributes of cheese that drive consumption and the emotions that such products may elicit, can guide manufacturers in the production of a low sodium product that is accepted and preferred by the consumers.

As emotion measurements become prominent in emerging sensory research, many questions arise in regards to the measurement tools and techniques. Most often, the questions are product and context related: do the emotions in the questionnaire capture the emotional characterization of the product at hand? (Cardello et al., 2012; King \& Meiselman, 2010) and how does the environment (context) affect the panelist's emotions in relation to the product (King et al., 2013)?

Current emotion measurement methodologies, such as the EsSense Profile ${ }^{\circledR}$ (King et al., 2010, 2013; King \& Meiselman, 2010) aim to measure consumers' emotional responses after exposure to a given product. Although highly valuable for market research and product developers, the initial emotional disposition of a panelist has not been a primary focus. Research accounting for the initial emotion, measured prior to consumption, has shown that a variety of products elicit an emotional change through the 
eating experience (Collinsworth, Lammert, Martinez, Leidheiser, et al., 2014). These findings have encouraged a deeper investigation of the initial emotion and how it may affect the end emotional responses. Is there variability between samples in the initial emotion that may dictate the intensity of the end emotion and if so, is the variability significant?

Throughout all sensory testing methodologies, it is common practice to include a palate cleanser before and between samples to establish a baseline oral environment (E. A. Johnson \& Vickers, 2004). This decreases any carryover effects that may influence a panelist's perception of future samples. A variety of palate cleansers have been employed for a wide spectrum of products determined by the study's objectives, including: water, sparkling water, carrots, crackers, plain cream cheese, rinsing six times ( Johnson \& Vickers, 2004), reverse osmosis, deionized, carbon filtered water, unsalted crackers, and apple slices (Rétiveau, Chambers, \& Esteve, 2005), lemon water and unsalted crackers (Lawless, Sheng, \& Knoops, 1995), water, carboxymethylcellulose, crackers, milk, chewing wax, or nothing (Lee \& Vickers, 2010), deionized water, pectin, carboxymethycellulose, and unsalted crackers (Ross, Hinken, \& Weller, 2006), table water crackers, spring water, pectin solution, whole milk, chocolate and warm water (Lucak \& Delwiche, 2009). Since sensory evaluation methods rely on consumer's senses, it is imperative that a palate cleanser is utilized in order to determine accurate perception and responses to the sensory stimuli presented.

Given that the goal of emotion measurement is to gain accurate information on the true emotion that a product evokes and considering the idea of palate cleansers, is it possible to "cleanse the mind" between samples? Can a panelist return to his/her 
emotional baseline between samples similar to the way that palate cleansers establish a baseline oral environment? Therefore, the current study includes an 'emotional calibration' step between samples of experimentally developed LMPS mozzarella cheese with partial $\mathrm{NaCl}$ substitution. The objectives of this study were to (1) determine if the emotion calibration step is effective in creating an emotional baseline between samples, (2) determine differences in product acceptance based on partial $\mathrm{NaCl}$ substitution, and (3) evaluate product preparation procedures during formulation of low sodium cheeses.

\section{Materials and Methods}

\section{Samples and Preparation}

Unsalted, bacteria-cultured mozzarella cheese curd (Rizo Lopez Foods, Inc., Modesto, CA) was used in manufacturing the six varieties of cheese tested. Salt $(\mathrm{NaCl})$ and salt replacers (potassium chloride, $\mathrm{KCl}$ and $\mathrm{Salona}^{\mathrm{TM}}$, a low sodium sea salt) were added individually to make the six-salt/salt replacer variables (salt replacers were added at 50 and $100 \%$ of manufacturer recommended usage levels): full sodium $(1.62 \% \mathrm{NaCl})$, low sodium $(0.56 \% \mathrm{NaCl}), 100 \% \mathrm{KCl}(89.1 \mathrm{~g} \mathrm{KCl}+65 \mathrm{~g} \mathrm{NaCl}$ per 22 pounds of curd; $\mathrm{KCl}$ by Morton Salt, Chicago, IL), $50 \% \mathrm{KCl}(44.6 \mathrm{~g} \mathrm{KCl}+65 \mathrm{~g} \mathrm{NaCl}$ per 22 pounds of curd), $100 \%$ Salona $^{\mathrm{TM}}$ (85.4 $\mathrm{g}$ Salona $^{\mathrm{TM}}+60 \mathrm{~g} \mathrm{NaCl}$ per 22 pounds of curd; Salona ${ }^{\mathrm{TM}}$ by BK Giulini, a member of ICL Performance Products, Overland Park KS), and 50\% Salona ${ }^{\mathrm{TM}}$ (42.7 $\mathrm{g} \mathrm{Salona}^{\mathrm{TM}}+60 \mathrm{~g} \mathrm{NaCl}$ per 22 pounds of curd).

Following salt addition, the six cheese variables were stored at $40^{\circ} \mathrm{F}$ overnight. All samples were cubed to $3 / 4$ inches and dipped in an antimicrobial solution. Half of the samples from each variable were dipped in two antimicrobial solutions: CytoGuard ${ }^{\mathbf{T M}}$ LA 
20 (0.1\%, A\&B Ingredients, Fairfield, NJ, lot \# 20591302) and NovaGARD® CB1 (1\%, Danisco, Madison, WI, batch \# CB1-223710), for 2 minutes and then allowed to air dry. All cubes were vacuum-sealed separately and stored at $37^{\circ} \mathrm{F}$ for aging. Table 10 shows the moisture content of each sample prior to dipping in the antimicrobial solutions.

Table 10. Moisture content of all cheese samples prior antimicrobial dip

\begin{tabular}{ll}
\hline Cheese & \% Moisture \\
\hline Full Sodium & 47.46 \\
Low Sodium & 47.79 \\
$\mathbf{1 0 0 \%}$ KCl & 46.67 \\
$\mathbf{5 0 \%}$ KCl & 47.93 \\
$\mathbf{1 0 0 \%}$ Salona & 47.69 \\
$\mathbf{5 0 \%}$ Salona & 48.35 \\
\hline
\end{tabular}

Seventy-four days post salt addition, samples were removed from the vacuumsealed pouches and placed in two-ounce clear plastic SOLO® soufflé cups (SOLO® Cup Company, Lake Forest, IL) sealed and labeled with randomized three-digit codes. Cheese samples were kept at $40^{\circ} \mathrm{F}$ overnight prior to testing and served to panelists at room temperature $\left(72^{\circ} \mathrm{F}\right)$. Testing occurred at 75 and 76 days post addition of salt and samples were presented in a William's design, where sample order was randomized within and across subjects, with subject receiving six samples each day of testing. An experiment conducted by the same team of researchers used a similar procedure, however, samples were vacuum-sealed in bulk and the cheeses were dipped in the antimicrobials prior to serving panelists (Collinsworth, Lammert, Martinez, Arnold, et al., 2014). The present study aimed to simulate a process more similar to industry practices. 


\section{Subjects}

Sensory testing was conducted in an open lab at California Polytechnic State University San Luis Obispo, CA. The university's human subjects board reviewed and approved all testing procedures.

A total of 54 subjects, including students, university staff, and community members, participated in both days of testing. Participants for this study were recruited by email and flyers; subjects were selected for testing based upon their willingness to consume low sodium mozzarella cheese, mozzarella cheese consumption frequency, and being a non-user of Crest Pro-Health products. The active ingredient in Crest Pro-Health, cetylpyridinium chloride, has been shown to alter taste perception (DeSimone \& Heck, 1991; Food and Drug Administration, 2003; St John \& Hallagan, 2005).

\section{Questionnaire and Testing Procedure}

The IMET method (Collinsworth, Lammert, Martinez, Leidheiser, et al., 2014) was used following the modified protocol described in Martinez et al. (2014). Participants were asked to create an emotion poster board by selecting and attaching images that they identified as representing each of the seven given emotions at each level of intensity (ranging from 1- "slightly" to 5-“extremely"). The seven emotions tested were excited, sociable, self-confident, fatigued, judgmental, raging and sad. Hedonic attributes, scored using a 9-point scale, and texture attributes were assessed at the beginning and end of consumption. The participants identified the emotion(s) he/she was experiencing before and after consuming each sample using a CATA format. In addition to the IMET procedure, participants were instructed to bring a picture of something they enjoyed 
looking at. This was used as the emotional calibration step between each sample and was specific to each individual.

\section{Data Analysis}

All data analyses were performed using JMP® Pro statistical software (JMP, Version 10. SAS Institute Inc., Cary, NC, 1989-2007). Tukey's test was used to compare means with p-values $<0.05$ considered statistically significant. Sample name and panelist (treated as a random effect) were included as model effects in each analysis.

\section{Emotional Baseline}

An Analysis of Variance (ANOVA) was performed to determine if the calibration step was effective in creating an emotional baseline between samples. The continuous initial emotion score, measured before each new sample, was the response variable accounting for type of cheese and panelist.

\section{Hedonics}

An ANOVA of the end hedonic scores (representing the final attribute liking) was performed to determine the differences in product acceptability based on the partial substitution of $\mathrm{NaCl}$. Product attributes tested included overall liking, flavor, texture, appearance, aroma and aftertaste. Each attribute was scored on a 9-point hedonic scale ( $1=$ dislike extremely to $9=$ like extremely) and treated as a continuous response variable. 


\section{Results and Discussion}

\section{Emotional Baseline}

As shown in Table 11, no significant differences were found when comparing the initial emotion scores between each sample. On average, panelists reported the same emotional intensity (for each emotion) prior to consuming each new sample. This may be due to several factors. First, the calibration step may be effective in producing an emotional baseline between samples. Further research is necessary to validate this conclusion. Although the study aimed to create an emotional calibration method and allow consumers to "cleanse their mind" between samples, there may in fact actually be little to no variation in initial emotion between samples and thus no differences are detected. Finally, since the selected emotions are product specific, perhaps this food form does not cause drastic fluctuations in the emotions elicited. Again, more research should be conducted to determine causation; however, this initial study provides groundwork for further investigations.

This method may be of particular interest to companies interested in IHUT (versus CLT) consumer testing. As sensory methods and consumer research are predicted to move beyond the laboratory into "uncontrollable" environments (Meiselman, 2013), calibration methods may provide the balance needed to receive natural, contextual data with less variability. 
Table 11. Self-reported emotion scores (with $0=$ not at all, $1=$ slightly and $5=$ extremely) reported prior to consuming each cheese sample (mean \pm standard deviation)*

\begin{tabular}{|c|c|c|c|c|c|c|c|c|c|c|c|c|c|c|c|c|c|c|c|c|c|}
\hline \multirow{2}{*}{$\begin{array}{c}\text { Sample Name } \\
100 \% \text { KCl + CytoGuard }\end{array}$} & \multicolumn{3}{|c|}{ Excited Initial } & \multicolumn{3}{|c|}{ Sociable Initial } & \multicolumn{3}{|c|}{$\begin{array}{c}\text { Self Confident } \\
\text { Initial } \\
\end{array}$} & \multicolumn{3}{|c|}{ Fatigued Initial } & \multicolumn{3}{|c|}{$\begin{array}{c}\text { Judgmental } \\
\text { Initial }\end{array}$} & \multicolumn{3}{|c|}{ Raging Initial } & \multicolumn{3}{|c|}{ Sad Initial } \\
\hline & 2.19 & \pm & 1.37 & 2.26 & + & 1.26 & 2.39 & \pm & 1.31 & 1.44 & & 1.27 & 0.89 & \pm & 1.06 & 0.30 & \pm & 0.72 & 0.39 & + & 0.71 \\
\hline $100 \%$ KCl + NovaGARD & 2.19 & & 1.44 & 2.00 & \pm & 1.45 & 2.37 & \pm & 1.44 & 1.65 & & 1.39 & 1.02 & \pm & 1.27 & 0.19 & \pm & 0.65 & 0.20 & \pm & 0.59 \\
\hline $100 \%$ Salona ${ }^{\mathrm{TM}}+$ CytoGuard & 2.19 & 1 & 1.44 & 2.13 & \pm & 1.39 & 2.43 & \pm & 1.40 & 1.67 & - & 1.44 & 1.13 & \pm & 1.37 & 0.31 & \pm & 0.91 & 0.43 & \pm & 0.88 \\
\hline $100 \%$ Salona $^{\mathrm{TM}}+$ NovaGARD & 2.15 & 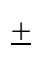 & 1.38 & 1.98 & \pm & 1.42 & 2.50 & \pm & 1.40 & 1.59 & \pm & 1.28 & 1.19 & \pm & 1.32 & 0.17 & \pm & 0.57 & 0.28 & \pm & 0.83 \\
\hline $50 \% \mathbf{K C l}+$ CytoGuard & 2.04 & & 1.27 & 2.04 & \pm & 1.29 & 2.33 & \pm & 1.30 & 1.78 & \pm & 1.54 & 1.15 & \pm & 1.38 & 0.33 & \pm & 0.85 & 0.39 & \pm & 0.83 \\
\hline $50 \%$ KCl + NovaGARD & 2.13 & $I$ & 1.35 & 1.96 & \pm & 1.36 & 2.30 & \pm & 1.31 & 1.70 & \pm & 1.42 & 1.22 & \pm & 1.34 & 0.37 & \pm & 0.85 & 0.35 & \pm & 0.97 \\
\hline $50 \%$ Salona $^{\mathrm{TM}}+$ CytoGuard & 2.22 & $\underline{-}$ & 1.49 & 2.06 & \pm & 1.43 & 2.44 & \pm & 1.37 & 1.85 & 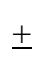 & 1.38 & 1.07 & \pm & 1.27 & 0.17 & \pm & 0.47 & 0.33 & \pm & 0.87 \\
\hline $50 \%$ Salona $^{\mathrm{TM}}+$ NovaGARD & 2.04 & & 1.44 & 1.89 & \pm & 1.38 & 2.33 & \pm & 1.45 & 1.74 & & 1.18 & 0.96 & \pm & 1.08 & 0.28 & \pm & 0.88 & 0.48 & [ & 0.93 \\
\hline Full Na + CytoGuard & 2.04 & & 1.33 & 2.06 & \pm & 1.39 & 2.37 & \pm & 1.40 & 1.70 & - & 1.35 & 0.93 & \pm & 1.21 & 0.17 & \pm & 0.72 & 0.41 & \pm & 0.84 \\
\hline Full Na + NovaGARD & 2.43 & 1 & 1.38 & 2.09 & \pm & 1.40 & 2.48 & \pm & 1.48 & 1.74 & 1 & 1.38 & 0.98 & \pm & 1.21 & 0.19 & \pm & 0.62 & 0.44 & \pm & 0.69 \\
\hline Low Na + CytoGuard & 2.07 & $I$ & 1.43 & 2.00 & \pm & 1.47 & 2.19 & \pm & 1.51 & 1.91 & $\underline{I}$ & 1.36 & 0.94 & \pm & 1.17 & 0.26 & \pm & 0.71 & 0.39 & \pm & 0.76 \\
\hline Low Na + NovaGARD & 2.22 & \pm & 1.22 & 2.02 & \pm & 1.41 & 2.37 & \pm & 1.46 & 1.61 & \pm & 1.22 & 1.19 & \pm & 1.32 & 0.28 & \pm & 0.63 & 0.46 & \pm & 0.75 \\
\hline
\end{tabular}

*No significant differences were found between samples within each emotion (column) 


\section{Hedonics}

The hedonic data indicates that significant differences exist between many of the cheese samples (Table 12). It is important to note that the hedonic scores are much lower than anticipated and are not reflective of well-liked products. On average, the Full $\mathrm{Na}+$ NovaGARD sample had consistently high hedonic scores for all attributes. Only the 100\% Salona + CytoGuard and the Full $\mathrm{Na}+$ CytoGuard were found to be significantly different in the appearance liking from the 50\% Salona + CytoGuard and Low Na + CytoGuard samples. No other significant differences were found for appearance. Also, the $100 \% \mathrm{KCl}+$ CytoGuard and the Low $\mathrm{Na}+$ CytoGuard samples differed significantly from the Low $\mathrm{Na}+\mathrm{CytoGuard} \mathrm{sample} \mathrm{for} \mathrm{the} \mathrm{average} \mathrm{aroma} \mathrm{liking.} \mathrm{When} \mathrm{only}$ considering the samples with partial $\mathrm{NaCl}$ substitution, the $100 \% \mathrm{KCl}$ samples preformed the best with higher hedonic scores for almost all attributes evaluated in this study. 
Table 12. End hedonics scores for each cheese sample (mean \pm standard deviation $)^{\text {a-f }}$

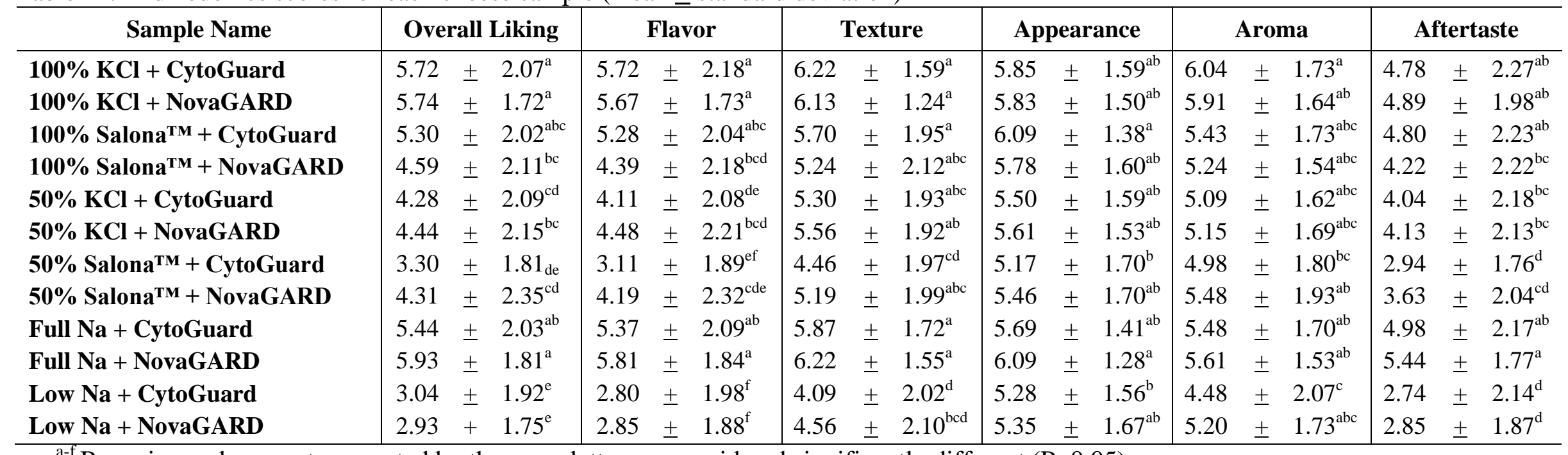

${ }^{\mathrm{a}-\mathrm{f}}$ Rows in a column not connected by the same letter are considered significantly different $(\mathrm{P}<0.05)$ 


\section{Evaluation of Product Preparation and Study Limitations}

The low hedonic scores among the cheese samples with variable $\mathrm{NaCl}$ concentration was concerning and may be due to the product preparation. As a result, valuable information was obtained regarding the production of experimental low sodium cheese.

The current study used cheese curd received from a manufacturer for the base of all samples in an effort to reduce variability between the cheese samples with different salt variables. We hypothesize that the procedures following the salt addition though, introduced many factors that may have negatively affected the product quality. Each 3/4" cube sample (approximately 15g) was vacuum-sealed individually. This sample size is relatively small compared to the $500 \mathrm{~g}$ blocks vacuum-sealed in other studies conducted to determine the effect of partial $\mathrm{NaCl}$ substitution on textural, functional and sensory properties of mozzarella cheese (Ayyash \& Shah, 2011a, 2011b; Ayyash et al., 2013). Additionally, the present study applied the antimicrobial solution to the cheese samples prior to storing and aging. No data on the chemical composition of the cheese was collected because the cheese base was consistent across all samples, only the salt replacers and antimicrobials varied; therefore, no conclusions can be drawn regarding how the antimicrobial may have affected the tested samples. Finally, the samples were tested 75 and 76 days post salt addition. The age of the samples may have contributed to any off flavors detected, resulting in low overall liking. 


\section{Conclusion}

Panelists' initial emotion did not vary significantly between samples. The emotion calibration step may be effective in creating an emotional baseline between samples, however, further investigation is necessary to validate and refine this method.

Additionally, this calibration step raises further questions: if the goal is to create a baseline for each individual between samples, how can consumer expectations be addressed and how does this affect the product experience during consumer testing? The current study provides preliminary research to future work aiming to answer these questions.

As expected, consumers consistently preferred the full sodium samples; however, the $100 \% \mathrm{KCl}$ samples were not significantly different from the full sodium samples in many of the attributes tested. In all, careful consideration should be given to product preparation when producing experimental low sodium cheese. 


\section{REFERENCES}

Anonymous. (1975). Minutes of Division Business Meeting. In Institute of Food Technologists- Sensory Evaluation Division, IFT. Chicago.

Ayyash, M. M., \& Shah, N. P. (2011a). Proteolysis of low-moisture mozzarella cheese as affected by substitution of $\mathrm{NaCl}$ with $\mathrm{KCl}$. Journal of Dairy Science, 94(8), 376977. doi:10.3168/jds.2010-4104

Ayyash, M. M., \& Shah, N. P. (2011b). The effect of substitution of $\mathrm{NaCl}$ with $\mathrm{KCl}$ on chemical composition and functional properties of low-moisture Mozzarella cheese. Journal of Dairy Science, 94, 3761-8. doi:10.3168/jds.2010-4103

Ayyash, M. M., Sherkat, F., \& Shah, N. P. (2013). Effect of partial NaCl substitution with $\mathrm{KCl}$ on the texture profile, microstructure, and sensory properties of lowmoisture mozzarella cheese. The Journal of Dairy Research, 80, 7-13. doi:10.1017/S002202991200043X

Beckley, J., Paredes, D., \& Lopetcharat, K. (Eds.). (2012). Product innovation toolbox: A field guide to consumer understanding and research. Ames, Iowa: John Wiley \& Sons, Inc.

Berridge, K. C. (1996). Food reward: brain substrates of wanting and liking. Neuroscience and Biobehavioral Reviews, 20(1), 1-25. Retrieved from http://www.ncbi.nlm.nih.gov/pubmed/8622814

Berridge, K. C. (2009). "Liking" and "wanting" food rewards: brain substrates and roles in eating disorders. Physiology \& Behavior, 97(5), 537-50.

doi:10.1016/j.physbeh.2009.02.044

Berridge, K. C., Ho, C. Y., Richard, J. M., \& DiFeliceantonio, A. G. (2010). The tempted brain eats: pleasure and desire circuits in obesity and eating disorders. Brain Research, 1350, 43-64. doi:10.1016/j.brainres.2010.04.003

Berridge, K. C., Robinson, T. E., \& Aldridge, J. W. (2009). Dissecting components of reward: "liking", "wanting", and learning. Current Opinion in Pharmacology, 9(1), 65-73. doi:10.1016/j.coph.2008.12.014

Berthoud, H. R. (2002). Multiple neural systems controlling food intake and body weight. Neuroscience and Biobehavioral Reviews, 26(4), 393-428. Retrieved from http://www.ncbi.nlm.nih.gov/pubmed/12204189

Berthoud, H. R. (2006). Homeostatic and non-homeostatic pathways involved in the control of food intake and energy balance. Obesity (Silver Spring, Md.), 14 Suppl 5(August), 197S-200S. doi:10.1038/oby.2006.308 
Cardello, A. V., Meiselman, H. L., Schutz, H. G., Craig, C., Given, Z., Lesher, L. L., \& Eicher, S. (2012). Measuring emotional responses to foods and food names using questionnaires. Food Quality and Preference, 24(2), 243-250. doi:10.1016/j.foodqual.2011.12.002

Carver, C. S., \& White, T. L. (1994). Behavioral inhibition, behavioral activation, and affective responses to impending reward and punishment: The BIS/BAS Scales. Journal of Personality and Social Psychology, 67(2), 319-333. doi:10.1037//00223514.67.2.319

Centers for Disease Control and Prevention. (2011). Americans Consume Too Much Sodium (Salt).

Centers for Disease Control and Prevention. (2012a). Defining Overweight and Obesity. Retrieved February 01, 2013, from http://www.cdc.gov/obesity/adult/defining.html

Centers for Disease Control and Prevention. (2012b). Where's the sodium ? (pp. 1-4).

Centers for Disease Control and Prevention. (2013). High Blood Pressure. Retrieved from http://www.cdc.gov/bloodpressure/

Chapman, K. W., Lawless, H. T., \& Boor, K. J. (2001). Quantitative descriptive analysis and principal component analysis for sensory characterization of ultrapasteurized milk. Journal of Dairy Science, 84(1), 12-20. doi:10.3168/jds.S00220302(01)74446-3

Chrea, C., Grandjean, D., Delplanque, S., Cayeux, I., Le Calvé, B., Aymard, L., ... Scherer, K. R. (2009). Mapping the semantic space for the subjective experience of emotional responses to odors. Chemical Senses, 34(1), 49-62. doi:10.1093/chemse/bjn052

Collinsworth, L. A., Lammert, A. M., Martinez, K. P., Arnold, M., Farkye, N., Garza, J., \& Ashman, H. (2014). Using IMET to evaluate consumer emotional responses and liking to reduced sodium LMPS mozzarella cheese. Food Quality and Preference, submitted.

Collinsworth, L. A., Lammert, A. M., Martinez, K. P., Leidheiser, M., Garza, J., Keener, M., \& Ashman, H. (2014). Development of a novel sensory method: Image measurement of emotion and texture (IMET). Food Quality and Preference, submitted.

Cruz, A. G., Faria, J. A. F., Pollonio, M. A. R., Bolini, H. M. A., Celeghini, R. M. S., Granato, D., \& Shah, N. P. (2011). Cheeses with reduced sodium content: Effects on functionality, public health benefits and sensory properties. Trends in Food Science \& Technology, 22, 276-291. doi:10.1016/j.tifs.2011.02.003 
De Wijk, R. A., Kooijman, V., Verhoeven, R. H. G., Holthuysen, N. T. E., \& de Graaf, C. (2012). Autonomic nervous system responses on and facial expressions to the sight, smell, and taste of liked and disliked foods. Food Quality and Preference, 26(2), 196-203. doi:10.1016/j.foodqual.2012.04.015

Delplanque, S., Chrea, C., Grandjean, D., Ferdenzi, C., Cayeux, I., Porcherot, C., ... Scherer, K. R. (2012). How to map the affective semantic space of scents. Cognition \& Emotion, 26(5), 885-98. doi:10.1080/02699931.2011.628301

DeSimone, J. A., \& Heck, G. L. (1991). Salt Taste Enhancer. United States.

Desmet, P. (2005). Measuring emotion: Development and application of an instrument to measure emotional responses to products. In Funology (pp. 111-123). Springer Netherlands.

Desmet, P., Hekkert, P., \& Jacobs, J. J. (2000). When a Car Makes You Smile : Development and Application of an Instrument to Measure Product Emotions. Advances in Consumer Research, 27.

Desmet, P., \& Schifferstein, H. N. J. (2008). Sources of positive and negative emotions in food experience. Appetite, 50(2-3), 290-301. doi:10.1016/j.appet.2007.08.003

Drake, S. L., Lopetcharat, K., \& Drake, M. A. (2009). Comparison of two methods to explore consumer preferences for cottage cheese. Journal of Dairy Science, 92(12), 5883-97. doi:10.3168/jds.2009-2389

Ekman, P. (1994). Strong evidence for universals in facial expressions: A reply to Russell's mistaken critique. Psychological Bulletin, 115(2), 268-287.

Ekman, P., \& Friesen, W. V. (1986). A new pan-cultural facial expression of emotion. Motivation and Emotion, 10(2), 159-168.

Evers, C., Adriaanse, M., de Ridder, D. T. D., \& de Witt Huberts, J. C. (2013). Good mood food. Positive emotion as a neglected trigger for food intake. Appetite, 68, 17. doi:10.1016/j.appet.2013.04.007

Faccia, M., Mastromatteo, M., Conte, A., \& Del Nobile, M. A. (2012). Influence of the different sodium chloride concentrations on microbiological and physico-chemical characteristics of mozzarella cheese. The Journal of Dairy Research, 79, 390-6. doi:10.1017/S0022029912000209

Finlayson, G., King, N., \& Blundell, J. (2008). The role of implicit wanting in relation to explicit liking and wanting for food: implications for appetite control. Appetite, 50(1), 120-7. doi:10.1016/j.appet.2007.06.007 
Finlayson, G., King, N., \& Blundell, J. E. (2007). Is it possible to dissociate "liking" and "wanting" for foods in humans? A novel experimental procedure. Physiology \& Behavior, 90(1), 36-42. doi:10.1016/j.physbeh.2006.08.020

Foegeding, E. A., \& Drake, M. A. (2007). Invited review: Sensory and mechanical properties of cheese texture. Journal of Dairy Science, 90(4), 1611-24. doi:10.3168/jds.2006-703

Foegeding, E., Brown, J., Drake, M., \& Daubert, C. R. (2003). Sensory and mechanical aspects of cheese texture. International Dairy Journal, 13(8), 585-591. doi:10.1016/S0958-6946(03)00094-3

Food and Drug Administration. (2003). Oral Health Care Drug Products for Over- theCounter Human Use; Antigingivitis/ Antiplaque Drug Products; Establishment of a Monograph; Proposed Rules (pp. 1-57).

Garcia-Burgos, D., \& Zamora, M. C. (2013). Facial affective reactions to bitter-tasting foods and body mass index in adults. Appetite, 71C, 178-186.

doi:10.1016/j.appet.2013.08.013

Ghirri, A., \& Bignetti, E. (2009). The role of orbitofrontal cortex in emotion-based decision making and food choice. Ann. Fac. Medic. Vet. Di Pharma, 29, 27-32.

Gibson, E. L. (2006). Emotional influences on food choice: sensory, physiological and psychological pathways. Physiology \& Behavior, 89(1), 53-61.

doi:10.1016/j.physbeh.2006.01.024

Harris, B. S. (1990). Role of set-point weight theory in regulation of body. The Journal of the Federation of American Societies for Experimental Biology, 4(15), 3310-3318.

Hein, K. A., Jaeger, S. R., Carr, T. B., \& Delahunty, C. M. (2008). Comparison of five common acceptance and preference methods. Food Quality and Preference, 19(7), 651-661. doi:10.1016/j.foodqual.2008.06.001

Hill, D. (2007). Emotionomics: Leveraging emotions for business success. London: Kogan Page.

Holland, P. C., \& Gallagher, M. (2004). Amygdala - frontal interactions and reward expectancy. Current Opinion in Neurobiology, 14, 148-155. doi:10.1016/j.conb.2004.03.007

International Dairy Foods Association. (2013). Cheese Sales \& Trends. Retrieved from http://www.idfa.org/news--views/media-kits/cheese/cheese-sales-and-trends/ 
Jaeger, S. R., \& Cardello, A. V. (2009). Direct and indirect hedonic scaling methods: A comparison of the labeled affective magnitude (LAM) scale and best-worst scaling. Food Quality and Preference, 20(3), 249-258. doi:10.1016/j.foodqual.2008.10.005

Jaeger, S. R., Cardello, A. V., \& Schutz, H. G. (2013). Emotion questionnaires: A consumer-centric perspective. Food Quality and Preference, 30, 229-241. doi:10.1016/j.foodqual.2013.05.015

Jaeger, S. R., \& Hedderley, D. I. (2013). Impact of individual differences in emotional intensity and private body consciousness on EsSense Profile® responses. Food Quality and Preference, 27(1), 54-62. doi:10.1016/j.foodqual.2012.06.004

Johnson, E. A., \& Vickers, Z. (2004). The effectiveness of palate cleansing strategies for evaluating the bitterness of caffeine in cream cheese. Food Quality and Preference, 15, 311-316. doi:10.1016/S0950-3293(03)00071-5

Johnson, M. E., Kapoor, R., Mcmahon, D. J., Mccoy, D. R., \& Narasimmon, R. G. (2009). Reduction of sodium and fat levels in natural and processed cheeses : Scientific and technological aspects. Comprehensive Reviews in Food Science and Food Safety, 8.

Kenny, P. J. (2011). Reward mechanisms in obesity: new insights and future directions. Neuron, 69(4), 664-79. doi:10.1016/j.neuron.2011.02.016

King, S. C., \& Meiselman, H. L. (2010). Development of a method to measure consumer emotions associated with foods. Food Quality and Preference, 21(2), 168-177. doi:10.1016/j.foodqual.2009.02.005

King, S. C., Meiselman, H. L., \& Carr, B. T. (2010). Measuring emotions associated with foods in consumer testing. Food Quality and Preference, 21(8), 1114-1116. doi:10.1016/j.foodqual.2010.08.004

King, S. C., Meiselman, H. L., \& Thomas Carr, B. (2013). Measuring emotions associated with foods: Important elements of questionnaire and test design. Food Quality and Preference, 28(1), 8-16. doi:10.1016/j.foodqual.2012.08.007

Laros, F. J. M., \& Steenkamp, J. B. E. M. (2005). Emotions in consumer behavior: a hierarchical approach. Journal of Business Research, 58(10), 1437-1445. doi:10.1016/j.jbusres.2003.09.013

Lawless, H. T., Sheng, N., \& Knoops, S. S. (1995). Multideminsional scaling of sorting data applied to cheese perception. Food Quality and Preference, 6, 91-98.

Lee, C. A., \& Vickers, Z. M. (2010). Discrimination among astringent samples is affected by choice of palate cleanser. Food Quality and Preference, 21, 93-99.

doi:10.1016/j.foodqual.2009.08.003 
Let's Move. (2014). Retrieved April 05, 2014, from http://www.letsmove.gov/

Lim, J. (2011). Hedonic scaling: A review of methods and theory. Food Quality and Preference, 22(8), 733-747. doi:10.1016/j.foodqual.2011.05.008

Lucak, C. L., \& Delwiche, J. F. (2009). Efficacy of various palate cleansers with representative foods. Chemosensory Perception, 2, 32-39. doi:10.1007/s12078-0099036-6

Lucey, J. A., Johnson, M. E., \& Horne, D. S. (2003). Invited review: perspectives on the basis of the rheology and texture properties of cheese. Journal of Dairy Science, 86(9), 2725-43. doi:10.3168/jds.S0022-0302(03)73869-7

Macht, M. (2008). How emotions affect eating: a five-way model. Appetite, 50(1), 1-11. doi:10.1016/j.appet.2007.07.002

Macht, M., Meininger, J., \& Roth, J. (2005). The pleasures of eating: A qualitative analysis. Journal of Happiness Studies, 6(2), 137-160. doi:10.1007/s10902-0050287-x

Macht, M., \& Mueller, J. (2007). Immediate effects of chocolate on experimentally induced mood states. Appetite, 49(3), 667-74. doi:10.1016/j.appet.2007.05.004

McMahon, D. J., \& Oberg, C. J. (1998). Influence of fat, moisture and salt on functional properties of mozzarella cheese. Austrialian Journal of Dairy Technology, 53(2). Retrieved from http://ezproxy.lib.calpoly.edu/login?url=http://search.proquest.com/docview/199495 464 ? accountid $=10362$

Meiselman, H. L. (2013). The future in sensory/consumer research: evolving to a better science. Food Quality and Preference, 27(2), 208-214. doi:10.1016/j.foodqual.2012.03.002

Moskowitz, H., Beckley, J., \& Resurreccion, A. (2006). Sensory and consumer research in food product design and development (First.). Ames: Blackwell Publishing Professional.

Mulligan, K., \& Scherer, K. R. (2012). Toward a working definition of emotion. Emotion Review, 4(4), 345-357. doi:10.1177/1754073912445818

Murray, J. M., Delahunty, C. M., \& Baxter, I. A. (2001). Descriptive sensory analysis: past, present and future. Food Research International, 34(6), 461-471. doi:10.1016/S0963-9969(01)00070-9

National Institute of Health. (1998). Clinical Guidelines on the Identification, Evaluation, and Treatment of Overweight and Obesity in Adults. 
Ng, M., Chaya, C., \& Hort, J. (2013). Beyond liking: Comparing the measurement of emotional response using EsSense Profile and consumer defined check-all-thatapply methodologies. Food Quality and Preference, 28(1), 193-205. doi:10.1016/j.foodqual.2012.08.012

Ogden, C. L., Carroll, M. D., Kit, B. K., \& Flegal, K. M. (2012). Prevalence of obesity in the United States, 2009-2010. NCHS Data Brief, (82), 1-8. Retrieved from http://www.ncbi.nlm.nih.gov/pubmed/22617494

Paulson, B. M., Mcmahon, D. J., \& Oberg, C. J. (1998). Influence of sodium chloride on appearance, functionality, and protein arrangements in nonfat mozzarella cheese. Journal of Dairy Science, 81(8), 2053-2064. doi:10.3168/jds.S00220302(98)75780-7

Peciña, S., \& Smith, K. S. (2010). Hedonic and motivational roles of opioids in food reward: implications for overeating disorders. Pharmacology, Biochemistry, and Behavior, 97(1), 34-46. doi:10.1016/j.pbb.2010.05.016

Peryam, D., \& Girardot, N. (1952). QM pins foods "likes" and "dislikes" with advanced taste-test method. Food Engineering, 58-61.

Peryam, D. R., \& Pilgrim, F. J. (1957). Hedonic scale method of measuring food preferences. Food Technology, 11, 9-14. Retrieved from http://search.proquest.com/docview/615352261? accountid=13158

Porcherot, C., Delplanque, S., Planchais, A., Gaudreau, N., Accolla, R., \& Cayeux, I. (2012). Influence of food odorant names on the verbal measurement of emotions. Food Quality and Preference, 23(2), 125-133. doi:10.1016/j.foodqual.2011.07.006

Porcherot, C., Delplanque, S., Raviot-Derrien, S., Calvé, B. Le, Chrea, C., Gaudreau, N., \& Cayeux, I. (2010). How do you feel when you smell this? Optimization of a verbal measurement of odor-elicited emotions. Food Quality and Preference, 21(8), 938-947. doi:10.1016/j.foodqual.2010.03.012

Rétiveau, A., Chambers, D. H., \& Esteve, E. (2005). Developing a lexicon for the flavor description of French cheeses. Food Quality and Preference, 16(6), 517-527. doi:10.1016/j.foodqual.2004.11.001

Richins, M. L. (1997). Measuring emotions in the consumption experience. Journal of Consumer Research, 24(2), 127-146.

Rolls, E. T. (2006). Brain mechanisms of emotion and decision-making. International Congress Series, 1291, 3-13. doi:10.1016/j.ics.2005.12.079

Rolls, E. T., Verhagen, J. V, \& Kadohisa, M. (2003). Representations of the texture of food in the primate orbitofrontal cortex: neurons responding to viscosity, grittiness, 
and capsaicin. Journal of Neurophysiology, 90(6), 3711-24.

doi:10.1152/jn.00515.2003

Ross, C. F., Hinken, C., \& Weller, K. (2006). Efficacy of palate cleansers for reduction of astringency carryover during repeated ingestions of red wine. Journal of Sensory Studies, 22, 293-312.

Rulikowska, A., Kilcawley, K. N., Doolan, I. A., Alonso-Gomez, M., Nongonierma, A. B., Hannon, J. A., \& Wilkinson, M. G. (2013). The impact of reduced sodium chloride content on Cheddar cheese quality. International Dairy Journal, 28(2), 4555. doi:10.1016/j.idairyj.2012.08.007

Saper, C. B., Chou, T. C., \& Elmquist, J. K. (2002). The need to feed : Homeostatic and hedonic control of eating. Neuron, 36, 199-211.

Scherer, K. R. (2005). What are emotions? And how can they be measured? Social Science Information, 44(4), 695-729. doi:10.1177/0539018405058216

Schifferstein, H. N. J., \& Desmet, P. (2010). Hedonic asymmetry in emotional responses to consumer products. Food Quality and Preference, 21(8), 1100-1104. doi:10.1016/j.foodqual.2010.07.004

Sescousse, G., Redouté, J., \& Dreher, J. C. (2010). The architecture of reward value coding in the human orbitofrontal cortex. The Journal of Neuroscience: The Official Journal of the Society for Neuroscience, 30(39), 13095-104. doi:10.1523/JNEUROSCI.3501-10.2010

Shin, A. C., Zheng, H., \& Berthoud, H.-R. (2009). An expanded view of energy homeostasis: neural integration of metabolic, cognitive, and emotional drives to eat. Physiology \& Behavior, 97(5), 572-80. doi:10.1016/j.physbeh.2009.02.010

Society of Sensory Professionals. (2010). Quantitative Descriptive Analysis. Retrieved November 27, 2013, from http://www.sensorysociety.org/ssp/wiki/Quantitative_Descriptive_Analysis/

Spinelli, S., Masi, C., Dinnella, C., Zoboli, G. P., \& Monteleone, E. (2013). How does it make you feel? A new approach to measuring emotions in food product experience. Food Quality and Preference, In Press. doi:10.1016/j.foodqual.2013.11.009

St John, S. J., \& Hallagan, L. D. (2005). Psychophysical investigations of cetylpyridinium chloride in rats: its inherent taste and modifying effects on salt taste. Behavioral Neuroscience, 119(1), 265-79. doi:10.1037/0735-7044.119.1.265

Steptoe, A., Pollard, T. M., \& Wardle, J. (2013). Development of a measure of the motives underlying the selection of food: The food choice questionnaire, 267-284. 
Stone, H., Blieibaum, R. N., \& Thomas, H. A. (2012). Sensory Evaluation Practices (Fourth.). San Diego, CA: Elsevier Inc.

Stone, H., \& Sidel, J. L. (2004). Sensory Evaluation Practices (Third.). San Diego, CA: Elsevier Academic Press.

Thomson, D. M. H., Crocker, C., \& Marketo, C. G. (2010). Linking sensory characteristics to emotions: An example using dark chocolate. Food Quality and Preference, 21(8), 1117-1125. doi:10.1016/j.foodqual.2010.04.011

U.S. Department of Agriculture, \& U.S. Department of Health and Human Services. (2010). Dietary Guidelines for Americans. Retrieved from http://www.health.gov/dietaryguidelines/dga2010/DietaryGuidelines2010.pdf

USDA Agricultural Research Service. (2010). What We Eat in America, NHANES: Nutrient Intakes from Food. Retrieved from http://www.ars.usda.gov/SP2UserFiles/Place/12355000/pdf/0910/Table_1_NIN_GE N_09.pdf

USDA Agricultural Research Service. (2013). National Nutrient Database for Standard Reference, Release 26.

USDA Economic Research Service. (2013). Per capita consumption of selected cheese varieties (Anпиаl).

Woods, S. C., Schwartz, M. W., Baskin, D. G., \& Seeley, R. J. (2000). Food intake and the regulation of body weight. Annual Review of Psychology, 51, 255-277.

Zeinstra, G. G., Koelen, M. A., Colindres, D., Kok, F. J., \& de Graaf, C. (2009). Facial expressions in school-aged children are a good indicator of "dislikes", but not of "likes." Food Quality and Preference, 20(8), 620-624. doi:10.1016/j.foodqual.2009.07.002

Zheng, H., \& Berthoud, H. R. (2007). Eating for pleasure or calories. Current Opinion in Pharmacology, 7(6), 607-12. doi:10.1016/j.coph.2007.10.011 


\section{APPENDIX A}

\section{Homework}

\section{Cheese Homework for 2/6/13 Test}

Thank you for agreeing to our cheese sensory test!!!

You will have 1 piece of homework to complete *before* the product tasting. We would like you to bring a total of 7 sets of 5 images, one for each emotion listed below (grand total of 35 images), that represent the different emotions to you. These could be images from magazines, the internet, your personal photos (they will not be returned to you), or a mixture of these. Within each of the emotions, select five pictures with varying levels of intensity of that emotion. For example, if we were to evaluate the emotion "happy," you would have one picture for slightly happy (level 1) and one picture for extremely happy (level 5) with the remaining three pictures that define happiness between those two levels. These should be images that are meaningful to you.

1. Excited including energetic, happy, overjoyed

2. Sociable including sharing, light hearted, positive, relaxed

3. Self Confident including purposeful, superior, willful

4. Fatigued including sluggish, tired

5. Judgmental including suspicious, jealous, disgusted, disapproving

6. Raging including arrogant, aggressive furious, irate

7. Sad including nostalgic, regretful, depressed, discontent

Your images are part of the test and will not be returned to you when completed. Please remember: because you will be participating in a research study on food, it is *VERY* important that you follow the following guidelines:

- Refrain from drinking coffee or eating at least 30 minutes before your scheduled test time.

- Do not wear any fragrances. Those that arrive with fragrances will be asked to leave without payment.

- No children will be allowed to wait alone at the facility. (WHY: To eliminate distractions and because we cannot provide supervision.)

- To allow for the check-in process, give yourself enough time to get here approximately 20 minutes before your scheduled testing time. The test will take approximately 30 minutes to complete.

- If you need glasses to read, please bring them as you will be reading and completing an online questionnaire. 
ALSO, prior to the testing day please go to the following link and complete the online questionnaire using your log in code (as the username) and password on the back of your poster board.

\section{http://qry.ca/kthffa}

The questionnaire will be available from Friday, February 1st at 6:01am until Tuesday, February 5 th at 8:59pm PST. If you do not complete the questionnaire you will be unable to participate in the tasting session. 


\section{Cheese Homework for May 29th and 30th Sensory Test}

Thank you for agreeing to our cheese sensory test!!! You will have 2 pieces of homework to complete *before* the product tasting.

First, we would like you to bring a total of 7 sets of 5 images, one for each emotion listed below (grand total of 35 images), that represent the different emotions to you. These could be images from magazines, the internet, your personal photos (they will not be returned to you), or a mixture of these. Within each of the emotions, select five pictures with varying levels of intensity of that emotion. For example, if we were to evaluate the emotion "happy," you would have one picture for slightly happy (level 1) and one picture for extremely happy (level 5) with the remaining three pictures that define happiness between those two levels. These should be images that are meaningful to you.

8. Excited including energetic, happy, overjoyed

9. Sociable including sharing, light hearted, positive, relaxed

10. Self Confident including purposeful, superior, willful

11. Fatigued including sluggish, tired

12. Judgmental including suspicious, jealous, disgusted, disapproving

13. Raging including arrogant, aggressive furious, irate

14. Sad including nostalgic, regretful, depressed, discontent

Your images are part of the test and will not be returned to you when completed.

Second, please bring 1 image (printed or pasted to $8.5^{\prime \prime} \times 11^{\prime \prime}$ paper) that you enjoy looking at.

Please remember: because you will be participating in a research study on food, it is

*VERY* important that you follow the following guidelines:

- Refrain from drinking coffee or eating at least 30 minutes before your scheduled test time.

- Do not wear any fragrances. Those that arrive with fragrances will be asked to leave without payment.

- No children will be allowed to wait alone at the facility. (WHY: To eliminate distractions and because we cannot provide supervision.)

- To allow for the check-in process, give yourself enough time to get here approximately 20 minutes before your scheduled testing time. The test will take approximately 30 minutes to complete.

- If you need glasses to read, please bring them as you will be reading and completing an online questionnaire. 
ALSO, prior to the testing day please go to the following link and complete the online questionnaire

https://www.surveymonkey.com/s/BASQuestionnaire 


\section{APENDIX B}

\section{BAS Questionnaire}

\section{Directions:}

Each item of this questionnaire is a statement that a person may either agree with or disagree with. For each item, indicate how much you agree or disagree with what the item says. Please respond to all the items; do not leave any blank. Choose only one response to each statement. Please be as accurate and honest as you can be. Respond to each item as if it were the only item. That is, don't worry about being "consistent" in your responses. Choose from the following four response options:

$1=$ very true for me

2 = somewhat true for me

3 = somewhat false for me

$4=$ very false for me

\begin{tabular}{|c|c|c|c|c|c|}
\hline & & $\begin{array}{l}\text { Very } \\
\text { true }\end{array}$ & $\begin{array}{c}\text { Somewhat } \\
\text { true }\end{array}$ & $\begin{array}{l}\text { Somewhat } \\
\text { false }\end{array}$ & $\begin{array}{l}\text { Very } \\
\text { false }\end{array}$ \\
\hline 1) & $\begin{array}{l}\text { A person's family is the most important } \\
\text { thing in life. }\end{array}$ & 1 & 2 & 3 & 4 \\
\hline 2) & $\begin{array}{l}\text { Even if something bad is about to happen } \\
\text { to me, I rarely experience fear or } \\
\text { nervousness. }\end{array}$ & 1 & 2 & 3 & 4 \\
\hline 3) & I go out of my way to get things I want. & 1 & 2 & 3 & 4 \\
\hline 4) & $\begin{array}{l}\text { When I'm doing well at something I love } \\
\text { to keep at it. }\end{array}$ & 1 & 2 & 3 & 4 \\
\hline 5) & $\begin{array}{l}\text { I'm always willing to try something new if } \\
\text { I think it will be fun. }\end{array}$ & 1 & 2 & 3 & 4 \\
\hline 6$)$ & How I dress is important to me. & 1 & 2 & 3 & 4 \\
\hline 7) & $\begin{array}{l}\text { When I get something I want, I feel } \\
\text { excited and energized. }\end{array}$ & 1 & 2 & 3 & 4 \\
\hline 8) & Criticism or scolding hurts me quite a bit. & 1 & 2 & 3 & 4 \\
\hline 9) & $\begin{array}{l}\text { When I want something I usually go all- } \\
\text { out to get it. }\end{array}$ & 1 & 2 & 3 & 4 \\
\hline
\end{tabular}




\begin{tabular}{|c|c|c|c|c|c|}
\hline & & $\begin{array}{l}\text { Very } \\
\text { true }\end{array}$ & $\begin{array}{c}\text { Somewhat } \\
\text { true }\end{array}$ & $\begin{array}{l}\text { Somewhat } \\
\text { false }\end{array}$ & $\begin{array}{l}\text { Very } \\
\text { false }\end{array}$ \\
\hline 10) & $\begin{array}{l}\text { I will often do things for no other reason } \\
\text { than that they might be fun. }\end{array}$ & 1 & 2 & 3 & 4 \\
\hline 11) & $\begin{array}{l}\text { It's hard for me to find the time to do } \\
\text { things such as get a haircut. }\end{array}$ & 1 & 2 & 3 & 4 \\
\hline 12) & $\begin{array}{l}\text { If I see a chance to get something I want I } \\
\text { move on it right away. }\end{array}$ & 1 & 2 & 3 & 4 \\
\hline 13) & $\begin{array}{l}\text { I feel pretty worried or upset when I think } \\
\text { or know somebody is angry at me. }\end{array}$ & 1 & 2 & 3 & 4 \\
\hline 14) & $\begin{array}{l}\text { When I see an opportunity for something I } \\
\text { like I get excited right away. }\end{array}$ & 1 & 2 & 3 & 4 \\
\hline 15) & I often act on the spur of the moment. & 1 & 2 & 3 & 4 \\
\hline 16) & $\begin{array}{l}\text { If I think something unpleasant is going to } \\
\text { happen I usually get pretty "worked up". }\end{array}$ & 1 & 2 & 3 & 4 \\
\hline 17) & $\begin{array}{l}\text { I often wonder why people act the way } \\
\text { they do. }\end{array}$ & 1 & 2 & 3 & 4 \\
\hline 18) & $\begin{array}{l}\text { When good things happen to me, it affects } \\
\text { me strongly. }\end{array}$ & 1 & 2 & 3 & 4 \\
\hline 19) & $\begin{array}{l}\text { I feel worried when I think I have done } \\
\text { poorly at something important. }\end{array}$ & 1 & 2 & 3 & 4 \\
\hline 20) & I crave excitement and new sensations. & 1 & 2 & 3 & 4 \\
\hline 21) & $\begin{array}{l}\text { When I go after something I use a "no } \\
\text { holds barred" approach. }\end{array}$ & 1 & 2 & 3 & 4 \\
\hline 22) & $\begin{array}{l}\text { I have very few fears compared to my } \\
\text { friends. }\end{array}$ & 1 & 2 & 3 & 4 \\
\hline 23) & It would excite me to win a contest. & 1 & 2 & 3 & 4 \\
\hline 24) & I worry about making mistakes. & 1 & 2 & 3 & 4 \\
\hline
\end{tabular}


APPENDIX C

Testing Questionnaire

Generated by Compusense at-hand

\section{Compusense}

The future of consumer data collection is 'at-hand'...

\section{(a) Compusense at-hand}


You have finished the responses for your first sample.

Please select sample from the samples in front of you. Please drink some water and eat some cracker.

Please click 'Next' when the time elapses.

$$
\text { 0:00 }
$$


Please enter your First and Last name below...

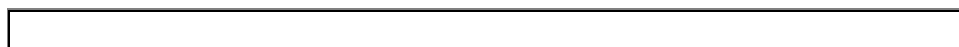

Please enter your Email address below...

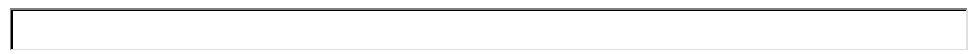


Using the poster board you created, please rank the emotions you are experiencing right now.

\begin{tabular}{|c|c|c|c|c|c|}
\hline \multicolumn{6}{|l|}{ Excited } \\
\hline $\begin{array}{l}\text { Not this } \\
\text { emotion at all }\end{array}$ & Slightly Excited & & & & Extremely Excited \\
\hline 0 & 1 & 2 & 3 & 4 & 5 \\
\hline \multicolumn{6}{|l|}{ Sociable } \\
\hline $\begin{array}{l}\text { Not this } \\
\text { emotion at all }\end{array}$ & Slightly Sociable & & & & Extremely Sociable \\
\hline 0 & 1 & 2 & 3 & 4 & 5 \\
\hline \multicolumn{6}{|l|}{ Self Confident } \\
\hline $\begin{array}{l}\text { Not this } \\
\text { emotion at all }\end{array}$ & $\begin{array}{l}\text { Slightly Self } \\
\text { Confident }\end{array}$ & & & & $\begin{array}{l}\text { Extremely Self } \\
\text { Confident }\end{array}$ \\
\hline 0 & 1 & 2 & 3 & 4 & 5 \\
\hline \multicolumn{6}{|l|}{ Fatigued } \\
\hline $\begin{array}{l}\text { Not this } \\
\text { emotion at all }\end{array}$ & Slightly Fatigued & & & & Extremely Fatigued \\
\hline 0 & 1 & 2 & 3 & 4 & 5 \\
\hline \multicolumn{6}{|l|}{ Judgmental } \\
\hline $\begin{array}{l}\text { Not this } \\
\text { emotion at all }\end{array}$ & Slightly Judgmental & & & & $\begin{array}{l}\text { Extremely } \\
\text { Judgmental }\end{array}$ \\
\hline 0 & 1 & 2 & 3 & 4 & 5 \\
\hline \multicolumn{6}{|l|}{ Raging } \\
\hline $\begin{array}{l}\text { Not this } \\
\text { emotion at all }\end{array}$ & Slightly Raging & & & & Extremely Raging \\
\hline 0 & 1 & 2 & 3 & 4 & 5 \\
\hline \multicolumn{6}{|l|}{ Sad } \\
\hline $\begin{array}{l}\text { Not this } \\
\text { emotion at all }\end{array}$ & Slightly Sad & & & & Extremely Sad \\
\hline 0 & 1 & 2 & 3 & 4 & \begin{tabular}{|l|}
5 \\
\end{tabular} \\
\hline
\end{tabular}


After the first bite of sample BC111,

How do you like the cheese overall?

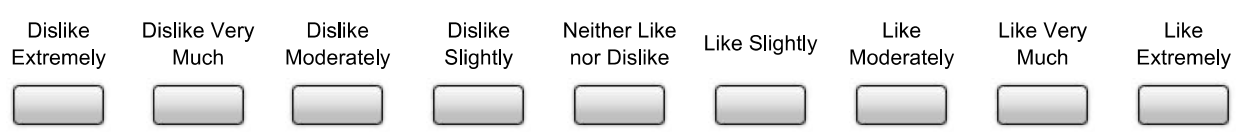

How do you like the flavor of the cheese?

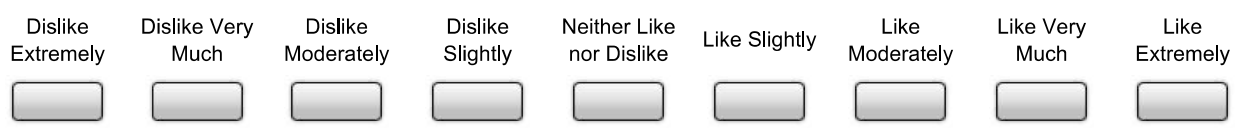

How do you like the texture of the cheese?

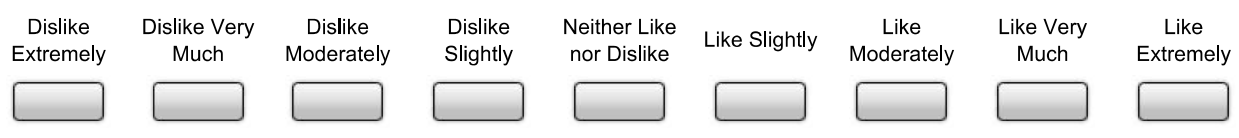

How do you like the appearance of the cheese?

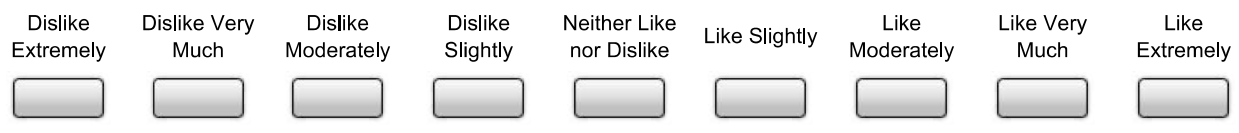

How do you like the aroma of the cheese?

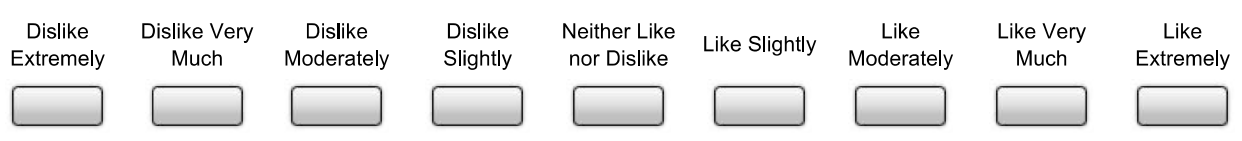

How do you like the aftertaste of the cheese?

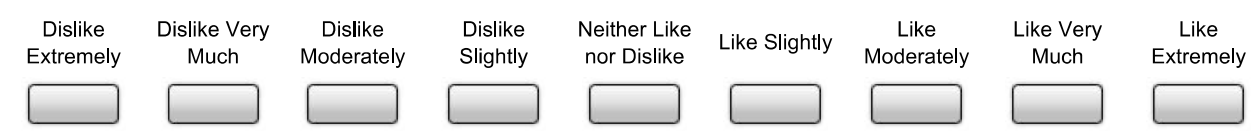


After the first bite or swallow, using the texture cards provided, choose the level that best represents your experience of each attribute.

This texture is...

Sample: BC111

Bite Location
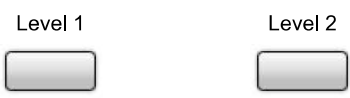

Level 3

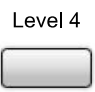

Level 5

Sample: BC111

Break Resistance

Not At All

Level 1

Level 2

Level 3

Level 4

A Lot or Level 5
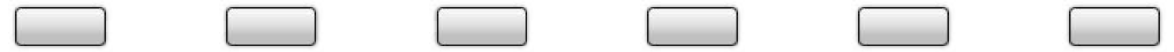

Sample: BC111

Bounciness
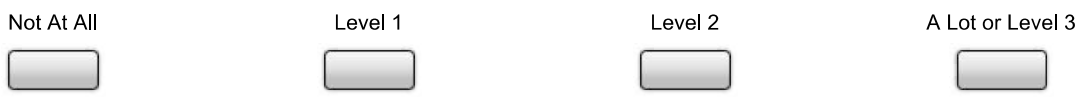

Sample: BC111

Fibrousity
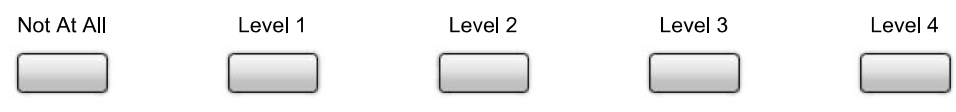

A Lot or Level 5

Sample: BC111

Shear
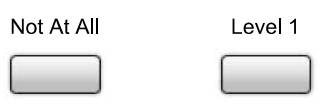

Level 2

Level 3

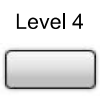

A Lot or Level 5
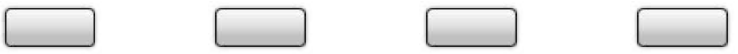

Sample: BC111

Resilience
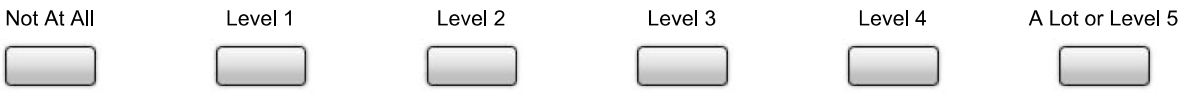

Sample: BC111

Stickiness
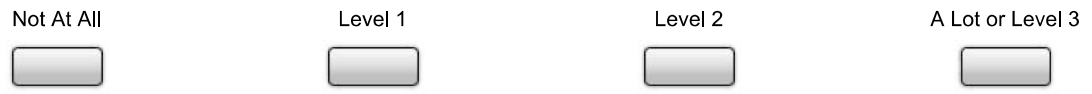

Sample: BC111

Surface Deviation

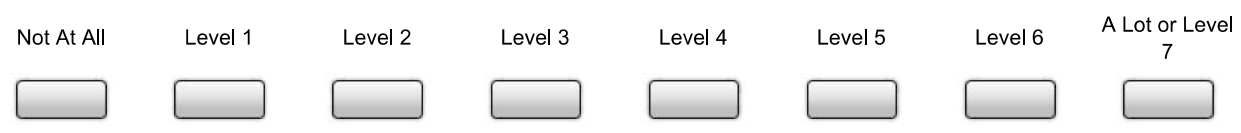

Sample: BC111 
Grittiness
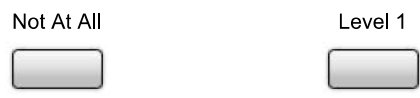

Level 2
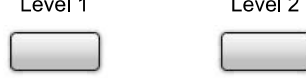

Level 3

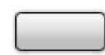

Sample: BC111

Soft

Not At All Level 1

Sample: BC111

Sponginess
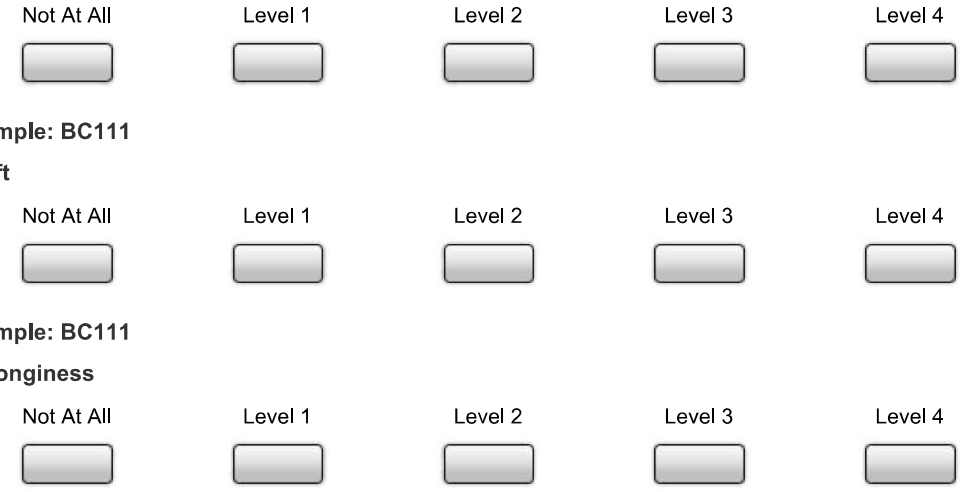

A Lot or Level 5

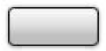

Sample: BC111

Rubbery

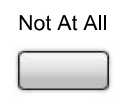

Level 1

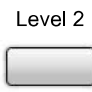

Level 3

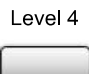

A Lot or Level 5

Sample: BC111

Sandy
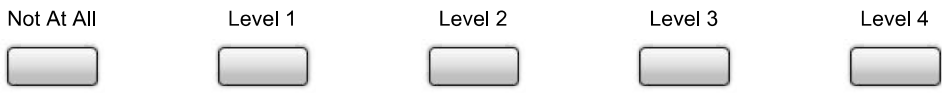

A Lot or Level 5

Sample: BC111

Hardness

Not At All Level 1 Level 2 Level 4

Sample: BC111

Waxy

Not At All Waxy
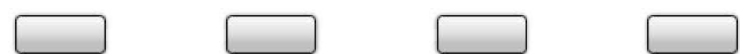

Very Waxy

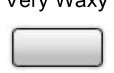


At the end of consuming sample BC111,

How do you like the cheese overall?

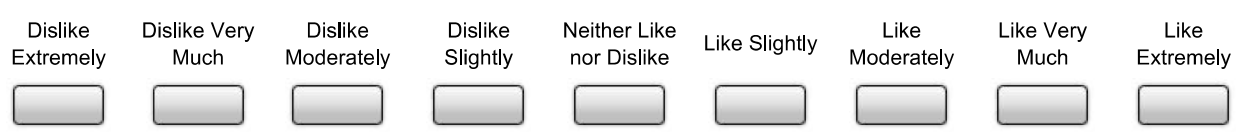

How do you like the flavor of the cheese?

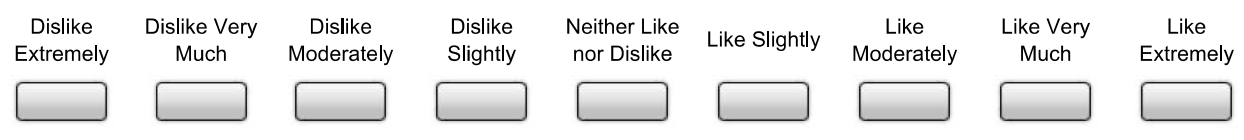

How do you like the texture of the cheese?

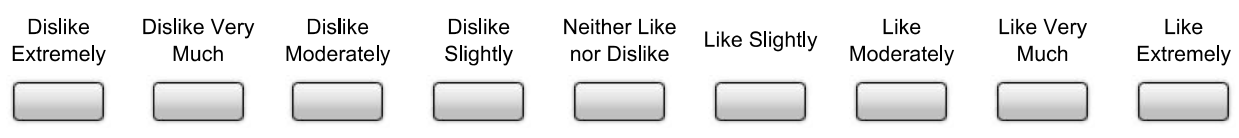

How do you like the appearance of the cheese?

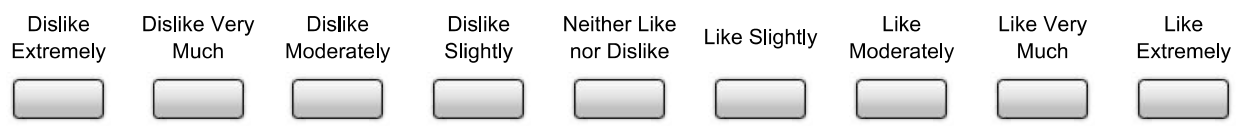

How do you like the aroma of the cheese?

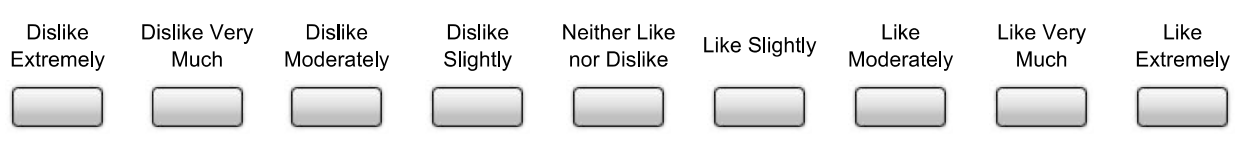

How do you like the aftertaste of the cheese?

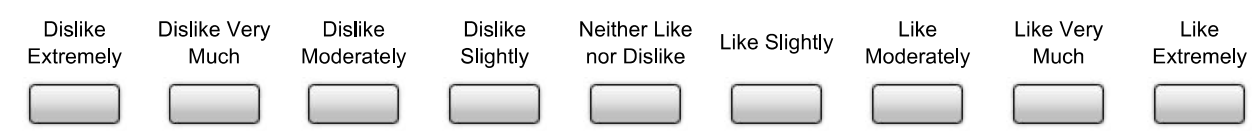


After the end of consumption, using the texture cards provided, choose the level that best represents your experience of each attribute.

This texture is...

Sample: BC111

Bite Location
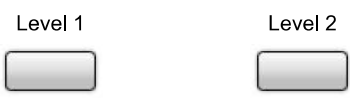

Level 3

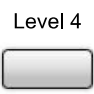

Level 5

Sample: BC111

Break Resistance

Not At All

Level 1

Level 2

Level 3

Level 4

A Lot or Level 5
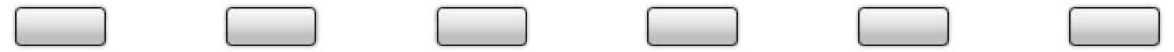

Sample: BC111

Bounciness

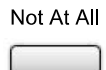

Level 1

Level 2

A Lot or Level 3

Sample: BC111

Fibrousity

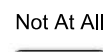

Level 1

Level 2
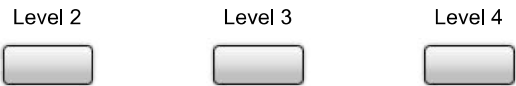

A Lot or Level 5

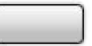

Sample: BC111

Shear

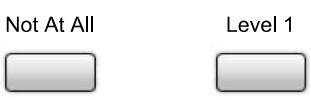

Level 2

Level 3

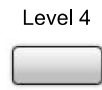

A Lot or Level 5
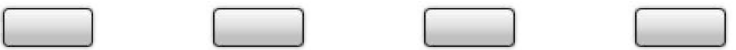

Sample: BC111

Resilience
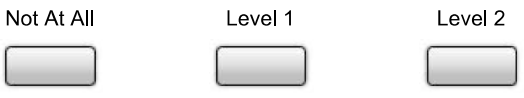

Level 3

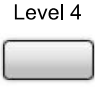

A Lot or Level 5

Sample: BC111

Stickiness
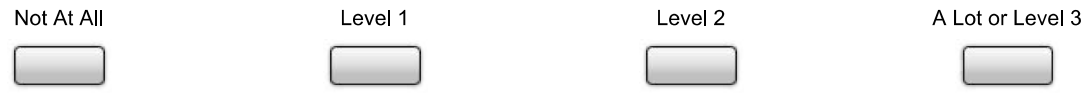

Sample: BC111

Surface Deviation

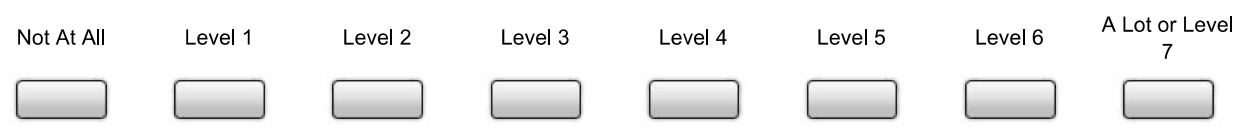

Sample: BC111 
Grittiness
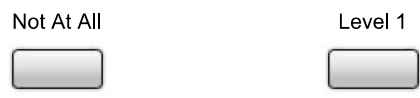

Level 2
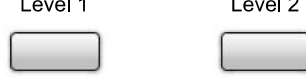

Level 3

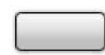

Sample: BC111

Soft

Not At All Level 1

Sample: BC111

Sponginess
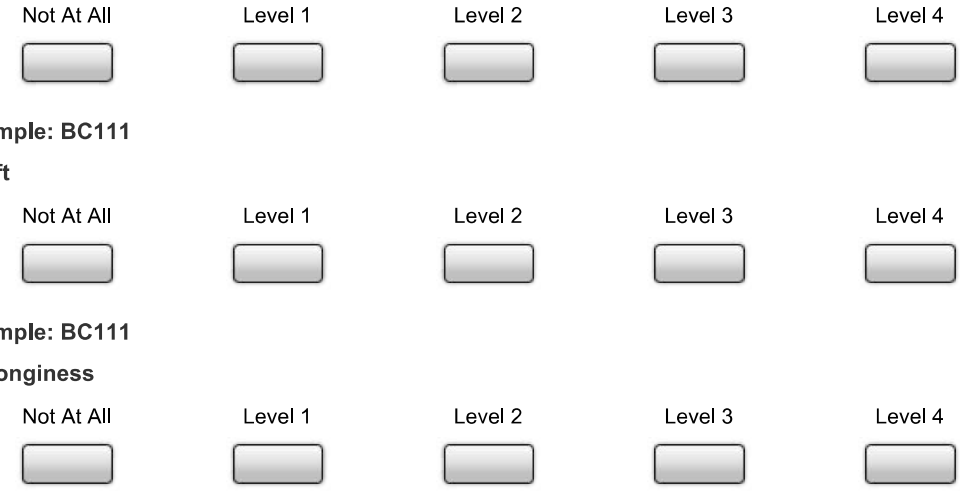

A Lot or Level 5

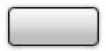

Sample: BC111

Rubbery

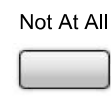

Level 1

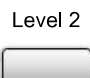

Level 3

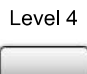

A Lot or Level 5

Sample: BC111

Sandy
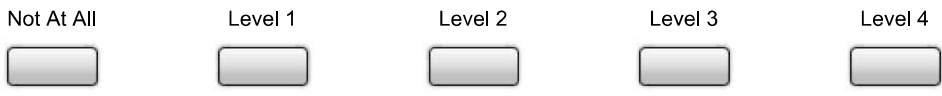

A Lot or Level 5

Sample: BC111

Hardness

Not At All Level 1 Level 2 Level 4

Sample: BC111

Waxy

Not At All Waxy
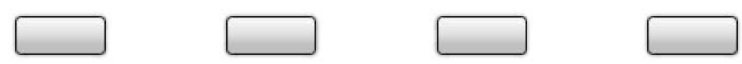

Very Waxy

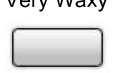


Using the poster board you created and after you have consumed sample BC111, please rank the emotions you are experiencing right now.

\begin{tabular}{|c|c|c|c|c|c|}
\hline Excited & & & & & \\
\hline $\begin{array}{l}\text { Not this } \\
\text { emotion at all }\end{array}$ & Slightly Excited & & & & Extremely Excited \\
\hline 0 & 1 & 2 & 3 & $4]$ & 5 \\
\hline Sociable & & & & & \\
\hline $\begin{array}{l}\text { Not this } \\
\text { emotion at all }\end{array}$ & Slightly Sociable & & & & Extremely Sociable \\
\hline \begin{tabular}{|l|}
0 \\
\end{tabular} & 1 & 2 & 3 & 4 & \begin{tabular}{|l|}
5 \\
\end{tabular} \\
\hline Self Confident & & & & & \\
\hline $\begin{array}{l}\text { Not this } \\
\text { emotion at all }\end{array}$ & $\begin{array}{l}\text { Slightly Self } \\
\text { Confident }\end{array}$ & & & & $\begin{array}{l}\text { Extremely Self } \\
\text { Confident }\end{array}$ \\
\hline 0 & 1 & 2 & 3 & 4 & 5 \\
\hline Fatigued & & & & & \\
\hline $\begin{array}{l}\text { Not this } \\
\text { emotion at all }\end{array}$ & Slightly Fatigued & & & & Extremely Fatigued \\
\hline 0 & 1 & 2 & 3 & 4 & \begin{tabular}{|l|}
5 \\
\end{tabular} \\
\hline Judgmental & & & & & \\
\hline $\begin{array}{l}\text { Not this } \\
\text { emotion at all }\end{array}$ & Slightly Judgmental & & & & $\begin{array}{l}\text { Extremely } \\
\text { Judgmental }\end{array}$ \\
\hline 0 & 1 & 2 & 3 & 4 & 5 \\
\hline Raging & & & & & \\
\hline $\begin{array}{l}\text { Not this } \\
\text { emotion at all }\end{array}$ & Slightly Raging & & & & Extremely Raging \\
\hline 0 & 1 & 2 & 3 & 4 & 5 \\
\hline Sad & & & & & \\
\hline $\begin{array}{l}\text { Not this } \\
\text { emotion at all }\end{array}$ & Slightly Sad & & & & Extremely Sad \\
\hline 0 & \begin{tabular}{|l|}
1 \\
\end{tabular} & 2 & 3 & 4 & \begin{tabular}{|l|}
5 \\
\end{tabular} \\
\hline
\end{tabular}


Generated by Compusense at-hand

Panelist Code

What one thing did you enjoy most about this product?

Sample: BC111

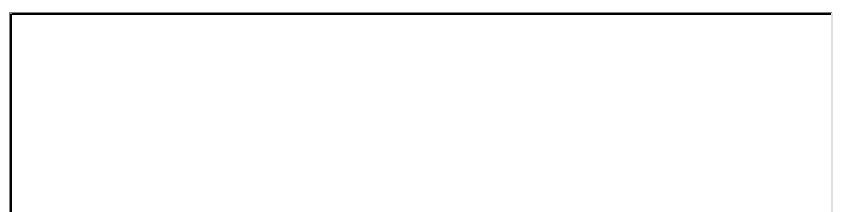


Thank You

(a) compusense

at-hand 


\section{e compusense}

The future of consumer data collection is 'at-hand'..

\section{@ compusense at-hand}


You have finished the responses for your first sample.

Please select sample from the samples in front of you. Please drink some water and eat some cracker.

During this time please direct your attention at your image you enjoy looking at.

Please click 'Next' when the time elapses.

$$
\text { 0:00 }
$$


Please enter your First and Last name below..

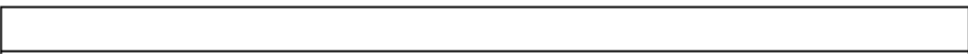

Please enter your Email address below. 
Please select sample from the samples in front of you.

Please click 'Next' to begin. 
Using the poster board you created, please rank the emotions you are experiencing right now.

Excited
Not this
emotion at all


After the first bite of sample BC111,

How do you like the cheese overall?

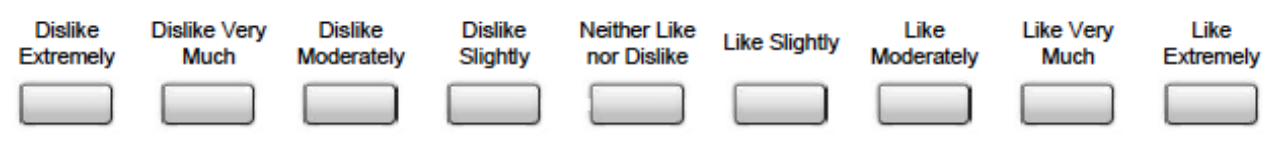

How do you like the flavor of the cheese?
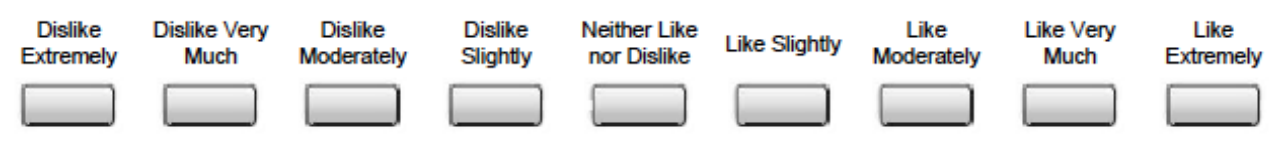

How do you like the texture of the cheese?
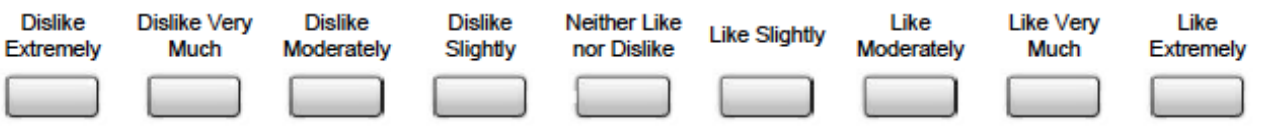

How do you like the appearance of the cheese?
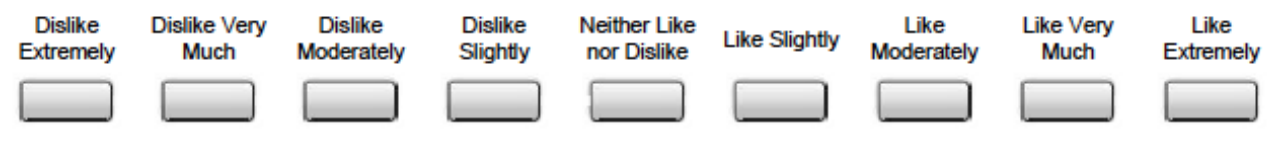

How do you like the aroma of the cheese?
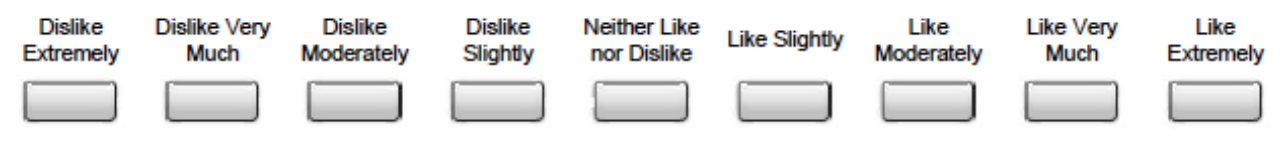

How do you like the aftertaste of the cheese?

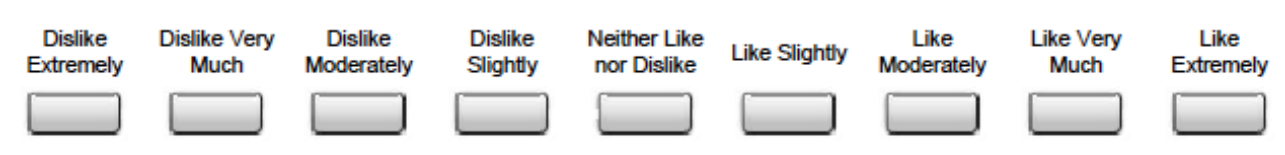


Panelist Code

After the first bite or swallow, using the texture cards provided, choose the level that best represents your experience of each attribute.

This texture is...

Bite Location

Level 1

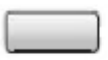

Level 2

Level 3

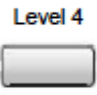

Level 5

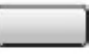

$\square$

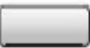

Break Resistance

Not At All
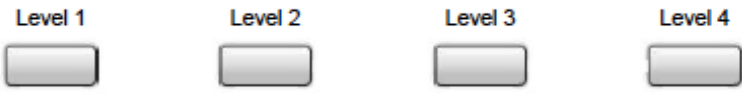

A Lot or Level 5

Bounciness

Not At All

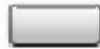

Fibrousity

Not At All

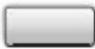

Shear

Not At A

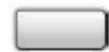

Resilience
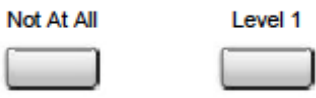

Level 1

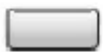

Level 2

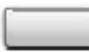

Level 3
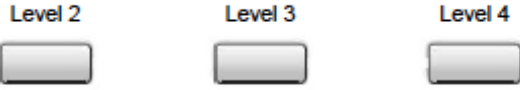

Level 2

Level 3
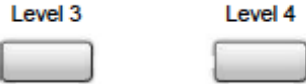

A Lot or Level 5

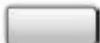

A Lot or Level 3
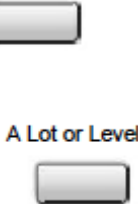

Level 3

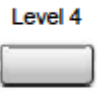

A Lot or Level 5

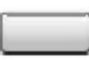

$\square$

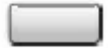

Stickiness
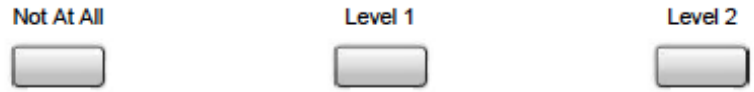

A Lot or Level 3

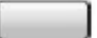

Surface Deviation
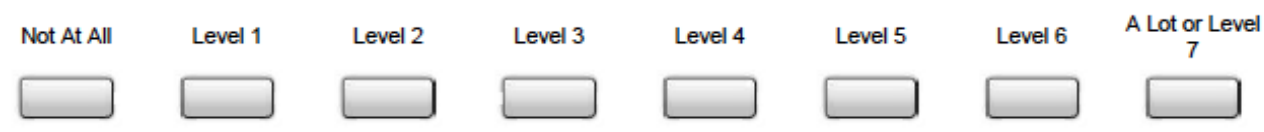

Grittiness
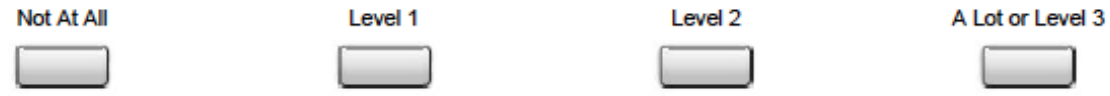

Crumble
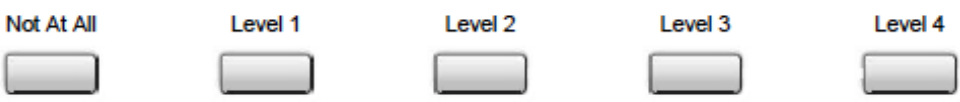

A Lot or Level 5

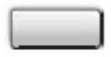

Soft 


Level 1


At the end of consuming sample $\mathrm{BC} 111$,

How do you like the cheese overall?

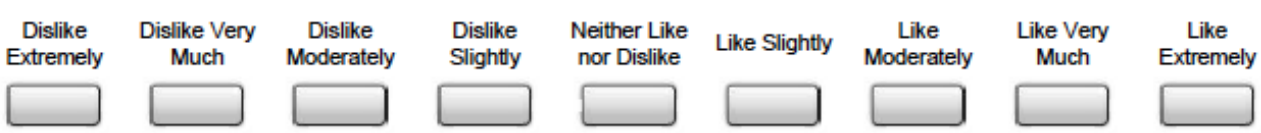

How do you like the flavor of the cheese?

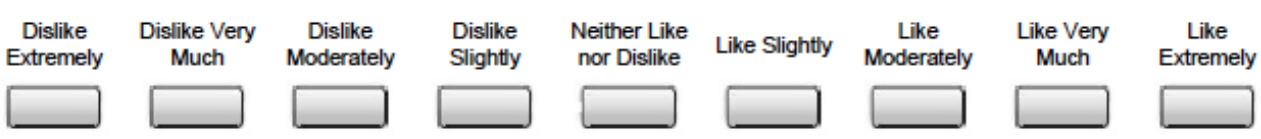

How do you like the texture of the cheese?

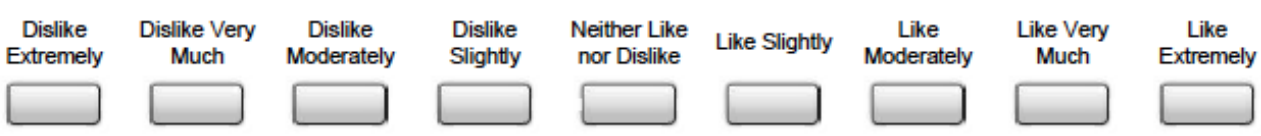

How do you like the appearance of the cheese?

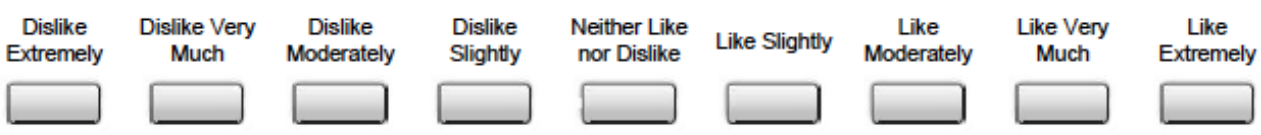

How do you like the aroma of the cheese?

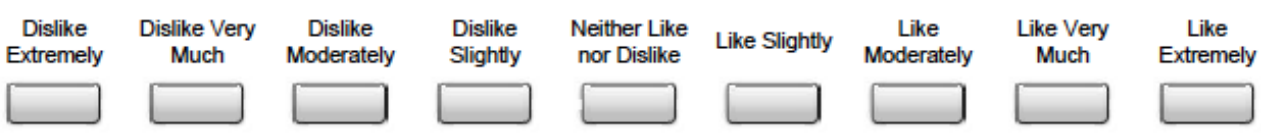

How do you like the aftertaste of the cheese?

$\begin{array}{ccccccc}\begin{array}{c}\text { Dislike } \\ \text { Extremely }\end{array} & \begin{array}{c}\text { Dislike Very } \\ \text { Much }\end{array} & \begin{array}{c}\text { Dislike } \\ \text { Moderately }\end{array} & \begin{array}{c}\text { Dislike } \\ \text { Slightly }\end{array} & \begin{array}{c}\text { Neither Like } \\ \text { nor Dislike }\end{array} & \text { Like Slightly } & \begin{array}{c}\text { Like } \\ \text { Moderately }\end{array}\end{array}$


Panelist Code

After the end of consumption, using the texture cards provided, choose the level that best represents your experience of each attribute.

This texture is...

Bite Location
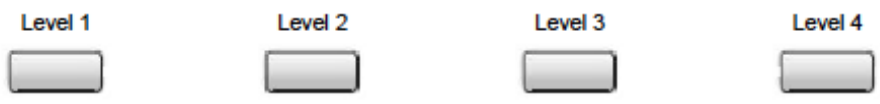

Level 5

Break Resistance

Not At All
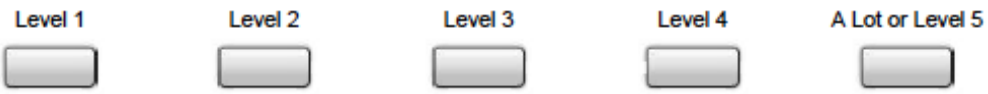

Bounciness

Not At All

Level 1
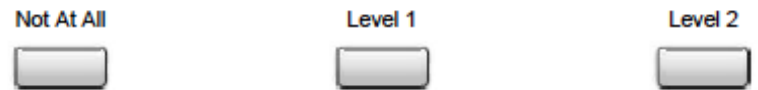

A Lot or Level 3

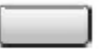

Fibrousity

Not At All

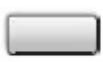

Shear

Not At All

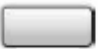

Resilience

Not At All
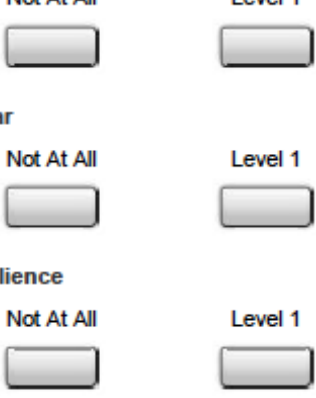
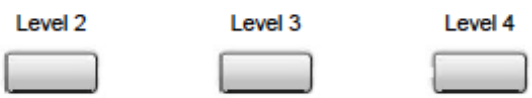

A Lot or Level 5
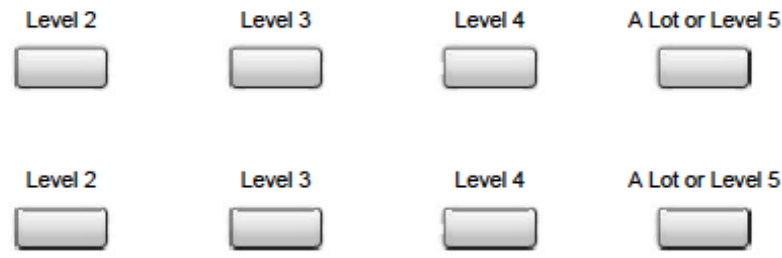

A Lot or Level 5

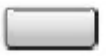

Stickiness

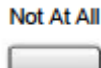

Level 1

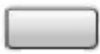

Level 2

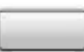

A Lot or Level 3

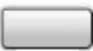

Surface Deviation

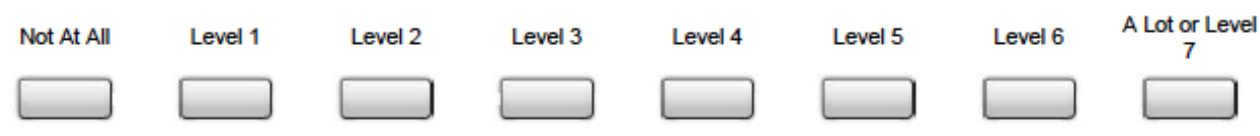

Grittiness
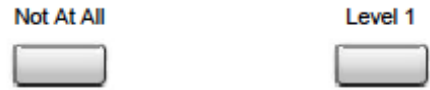

Level 2

A Lot or Level 3
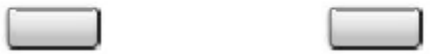

Crumble

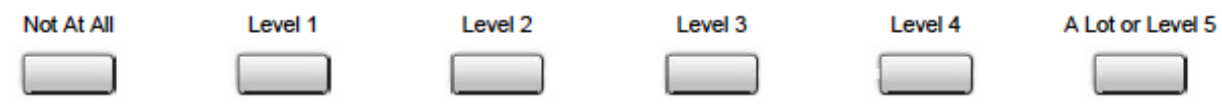

Soft 


Level 1


Using the poster board you created and after you have consumed sample BC111, please rank the emotions you are experiencing right now.

Excited

Not this
emotion at all

Sociable

Not this emotion at all

0

Slightly Sociable

1

3

Self Confident

\section{Not this}

emotion at all

0

Fatigued

Not this

emotion at all

0

Judgmental

Not this emotion at all

0

Raging

Not this emotion at all

0

Sad

Not this emotion at all

Slightly Sad

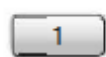

2

3

4

Extremely Raging

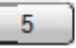

Extremely Sad
Extremely Sociable

5

Extremely Self

Confident

5

Extremely Fatigued

5

Extremely Judgmental

5

0

1

2

3

4

5 
What did you like about sample BC111?

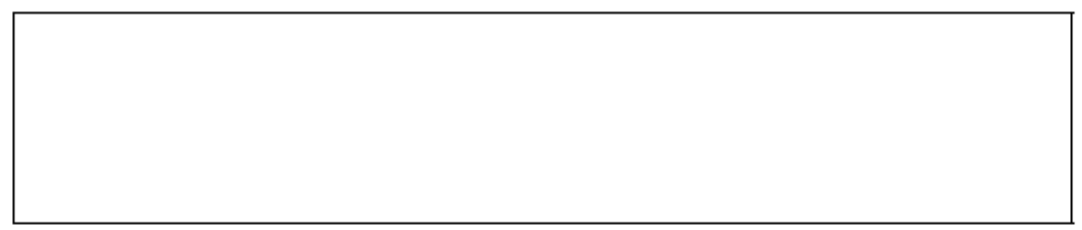

Comment - Disliked

What did you dislike about sample $\mathrm{BC} 111$ ?
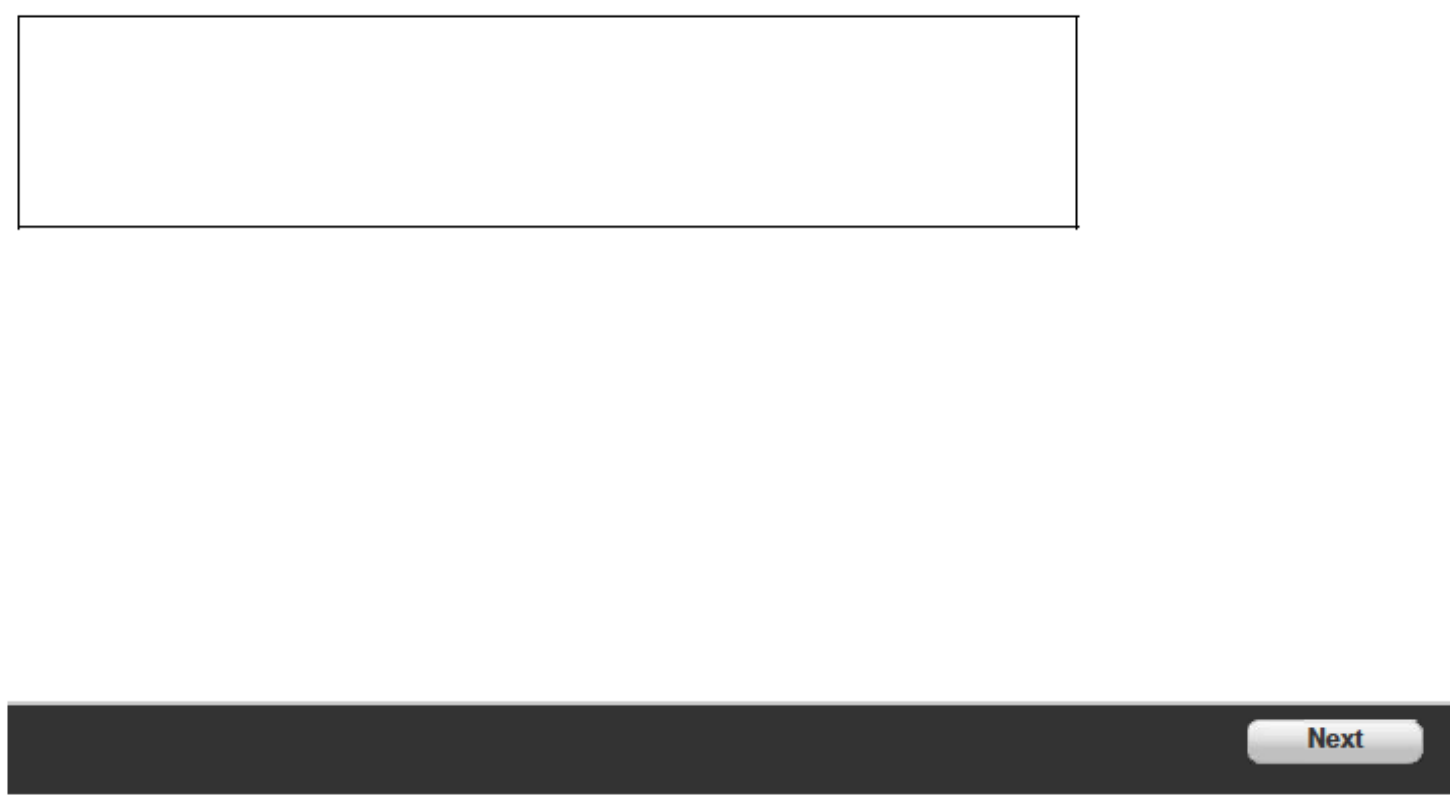
Thank You

@ compusense
at-hand 
APPENDIX D

Texture Card

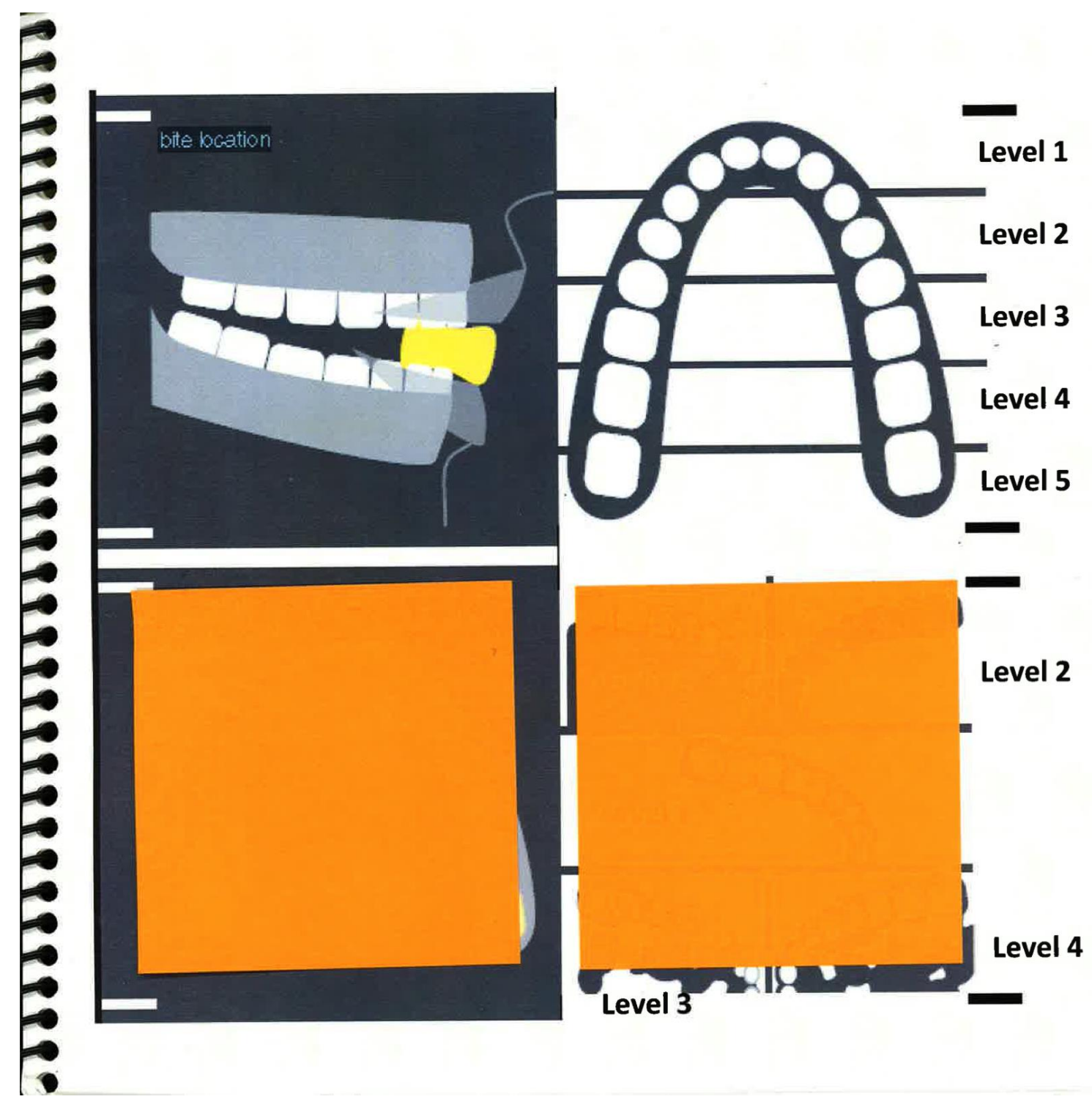




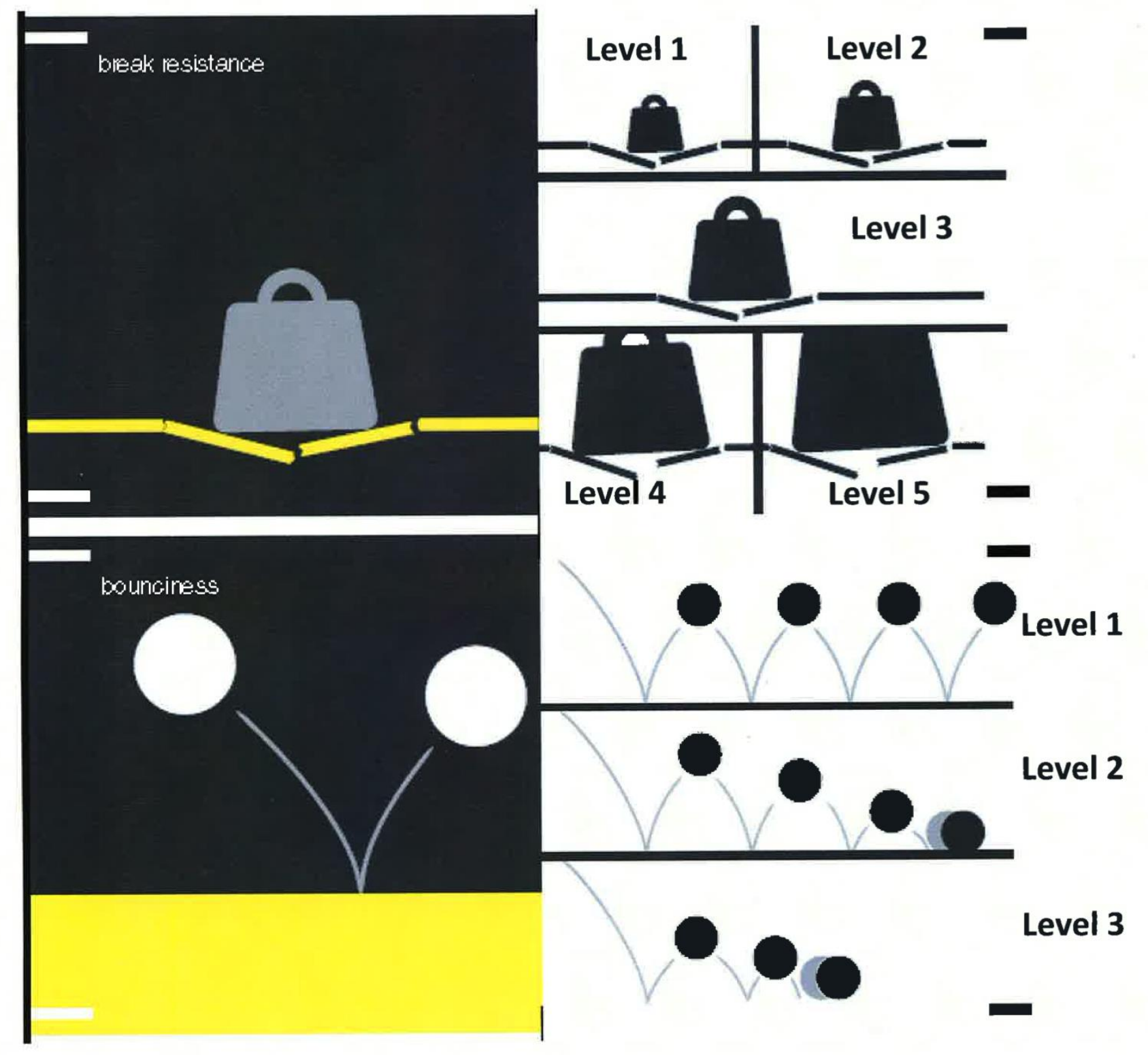




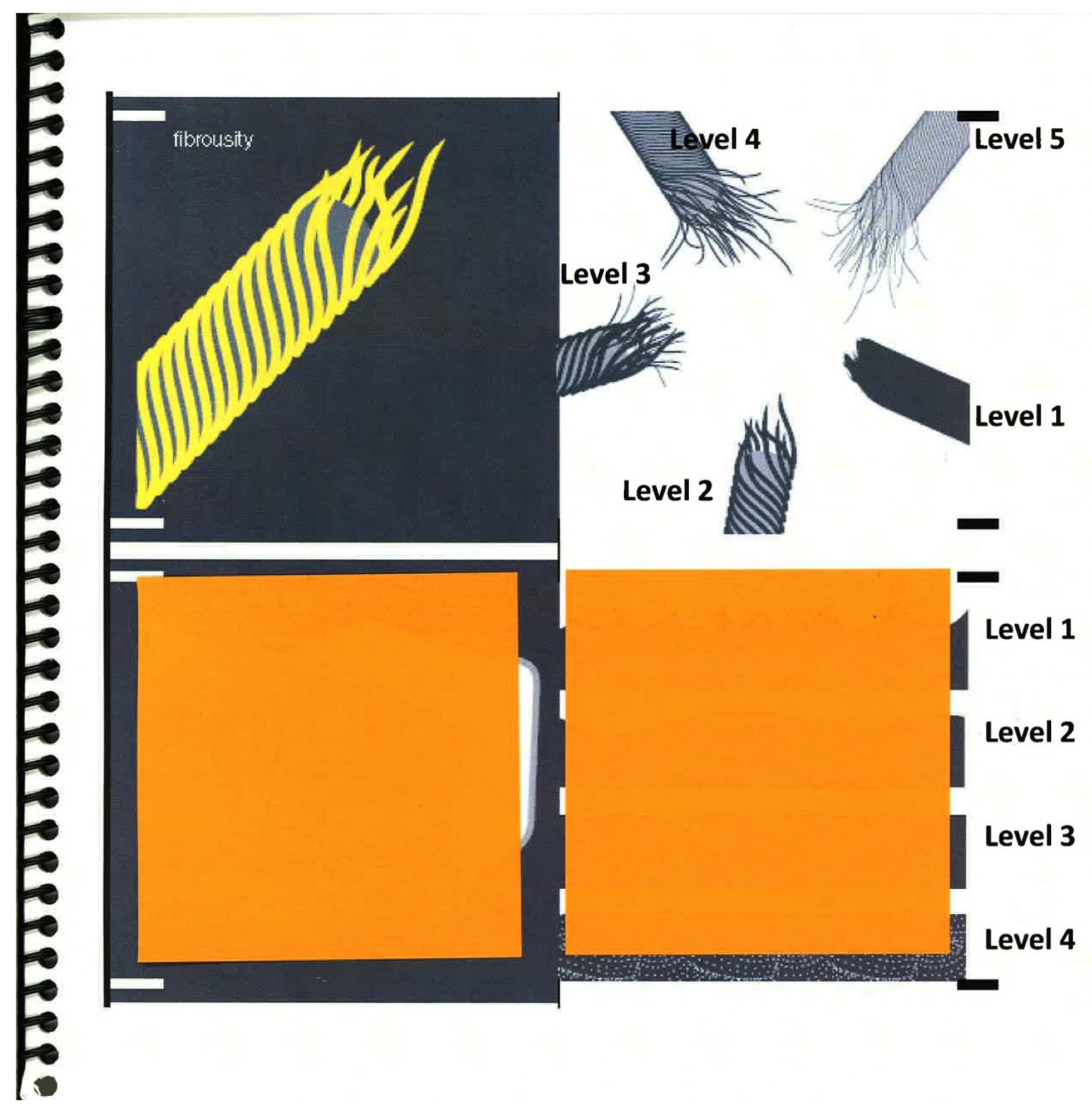




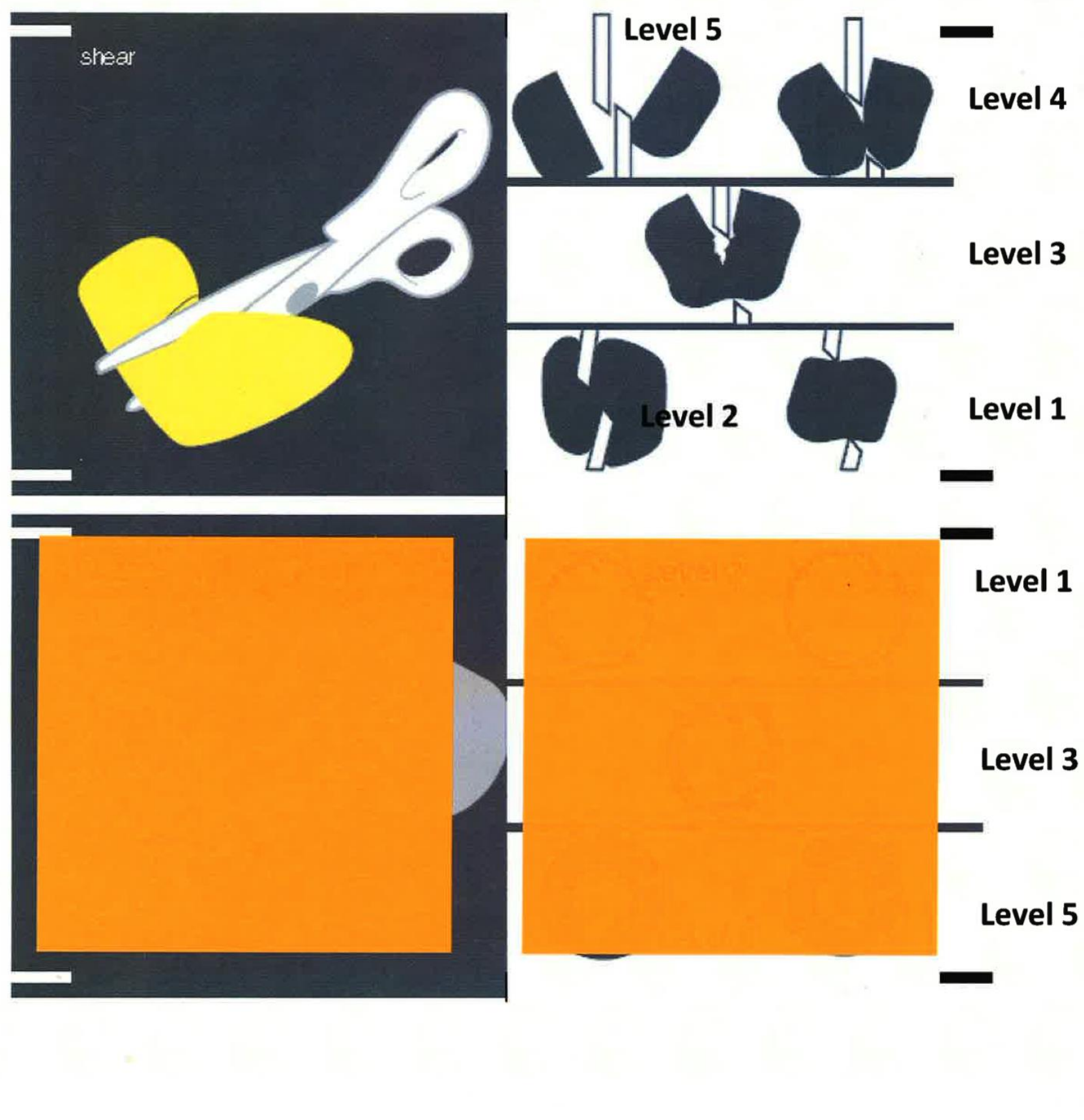




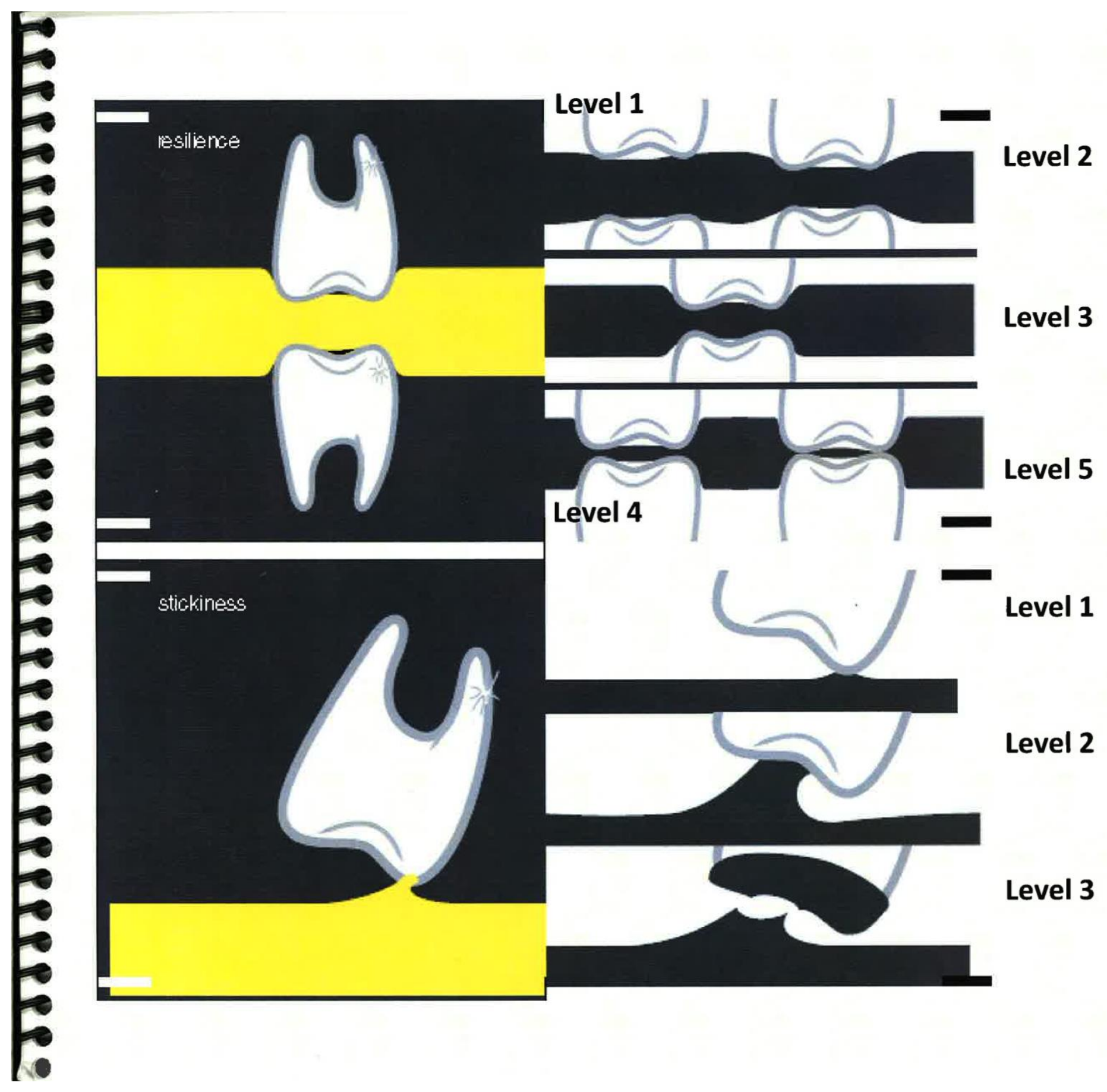




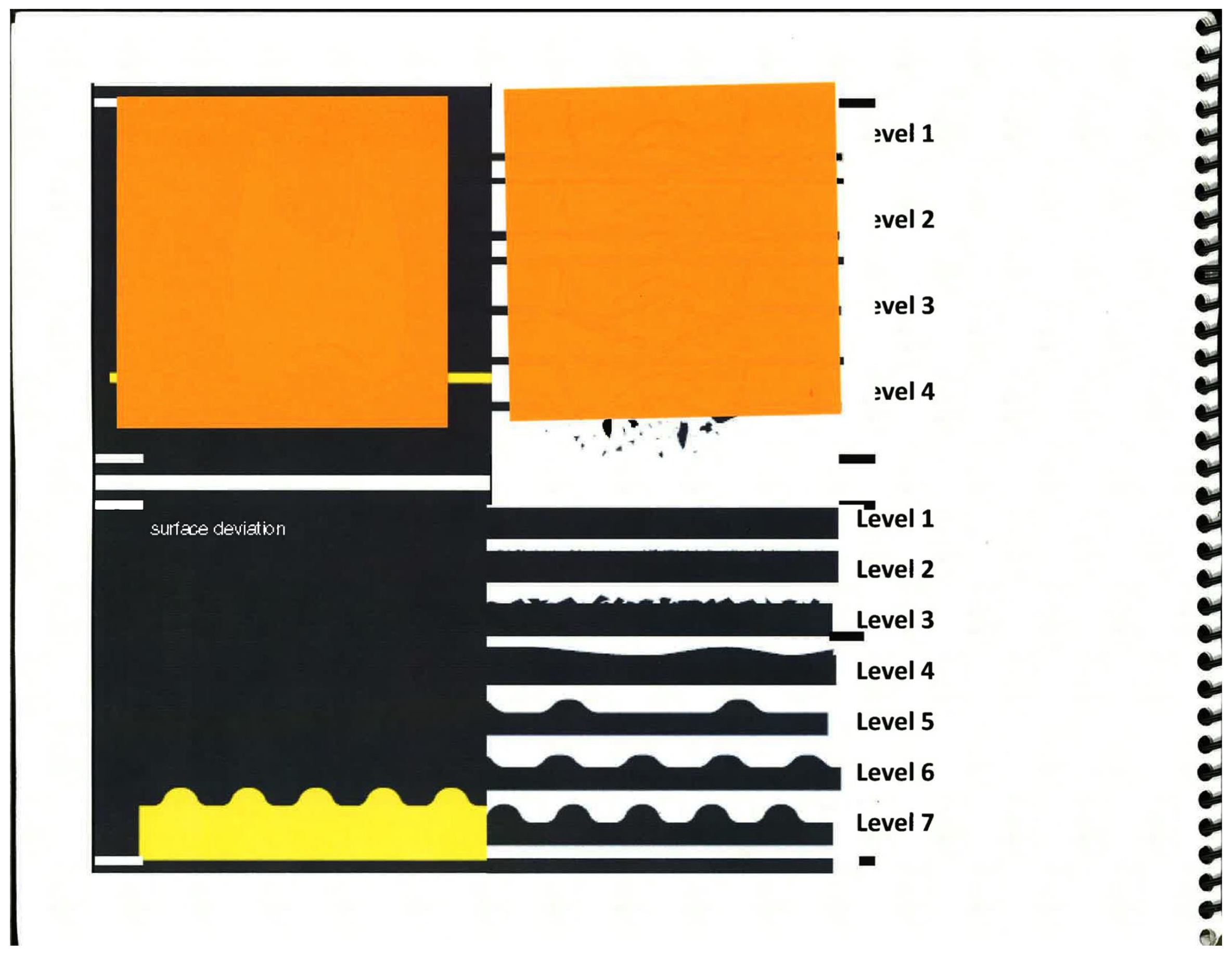




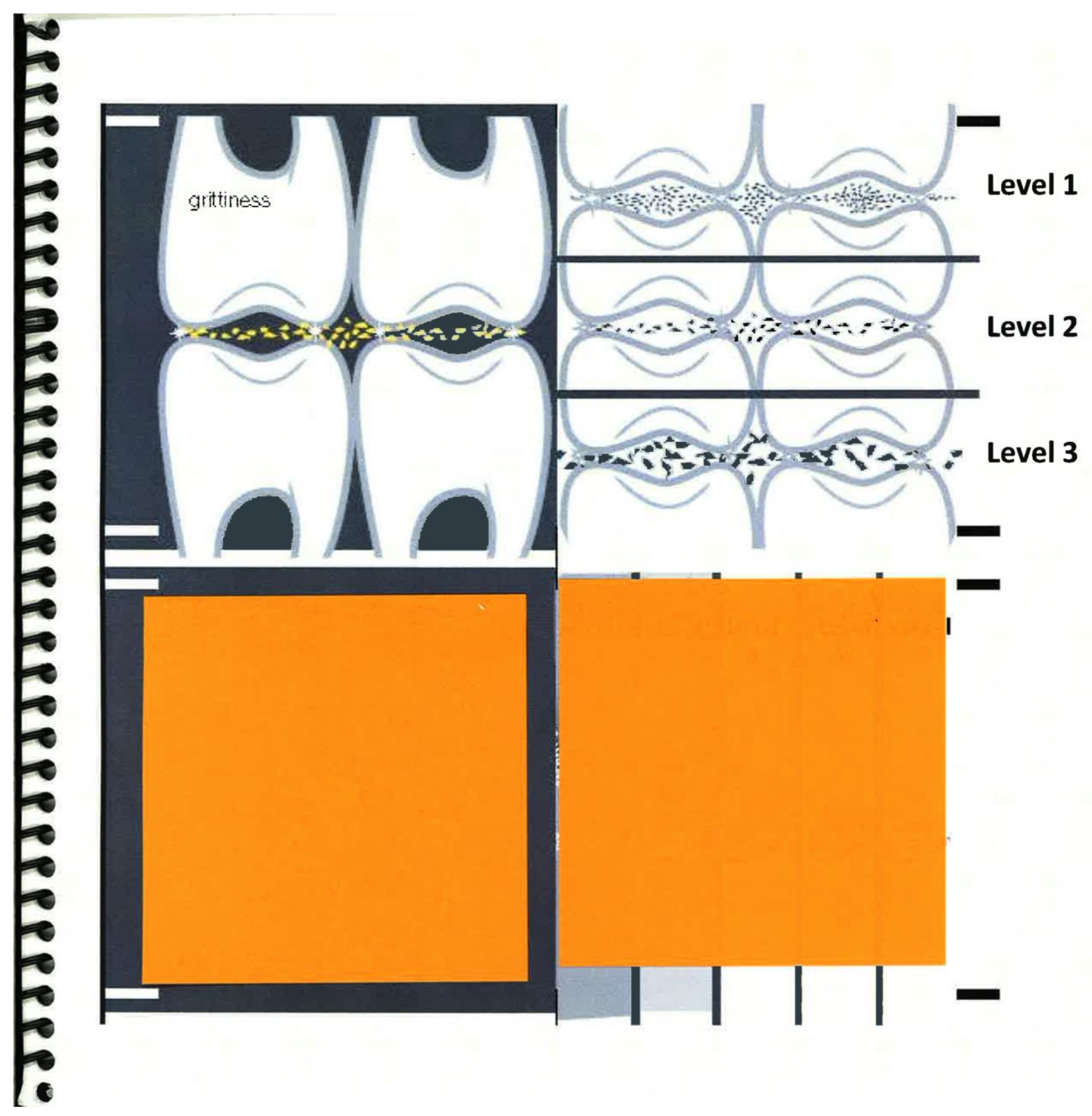





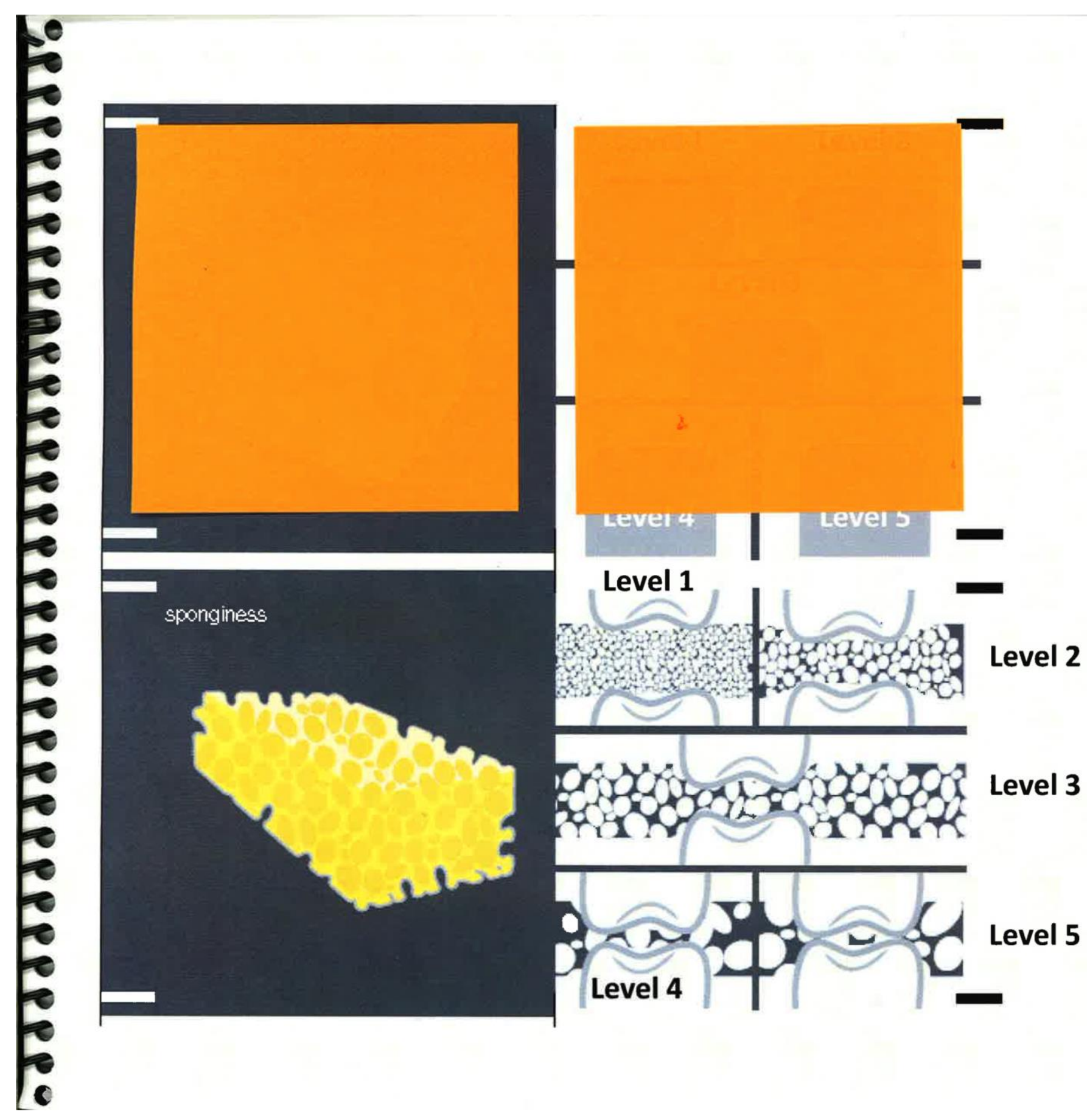




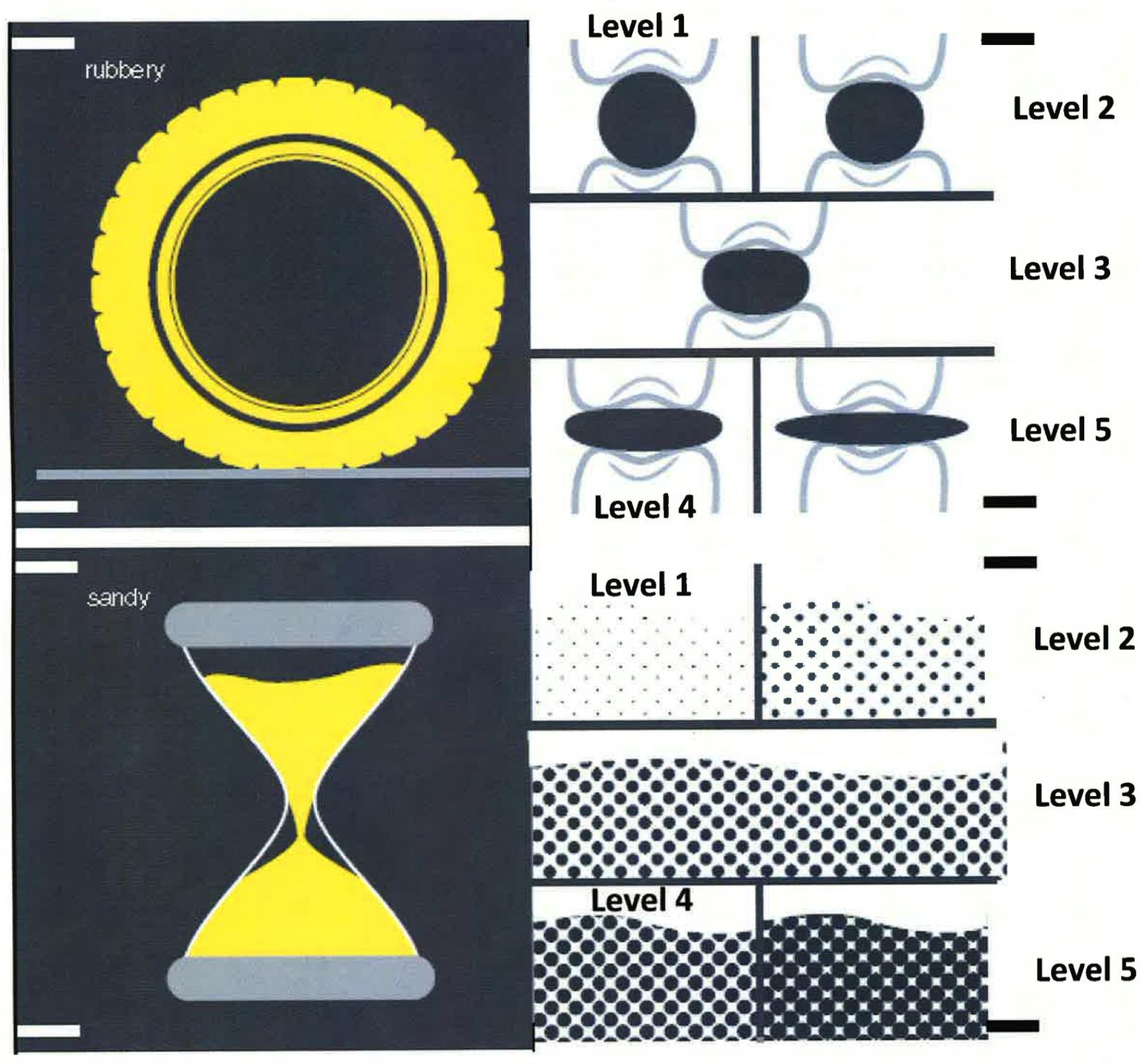




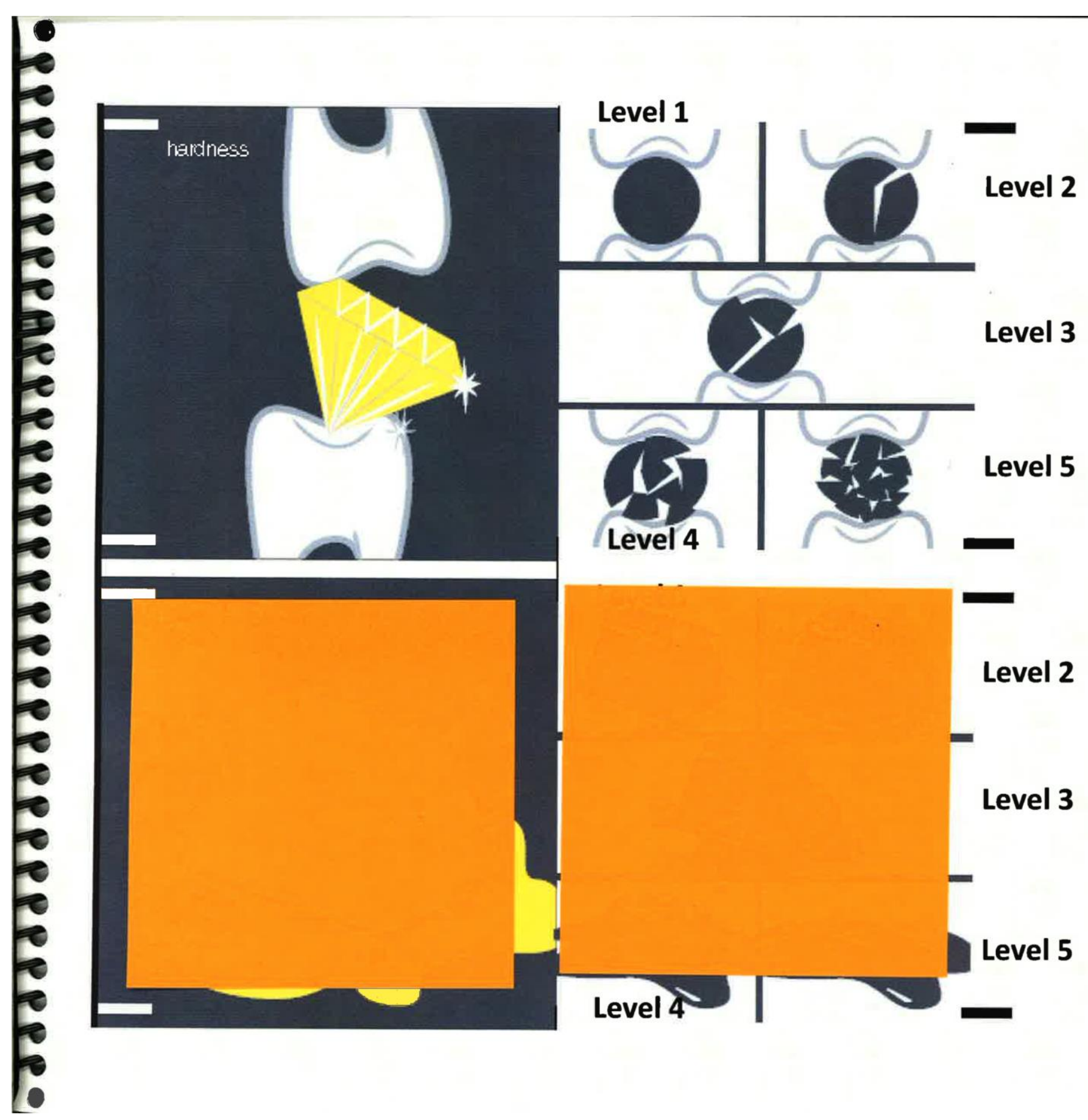



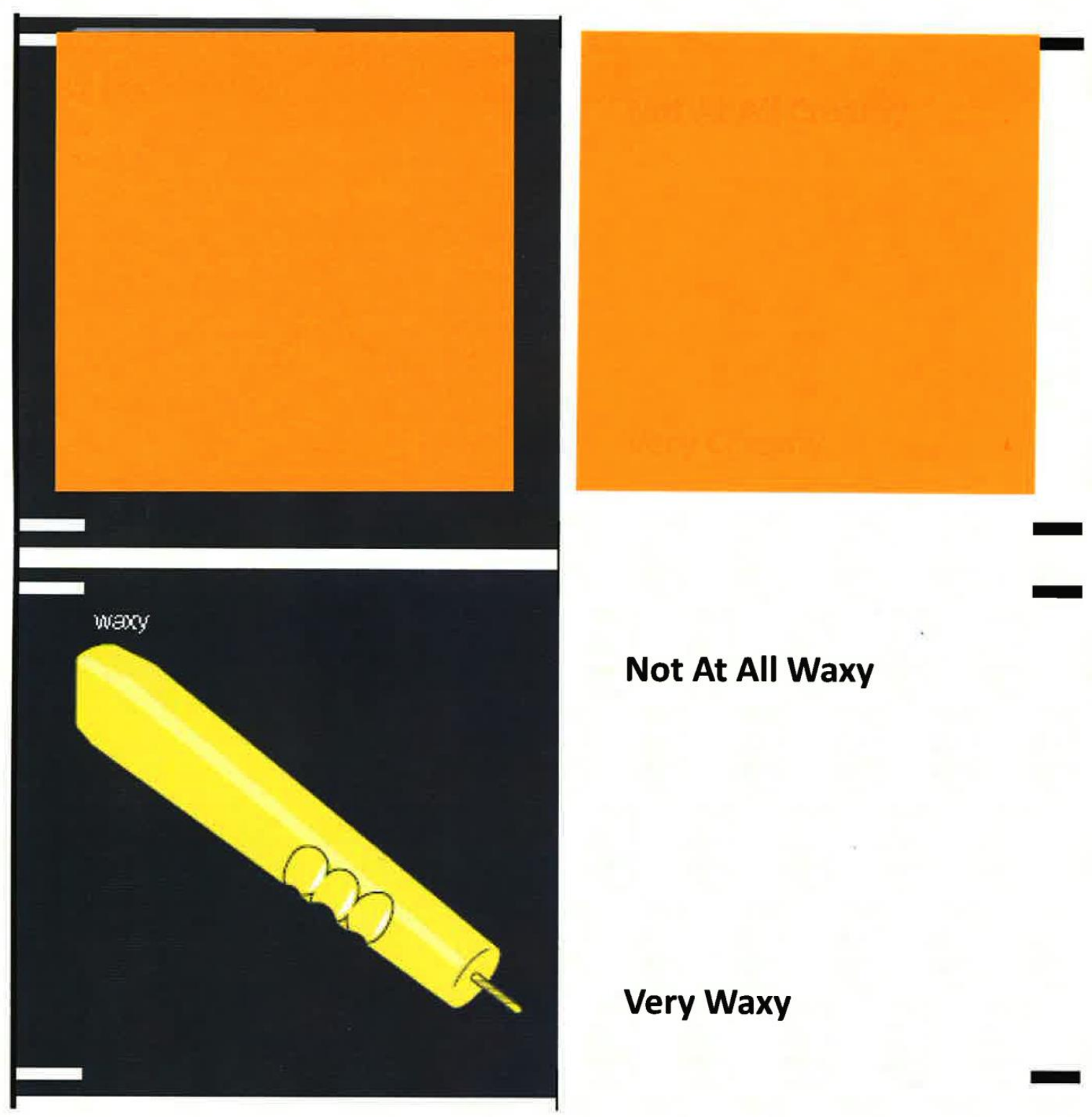

Not At All Waxy

\section{Very Waxy}

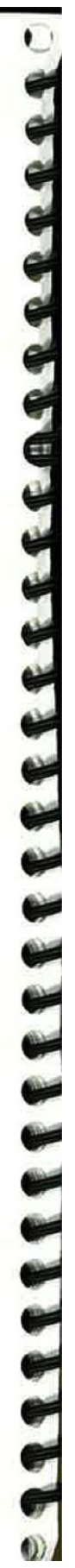




\section{APPENDIX E}

\section{Informed Consent}

\section{INFORMED CONSENT TO PARTICIPATE IN A RESEARCH PROJECT ON EMOTIONS AND LIKING OF COMMERCIAL BRAND CHEESES}

A research project on Emotions and Cheese (Regular, Low Fat, and Low Sodium) is being conducted by Dr. Amy Lammert in the Department of Food Science at Cal Poly, San Luis Obispo. The purpose of the study is to measure the emotional responses of consumers as they relate to the liking of commercial brand cheeses.

You are being asked to take part in this study by putting together a visual aid for emotions (the homework) and evaluating your emotional and liking response to commercially branded cheese products. Your participation will take approximately 2 hours; 1.5 hours for the homework and one -30 minute tasting session. Please be aware that you are not required to participate in this research and you may discontinue your participation at any time without penalty.

The possible risks associated with participation in this study include a potential stomachache and/or an allergic reaction to cheese or product ingredients. If you should experience gastric distress, please be aware that you may contact the Cal Poly Health Center at 805.756.2122 for assistance.

Your confidentiality will be protected as your name will not be used in any reports of this research. You will receive a code for data collection that will not be linked to your name. Potential benefits associated with the study include helping the researchers understand the influence of fat and sodium levels on liking and emotional response to commercial brand cheese products and you will receive one \$25 gift card to Target or Campus Dining upon the completion of the tasting session.

If you have questions regarding this study or would like to be informed of the results when the study is completed, please feel free to contact Dr. Amy Lammert @ 805.756.6108 or alammert@ calpoly.edu. If you have questions or concerns regarding the manner in which the study is conducted, you may contact Dr. Steve Davis, Chair of the Cal Poly Human Subjects Committee, at 805-756-2754, sdavis@ calpoly.edu.

If you agree to voluntarily participate in this research project as described, please indicate your agreement by signing below. Please keep one copy of this form for your reference, and thank you for your participation in this research.

Signature of Volunteer

Signature of Researcher

\section{Date}

Date 


\section{INFORMED CONSENT TO PARTICIPATE IN A RESEARCH PROJECT ON EMOTIONS AND LIKING OF REGULAR AND LOW SODIUM CHEESE}

A research project on Emotions and Liking of Regular and Low Sodium Cheese is being conducted by Dr. Amy Lammert in the Department of Food Science at Cal Poly, San Luis Obispo. The purpose of the study to measure the emotional responses of consumers as they relate to the liking of regular and low sodium mozzarella cheese.

You are being asked to take part in this study by putting together a visual aid for emotions (the homework) and evaluating your emotional and liking response to experimentally produced mozzarella cheese from Rizo Foods and the pilot plant at the Cal Poly Dairy Products Technology Center. Your participation will take approximately 2.5 hours; one hour for the homework and two - 40 minute tasting sessions (one session on May 8, 2013 and one session on May 9, 2013). Please be aware that you are not required to participate in this research and you may discontinue your participation at any time without penalty.

The possible risks associated with participation in this study include a potential stomachache and/or an allergic reaction to cheese or product ingredients. If you should experience gastric distress, please be aware that you may contact the Cal Poly Health Center at 805.756.2122 for assistance.

Your confidentiality will be protected as your name will not be used in any reports of this research. You will receive a code for data collection that will not be linked to your name. Potential benefits associated with the study include helping the researchers understand the influence of sodium level on the liking and emotional response to mozzarella cheese and you will receive one \$25 gift card to Target upon the completion of the first session and a $\$ 10$ campus gift card upon the completion of the second session.

If you have questions regarding this study or would like to be informed of the results when the study is completed, please feel free to contact Dr. Amy Lammert @ 805.756.6108 or alammert@calpoly.edu. If you have questions or concerns regarding the manner in which the study is conducted, you may contact Dr. Steve Davis, Chair of the Cal Poly Human Subjects Committee, at 805-756-2754, sdavis@ calpoly.edu.

If you agree to voluntarily participate in this research project as described, please indicate your agreement by signing below. Please keep one copy of this form for your reference, and thank you for your participation in this research.
Signature of Volunteer
Date

Signature of Researcher

Date 


\section{APPENDIX F}

\section{Video Release Form}

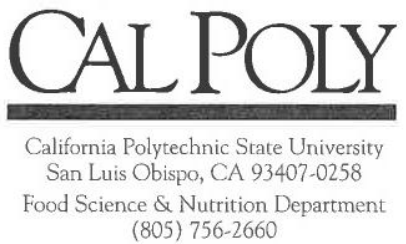

\section{Photographic Image and Video Recording Release Agreement - Personal Image}

I, hereby release to California Polytechnic State University San Luis Obispo (University), for use and reproduction by the University for representation, publicity, and/or promotional purposes which may include, but are not limited to: print and video recording materials: assessment for research purposes.

Such release is made without consideration beyond acknowledgement by the University of this Release Agreement.

This Release Agreement is intended to discharge the State of California, Trustees of the California State University, California Polytechnic State University, officers, employees, students and volunteers of each from and against any and all liability arising out of or connected in any way with my release of photographic image even though that liability may arise out of the negligence or carelessness on the part of persons or agencies mentioned above.

I understand that institutional data (including photographic image(s) may be protected under state and/or federal privacy acts (including but not limited to the Family Educational Rights and Privacy Act), nevertheless, I agree to assume the risks of authorizing the University to use my image and release hold harmless any of the persons or agencies mentioned above who (through negligence or carelessness) might otherwise be liable to me (or my heirs or assigns) for damages. It is further understood and agreed that this Photographic Image Release Agreement is to be binding on my heirs and assigns.

I have read this entire Release Agreement, I fully understand and agree to be legally bound by it. This is a release of your rights, read carefully before signing.

Releaser's Signature

Address

Phone (__

\section{Parent of Guardian, if Releaser is under 18 years of age:}

Guardian name

Signature

Address

Phone (_ ) 